Cochrane Database of Systematic Reviews

\title{
Partial breast irradiation for early breast cancer (Review)
}

Hickey BE, Lehman M, Francis DP, See AM

Hickey BE, Lehman M, Francis DP, See AM.

Partial breast irradiation for early breast cancer.

Cochrane Database of Systematic Reviews 2016, Issue 7. Art. No.: CD007077.

DOI: 10.1002/14651858.CD007077.pub3.

www.cochranelibrary.com 
TABLE OF CONTENTS

HEADER 1

ABSTRACT

PLAIN LANGUAGE SUMMARY

SUMMARY OF FINDINGS

BACKGROUND

OBJECTIVES

METHODS

RESULTS

Figure 1.

Figure 2.

Figure 3.

Figure 4.

Figure 5.

Figure 6.

DISCUSSION

AUTHORS' CONCLUSIONS

ACKNOWLEDGEMENTS

REFERENCES

CHARACTERISTICS OF STUDIES

DATA AND ANALYSES

Analysis 1.1. Comparison 1 Partial breast irradiation (PBI)/accelerated partial breast irradiation (APBI) versus whole breast radiotherapy (WBRT), Outcome 1 Local recurrence-free survival.

Analysis 1.2. Comparison 1 Partial breast irradiation (PBI)/accelerated partial breast irradiation (APBI) versus whole breast radiotherapy (WBRT), Outcome 2 Cosmesis, physician-reported.

Analysis 1.3. Comparison 1 Partial breast irradiation (PBI)/accelerated partial breast irradiation (APBI) versus whole breast radiotherapy (WBRT), Outcome 3 Overall survival.

Analysis 1.4. Comparison 1 Partial breast irradiation (PBI)/accelerated partial breast irradiation (APBI) versus whole breast radiotherapy (WBRT), Outcome 4 Acute radiotherapy (RT) skin toxicity.

Analysis 1.5. Comparison 1 Partial breast irradiation (PBI)/accelerated partial breast irradiation (APBI) versus whole breast radiotherapy (WBRT), Outcome 5 Late RT skin toxicity.

Analysis 1.6. Comparison 1 Partial breast irradiation (PBI)/accelerated partial breast irradiation (APBI) versus whole breast radiotherapy (WBRT), Outcome 6 Fat necrosis.

Analysis 1.7. Comparison 1 Partial breast irradiation (PBI)/accelerated partial breast irradiation (APBI) versus whole breast radiotherapy (WBRT), Outcome 7 'Elsewhere primary'.

Analysis 1.8. Comparison 1 Partial breast irradiation (PBI)/accelerated partial breast irradiation (APBI) versus whole breast radiotherapy (WBRT), Outcome 8 Cause-specific survival.

Analysis 1.9. Comparison 1 Partial breast irradiation (PBI)/accelerated partial breast irradiation (APBI) versus whole breast radiotherapy (WBRT), Outcome 9 Distant metastasis-free survival.

Analysis 1.10. Comparison 1 Partial breast irradiation (PBI)/accelerated partial breast irradiation (APBI) versus whole breast radiotherapy (WBRT), Outcome 10 Relapse-free survival.

Analysis 1.11. Comparison 1 Partial breast irradiation (PBI)/accelerated partial breast irradiation (APBI) versus whole breast radiotherapy (WBRT), Outcome 11 Loco-regional recurrence-free survival.

Analysis 1.12. Comparison 1 Partial breast irradiation (PBI)/accelerated partial breast irradiation (APBI) versus whole breast radiotherapy (WBRT), Outcome 12 Mastectomy.

ADDITIONAL TABLES

APPENDICES

WHAT'S NEW

HISTORY

CONTRIBUTIONS OF AUTHORS

DECLARATIONS OF INTEREST

SOURCES OF SUPPORT

DIFFERENCES BETWEEN PROTOCOL AND REVIEW

INDEX TERMS 
[Intervention Review]

\section{Partial breast irradiation for early breast cancer}

Brigid E Hickey1,2, Margot Lehman2,3, Daniel P Francis ${ }^{4}$, Adrienne M See ${ }^{1}$

1Radiation Oncology Mater Service, Princess Alexandra Hospital, Brisbane, Australia. ${ }^{2}$ School of Medicine, The University of Queensland, Brisbane, Australia. ${ }^{3}$ Radiation Oncology Unit, Princess Alexandra Hospital, Brisbane, Australia. ${ }^{4}$ School of Public Health and Social Work, Queensland University of Technology, Brisbane, Australia

Contact address: Margot Lehman, Radiation Oncology Unit, Princess Alexandra Hospital, Ground Floor, Outpatients F, Ipswich Road, Woollangabba, Brisbane, Queensland, 4102, Australia. margot.lehman@health.qld.gov.au.

Editorial group: Cochrane Breast Cancer Group.

Publication status and date: New search for studies and content updated (no change to conclusions), published in Issue 7, 2016.

Citation: Hickey BE, Lehman M, Francis DP, See AM. Partial breast irradiation for early breast cancer. Cochrane Database of Systematic Reviews 2016, Issue 7. Art. No.: CD007077. DOI: 10.1002/14651858.CD007077.pub3.

Copyright (c 2016 The Cochrane Collaboration. Published by John Wiley \& Sons, Ltd.

\section{A B S T R A C T}

\section{Background}

Breast-conserving therapy for women with breast cancer consists of local excision of the tumour (achieving clear margins) followed by radiotherapy (RT). RT is given to sterilize tumour cells that may remain after surgery to decrease the risk of local tumour recurrence. Most true recurrences occur in the same quadrant as the original tumour. Whole breast radiotherapy (WBRT) may not protect against the development of a new primary cancer developing in other quadrants of the breast. In this Cochrane review, we investigated the delivery of radiation to a limited volume of the breast around the tumour bed (partial breast irradiation (PBI)) sometimes with a shortened treatment duration (accelerated partial breast irradiation (APBI)).

\section{Objectives}

To determine whether PBI/APBI is equivalent to or better than conventional or hypo-fractionated WBRT after breast-conserving therapy for early-stage breast cancer.

\section{Search methods}

We searched the Cochrane Breast Cancer Group Specialized Register (4 May 2015), the Cochrane Central Register of Controlled Trials (CENTRAL) (2015, Issue 5), MEDLINE (January 1966 to 4 May 2015), EMBASE (1980 to 4 May 2015), CINAHL (4 May 2015) and Current Contents (4 May 2015). We searched the International Standard Randomised Controlled Trial Number Register (5 May 2015), the World Health Organization's International Clinical Trials Registry Platform (4 May 2015) and ClinicalTrials.gov (17 June 2015). We searched for grey literature: OpenGrey (17 June 2015), reference lists of articles, several conference proceedings and published abstracts, and applied no language restrictions.

\section{Selection criteria}

Randomized controlled trials (RCTs) without confounding, that evaluated conservative surgery plus PBI/APBI versus conservative surgery plus WBRT. Published and unpublished trials were eligible.

\section{Data collection and analysis}

Two review authors (BH and $\mathrm{ML}$ ) performed data extraction and used Cochrane's 'Risk of bias' tool, and resolved any disagreements through discussion. We entered data into Review Manager 5 for analysis.

\section{Main results}

We included seven RCTs and studied 7586 women of the 8955 enrolled. 
Local recurrence-free survival appeared worse for women receiving PBI/APBI compared to WBRT (hazard ratio (HR) 1.62, 95\% confidence interval ( $\mathrm{CI}) 1.11$ to 2.35; six studies, 6820 participants, low-quality evidence). Cosmesis (physician-reported) appeared worse with PBI/ $\mathrm{APBI}$ (odds ratio (OR) $1.51,95 \% \mathrm{Cl} 1.17$ to 1.95 , five studies, 1720 participants, low-quality evidence). Overall survival did not differ with $\mathrm{PBI} / \mathrm{APBI}$ (HR 0.90, 95\% $\mathrm{Cl} 0.74$ to 1.09, five studies, 6718 participants, high-quality evidence).

Late radiation toxicity (subcutaneous fibrosis) appeared worse with $\mathrm{PBI} / \mathrm{APBI}$ (OR 6.58, 95\% $\mathrm{Cl} 3.08$ to 14.06 , one study, 766 participants, moderate-quality evidence). Acute skin toxicity appeared reduced with $\mathrm{PBI} / \mathrm{APBI}$ (OR $0.04,95 \% \mathrm{Cl} 0.02$ to 0.09 , two studies, 608 participants). Telangiectasia (OR $26.56,95 \% \mathrm{Cl} 3.59$ to $196.51,1$ study, 766 participants) and radiological fat necrosis (OR $1.58,95 \% \mathrm{Cl} 1.02$ to 2.43, three studies, 1319 participants) appeared worse with PBI/APBI. Late skin toxicity (OR $0.21,95 \%$ Cl 0.01 to 4.39 , two studies, 608 participants) and breast pain (OR 2.17, $95 \% \mathrm{Cl} 0.56$ to 8.44 , one study, 766 participants) appeared not to differ with PBI/APBI.

'Elsewhere primaries' (new primaries in the ipsilateral breast) appeared more frequent with $\mathrm{PBI} / \mathrm{APBI}(\mathrm{OR} 3.97,95 \% \mathrm{CI} 1.51$ to 10.41 , three studies, 3009 participants).

We found no clear evidence of a difference for the comparison of PBI/APBI with WBRT for the outcomes of: cause-specific survival (HR 1.08, $95 \% \mathrm{Cl} 0.73$ to 1.58 , five studies, 6718 participants, moderate-quality evidence), distant metastasis-free survival ( $\mathrm{HR} 0.94,95 \% \mathrm{Cl} 0.65$ to 1.37 , four studies, 3267 participants, moderate-quality evidence), relapse-free survival (HR 1.36, $95 \% \mathrm{Cl} 0.88$ to 2.09 , three studies, 3811 participants), loco-regional recurrence-free survival ( $\mathrm{HR} 1.80,95 \% \mathrm{Cl} 1.00$ to 3.25, two studies, 3553 participants) or mastectomy rates (OR $1.20,95 \% \mathrm{Cl} 0.77$ to 1.87 , three studies, 4817 participants, low-quality evidence). Compliance was met: more than $90 \%$ of the women in all studies received the RT they were assigned to receive. We found no data for the outcomes of costs, quality of life or consumer preference.

\section{Authors' conclusions}

It appeared that local recurrence and 'elsewhere primaries' (new primaries in the ipsilateral breast) are increased with PBI/APBI (the difference was small), but we found no evidence of detriment to other oncological outcomes. It appeared that cosmetic outcomes and some late effects were worse with PBI/APBI but its use was associated with less acute skin toxicity. The limitations of the data currently available mean that we cannot make definitive conclusions about the efficacy and safety or ways to deliver of PBI/APBI. We await completion of ongoing trials.

\section{PLAIN LANGUAGE SUMMARY}

\section{Partial breast irradiation for early breast cancer}

\section{What is the issue?}

Women with early breast cancer who choose to keep their breast need to have radiotherapy (RT) as well as surgery to remove the cancer to make sure it does not regrow in the breast. RT is treatment with high energy x-rays. Having RT for breast cancer usually means 25 to 30 visits to the RT department, five times per week.

If breast cancer does regrow in the same breast (called local recurrence), it tends to come back in the area it was removed from. Women can also grow a new cancer (new 'elsewhere primary') in another part of the same breast. We are not sure if the RT given to stop cancer regrowth where the first cancer was does stop the growth of 'elsewhere primaries'.

Breast cancer is the most common cancer that women get. When women choose to keep their breast, it is important that they are happy with how it looks after treatment (cosmesis).

\section{Why does it matter?}

We always want to treat the smallest area we can with RT because this means fewer side effects. Treating only part of the breast could mean that RT might be able to be used again in another part of the same breast if needed. New ways of giving RT mean that treating part of the breast can be done with fewer treatments. This is likely to be easier for women and cost less money.

We asked if giving RT to part of the breast (called partial breast irradiation (PBI)) is as good as giving RT to the whole breast. It would need to control the cancer as well as giving RT to the whole breast does. It would also be important that the PBI gives about the same side effects and breast appearance as treating the whole breast.

We found seven studies, which involved 7586 women. Our evidence is current to May 2015. Local recurrence was rare, but more common with PBI (low-quality evidence) and the breast appearance (scored by doctors) was worse with PBI (low-quality evidence). Survival did not differ (high-quality evidence). Scarring in the breast was worse with PBI (moderate-quality evidence). The same number of women died of breast cancer with either treatment (moderate-quality evidence). The same number of women developed spread of breast cancer around their body with either treatment (moderate-quality evidence). There appeared to be the same number of women who eventually needed the breast removed (mastectomy) after both treatments. Mastectomy could happen because of cancer regrowth in the breast or bad side effects (low-quality evidence). 
This means that at the moment, PBI does not give the same cancer control in the breast as treating the whole breast, but the difference was small. It may cause worse side effects. There are five big ongoing studies that will be important to answer this question. We hope to have a clearer answer in the next update of this review. 
SUMMARY OF FINDINGS

Summary of findings for the main comparison. Partial breast irradiation (PBI)/accelerated partial breast irradiation (APBI) for early breast cancer

PBI/APBI for women with early breast cance

Patient or population: women with early breast cancer

Setting: radiotherapy centres

Intervention: $\mathrm{PBI} / \mathrm{APB}$

Comparison: whole breast radiotherapy (WBRT)

\begin{tabular}{|c|c|c|c|c|c|c|}
\hline \multirow[t]{2}{*}{ Outcomes } & \multicolumn{2}{|c|}{ Anticipated absolute effects ${ }^{\star}(95 \% \mathrm{Cl})$} & \multirow{2}{*}{$\begin{array}{l}\text { Relative effect } \\
(95 \% \mathrm{CI})\end{array}$} & \multirow{2}{*}{$\begin{array}{l}\text { No. of partic- } \\
\text { ipants } \\
\text { (studies) }\end{array}$} & \multirow{2}{*}{$\begin{array}{l}\text { Quality of the } \\
\text { evidence } \\
\text { (GRADE) }\end{array}$} & \multirow[t]{2}{*}{ Comments } \\
\hline & $\begin{array}{l}\text { Risk with } \\
\text { WBRT }\end{array}$ & Risk with PBI/APBI & & & & \\
\hline \multirow{2}{*}{$\begin{array}{l}\text { Local recurrence-free survival at } \\
5 \text { years }\end{array}$} & \multicolumn{2}{|c|}{ Study population } & \multirow{2}{*}{$\begin{array}{l}\text { HR } 1.62 \\
\text { (1.11 to } 2.35 \text { ) }\end{array}$} & \multirow{2}{*}{$\begin{array}{l}6820 \\
\text { (6 RCTs) }\end{array}$} & \multirow{2}{*}{$\begin{array}{l}\oplus \oplus \oplus \ominus \\
\text { Low 3,4,5,6 }\end{array}$} & \multirow[t]{2}{*}{-} \\
\hline & 10 per 10001 & $\begin{array}{l}16 \text { per } 1000 \\
\text { (11 to } 23)\end{array}$ & & & & \\
\hline \multirow{2}{*}{$\begin{array}{l}\text { Cosmesis assessed with 4-point } \\
\text { scale } \\
\text { Follow-up: range } 29-122 \text { months }\end{array}$} & \multicolumn{2}{|c|}{ Study population } & \multirow{2}{*}{$\begin{array}{l}\text { OR } 1.51 \\
(1.17 \text { to } 1.95)\end{array}$} & \multirow{2}{*}{$\begin{array}{l}1720 \\
\text { (5 RCTs) }\end{array}$} & \multirow{2}{*}{$\begin{array}{l}\oplus \oplus \ominus \odot \\
\text { Low } 6,7,8,9\end{array}$} & \multirow{2}{*}{$\begin{array}{l}\text { Cosmesis was assessed using a } \\
\text { 4-point scale. We reported those } \\
\text { women with poor/fair cosmesis at fi- } \\
\text { nal review }\end{array}$} \\
\hline & 150 per 1000 & $\begin{array}{l}218 \text { per } 1000 \\
(174 \text { to } 272)\end{array}$ & & & & \\
\hline \multirow{2}{*}{$\begin{array}{l}\text { Late radiotherapy toxicity (sub- } \\
\text { cutaneous fibrosis) } \\
\text { Follow-up: median } 36 \text { months }\end{array}$} & \multicolumn{2}{|c|}{ Study population } & \multirow{2}{*}{$\begin{array}{l}\text { OR } 6.58 \\
\text { (3.08 to 14.06) }\end{array}$} & \multirow{2}{*}{$\begin{array}{l}766 \\
(1 \mathrm{RCT})\end{array}$} & \multirow{2}{*}{$\begin{array}{l}\oplus \oplus \oplus \ominus \\
\text { Moderate } \\
5,7,10\end{array}$} & \multirow{2}{*}{$\begin{array}{l}\text { Assessed using National Cancer In- } \\
\text { stitute 3-point scale, events were de- } \\
\text { fined as: Grade II or higher toxicity } \\
\text { Physician assessors, at } 3 \text { years' fol- } \\
\text { low-up }\end{array}$} \\
\hline & 22 per 1000 & $\begin{array}{l}128 \text { per } 1000 \\
(64 \text { to } 239)\end{array}$ & & & & \\
\hline \multirow[t]{2}{*}{ Cause-specific survival at 5 years } & \multicolumn{2}{|c|}{ Study population } & \multirow{2}{*}{$\begin{array}{l}\text { HR } 1.08 \\
\text { (0.73 to } 1.58)\end{array}$} & \multirow{2}{*}{$\begin{array}{l}6718 \\
\text { (5 RCTs) }\end{array}$} & \multirow{2}{*}{$\begin{array}{l}\oplus \oplus \oplus \ominus \\
\text { Moderate 5,11 }\end{array}$} & \multirow[t]{2}{*}{-} \\
\hline & 20 per $1000^{2}$ & $\begin{array}{l}22 \text { per } 1000 \\
(15 \text { to } 32)\end{array}$ & & & & \\
\hline \multirow{2}{*}{$\begin{array}{l}\text { Distant metastasis-free survival } \\
\text { at } 5 \text { years }\end{array}$} & \multicolumn{2}{|c|}{ Study population } & \multirow{2}{*}{$\begin{array}{l}\text { HR } 0.94 \\
(0.65 \text { to } 1.37)\end{array}$} & \multirow{2}{*}{$\begin{array}{l}3267 \\
\text { (4 RCTs) }\end{array}$} & \multirow{2}{*}{$\begin{array}{l}\oplus \oplus \oplus \ominus \\
\text { Moderate 5,12 }\end{array}$} & \multirow[t]{2}{*}{-} \\
\hline & 33 per $1000^{2}$ & 31 per 1000 & & & & \\
\hline
\end{tabular}




\begin{tabular}{|c|c|c|c|c|c|c|}
\hline \multirow{3}{*}{ 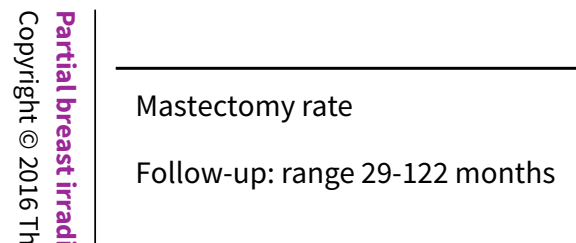 } & \multicolumn{2}{|r|}{ (21 to 44$)$} & & & & \\
\hline & \multicolumn{2}{|c|}{ Study population } & \multirow{2}{*}{$\begin{array}{l}\text { OR } 1.20 \\
(0.77 \text { to } 1.87)\end{array}$} & \multirow{2}{*}{$\begin{array}{l}4817 \\
\text { (3 RCTs) }\end{array}$} & \multirow{2}{*}{$\begin{array}{l}\oplus \oplus \ominus \ominus \\
\text { Low } 5,11,13\end{array}$} & \multirow{2}{*}{$\begin{array}{l}\text { Mastectomy rate reflected both lo- } \\
\text { cal recurrence and adverse cosmetic } \\
\text { outcome }\end{array}$} \\
\hline & 15 per 1000 & $\begin{array}{l}18 \text { per } 1000 \\
\text { (12 to } 28)\end{array}$ & & & & \\
\hline \multirow{2}{*}{$\begin{array}{l}\text { Mortality } \\
\text { (follow-up: } 5 \text { years survival) }\end{array}$} & \multicolumn{2}{|c|}{ Study population } & \multirow{2}{*}{$\begin{array}{l}\text { HR } 0.90 \\
(0.74 \text { to } 1.09)\end{array}$} & \multirow{2}{*}{$\begin{array}{l}6718 \\
\text { (5 RCTs) }\end{array}$} & \multirow{2}{*}{$\begin{array}{l}\oplus \oplus \oplus \oplus \\
\text { High }\end{array}$} & \multirow{2}{*}{$\begin{array}{l}\text { Survival advantage from radiothera- } \\
\text { py for breast cancer is not apparent } \\
\text { before } 15 \text { years' follow-up (EBCTCG } \\
\text { 2011) }\end{array}$} \\
\hline & 51 per $1000^{2}$ & $\begin{array}{l}46 \text { per } 1000 \\
(38 \text { to } 55)\end{array}$ & & & & \\
\hline
\end{tabular}

${ }^{*}$ The risk in the intervention group (and its 95\% confidence interval) is based on the assumed risk in the comparison group and the relative effect of the intervention (and its $95 \% \mathrm{Cl})$.

CI: confidence interval; HR: hazard ratio; OR: odds ratio; $\mathbf{R C T}$ : randomized controlled trial.

\section{GRADE Working Group grades of evidence}

High quality: We are very confident that the true effect lies close to that of the estimate of the effect

Moderate quality: We are moderately confident in the effect estimate: The true effect is likely to be close to the estimate of the effect, but there is a possibility that it is substantially different

Low quality: Our confidence in the effect estimate is limited: The true effect may be substantially different from the estimate of the effect

Very low quality: We have very little confidence in the effect estimate: The true effect is likely to be substantially different from the estimate of effect

1 The baseline risk for the control group was calculated at the 5-year time point from 5 studies

2 The baseline risks for the control groups were calculated at the 5 -year time point from 4 studies.

3 There was considerable clinical heterogeneity with respect to radiotherapy dose, technique and use of quality assurance procedures. However, the techniques employed delivered a dose that was the same or higher in the accelerated partial breast irradiation arm than the whole breast radiotherapy arm, which should mean the local recurrencefree survival is better or at least the same.

$438 \%$ of the women contributing to this outcome came from a study deemed at high risk of bias for short follow-up.

5 There were fewer than 300 events.

${ }^{6}$ Confidence intervals did not exclude both clinically important and clinically unimportant harms.

7 Optimum sample size was not met, therefore downgraded.

8 There was evidence of considerable heterogeneity on statistical testing $\left(I^{2}=71 \%\right.$; $P$ value $\left.<0.00001\right)$

${ }^{9}$ Less than $30 \%$ of events came from studies deemed at high risk of bias for subjective outcomes.

10 Testing for heterogeneity was not appropriate, given that there was only one study contributing to this outcome.

11 Confidence intervals did not exclude either clinically significant benefits or harms.

12 Confidence intervals did not exclude the possibility of clinically significant harms.

13 One of the two included studies had median follow-up of 29 months, which was too short to report this outcome. 


\section{B A C K G R O U N D}

\section{Description of the condition}

Breast cancer is the most common cancer occurring in women. One in eight women living in the US and the UK has a lifetime risk of being diagnosed with breast cancer; while one in nine women living in Australia are at risk (AlHW 2012; Howlader 2009; ONS 2010). Breast cancer is the second most common cause of cancer death in women.

Historically, mastectomy was the recommended therapeutic option for all stages of breast cancer. However, large randomised controlled trials (RCTs) demonstrated equivalent survival for women with early-stage disease (Stages I, II) whether they were treated with breast-conserving therapy or mastectomy (EBCTCG 1995; Fisher 1995; Fisher 2002; Jacobson 1995; Poggi 2003; van Dongen 2000; Veronesi 1995; Veronesi 2002). Consequently, breast conservation has become the preferred management option for these women.

Breast-conserving therapy consists of local excision of the tumour (achieving clear margins) followed by radiotherapy (RT). RT is given to sterilize tumour cells that may remain after surgery. This practice is supported by data from detailed pathological examination of mastectomy specimens where residual tumour was found more than $2 \mathrm{~cm}$ from the original tumour in $41 \%$ of participants (Holland 1985). Conventional RT delivers 45 to 50 Gray (Gy) to the whole breast over five weeks frequently followed by a boost to the tumour bed (the most likely site of residual tumour cells) of 10 to 16 Gy over one to two weeks. This prolonged duration of treatment negatively impacts on quality of life (Whelan 2000), and contributes to the higher mastectomy rates observed in women residing in rural and remote areas who wish to avoid being away from home and family for extended periods (Schroen 2005).

Hypofractionated whole breast radiotherapy (WBRT) regimens, in which 40 to $42.5 \mathrm{~Gy}$ is delivered to the whole breast over three to four weeks using a larger radiation dose with each treatment have been investigated. Compared to conventional WBRT, hypofractionated WBRT results in no difference in breast recurrence rates at five and 10 years, no difference in overall survival (OS) and an improvement in cosmetic outcomes (START 2008; START B 2008; Whelan 2002).

RCTs have shown that the addition of conventional or hypofractionated WBRT to local excision decreases ipsilateral breast (same breast) recurrence rates from 30\% to 40\% (Fisher 1995; Fisher 2002; Freeman 1981; Lagios 1983; Montgomery 1978) to $10 \%$ to $20 \%$ with 10 to 15 years of follow-up (Fisher 1995; Fisher 2002). Modern breast-conserving therapy with postoperative WBRT achieves local control rates of $3.3 \%$ to $3.4 \%$ at five years and $5.2 \%$ to $6.7 \%$ at 10 years (Haviland 2013). With careful patient selection (aged 65 years or greater, T1-2 tumours, tumour not greater than $3 \mathrm{~cm}$, margin negative, oestrogen receptor positive and all receiving tamoxifen), surgery alone can achieve local recurrence rates of $4.1 \%$ at five years (Kunkler 2015). An ipsilateral recurrence can either be a true recurrence of the original cancer (typically arising in the same quadrant as the original tumour and known as local recurrence) or a second primary tumour developing elsewhere in that same breast. Studies evaluating ipsilateral breast tumour recurrence patterns showed that new primaries increasingly contribute to the rate of recurrence after five to eight years while true recurrence rates stabilize (Krauss 2004; Smith 2000). If WBRT was successful in preventing the recurrence of new primary cancers, the rate of such cancers in the treated breast should be lower than the rate of development of cancers in the other breast (contralateral breast cancer). Studies of ipsilateral breast tumour recurrence patterns have not found this (Krauss 2004; Smith 2000). Furthermore, studies examining primary and re-excision pathological specimens removed at the time of breastconserving surgery revealed residual tumour $15 \mathrm{~mm}$ or less from the primary tumour in $91 \%$ of the specimens (Wallner 2004).

Thus, as most true recurrences occur in the same quadrant as the original tumour and as WBRT does not appear to protect against the development of new primary cancer, investigators are examining the role of partial breast irradiation (PBI).

\section{Description of the intervention}

PBI (also known as less than WBRT) refers to irradiation of a limited volume of breast tissue around the tumour bed. It may be achieved by any of the following techniques.

1. Intracavitary brachytherapy or MammoSite ${ }^{\circledR}$ (applying radioactive sources directly into the cavity left after surgical removal of the tumour either at the time of surgery or at a later date, the latter requiring a second procedure).

2. Interstitial brachytherapy (inserting catheters into the surgical cavity and surrounding tissue to temporarily deliver radioactive sources).

3. Intra-operative techniques using electrons or x-rays at $50 \mathrm{kVp}$ (using a dedicated machine to deliver a very localized radiation dose to the surgical cavity in the operating room or by moving the person with an open wound to the radiation machine, which may be in a different part of the hospital).

4. External beam radiotherapy (EBRT) using either threedimensional conformal radiotherapy (3D-CRT) (EBRT delivered in the postoperative setting to a volume of breast tissue around the tumour cavity using a standard linear accelerator in a radiation oncology department) or other methods.

Conventional RT typically delivers a radiation dose of $2 \mathrm{~Gy}$ with each treatment. Some PBI techniques deliver a larger than standard dose of radiation with each treatment, allowing the overall duration of treatment to be shortened. This is termed accelerated partial breast irradiation (APBI).

\section{How the intervention might work}

PBI/APBI will only be of benefit if it confers the same local control benefit as standard WBRT with acceptable toxicity and cosmesis. Currently, some authorities consider PBI/APBI to be an experimental therapy (Clinical Evidence). The National Comprehensive Cancer Network (NCCN) state, "Preliminary studies of APBI suggest rates of local control in patients with early-stage breast cancer may be comparable to those treated with WBRT. Follow-up, however is limited and studies are ongoing" (NCCN). Because this technique has been widely adopted outside the context of clinical trials, published guidelines exist that identify women with early breast cancer for whom this technique may be safe. For those women ineligible for a trial, carefully selected women with early breast cancer may be offered PBI/APBI (Bellon 2011; Polgár 2010; Smith 2009). 
PBI/APBI has a number of potential advantages including:

1. a reduction in treatment-related toxicities, as a smaller volume of breast tissue is irradiated;

2. increased utilization of breast conservation;

3. a reduction in RT waiting times; a reduction in the overall treatment duration of a common malignancy has the potential to substantially impact on RT waiting times in countries with strained resources (including the UK, Canada, Australia and New Zealand);

4. a greater chance of preserving the breast should a recurrence occur elsewhere in the breast;

5. easier integration with chemotherapy schedules because RT time will be shorter, thus avoiding delays.

$\mathrm{PBI} / \mathrm{APBI}$ has a number of potential disadvantages including:

1. an increased risk of local recurrence due to geographic miss. This is either because treatment was delivered before full pathological examination was obtained or because of difficulty in reproducing the target volume (the tissue that needed to be treated with RT) daily;

2. increased late toxicity. The late effects of radiation are dependent on the dose of radiation given at each treatment and, as PBI/APBI delivers a large radiation dose per fraction, late toxicity may be increased with resultant poor cosmetic outcome or breast appearance (cosmesis);

3. more patient inconvenience as some techniques may require a second anaesthetic or a further invasive procedure;

4. a number of techniques (e.g. interstitial and intracavitary brachytherapy) require operator expertise and specialized equipment that may not be available in all centres;

5. invasive techniques of delivering PBI/APBI (e.g. interstitial and intracavitary brachytherapy) may be associated with toxicity such as infection and delays in wound healing. Scarring postinsertion of interstitial brachytherapy catheters can negatively impact on cosmetic appearance.

\section{Why it is important to do this review}

$\mathrm{PBI} / \mathrm{APBI}$ has the potential to change the pattern of practice for a common malignancy and thereby impact on resource utilization, patient satisfaction and quality of life. However, as PBI/APBI is currently an experimental therapy, it must be thoroughly evaluated before being adopted as the new standard of care for early-stage breast cancer. PBI/APBI can be recommended if it is as effective or better than conventional or hypofractionated WBRT for cancerrelated outcomes (local relapse-free survival (LR-FS), survival, breast cancer-specific survival and metastasis-free survival) as well as patient-orientated outcomes (cosmesis, quality of life and consumer preference). We found one systematic review that concluded, "The data on PBI/APBI compared to whole-breast irradiation are insufficient to draw any conclusions about the relative effectiveness of these modalities" (BlueCross BlueShield). The fact that the benefit versus risk profile of PBI/APBI is currently unknown makes it an ideal topic for a systematic review.

\section{OB JECTIVES}

To determine whether $\mathrm{PBI} / \mathrm{APBI}$ is equivalent to or better than conventional or hypofractionated WBRT after breast-conserving therapy for early-stage breast cancer.

\section{METHODS}

\section{Criteria for considering studies for this review Types of studies}

Randomized controlled trials (RCTs) evaluating conservative surgery plus $\mathrm{PBI} / \mathrm{APBI}$ versus conservative surgery plus WBRT. The comparisons had to be unconfounded (i.e. treatments given to the randomized groups had to differ only in relation to the volume of the breast irradiated). Trials incorporating adjuvant treatments, such as chemotherapy, monoclonal antibodies or hormonal therapy, were eligible if the RCT applied these other treatments in exactly the same way to both groups. Published and unpublished studies were eligible.

We did not consider studies in which PBI was used as a boost following conventional EBRT for inclusion.

\section{Types of participants}

Women with histologically confirmed early-stage breast cancer who had conservative surgery. Early breast cancer included tumours classified as American Joint Committee on Cancer (AJCC) stage T1-2N0-1M0 (Fleming 1997). Surgery could include lumpectomy and wide local excision or quadrantectomy, with or without axillary dissection, axillary sampling or sentinel node biopsy. Women with a previous diagnosis of breast cancer were not eligible for inclusion.

\section{Types of interventions}

Radiation delivered to the partial breast (PBI) and PBI using larger than standard radiation dose per fraction such that the overall treatment time was reduced (APBI). We considered any method of $\mathrm{PBI} / \mathrm{APBI}$ delivery including, but not limited to, intracavitary brachytherapy or MammoSite ${ }^{\circledast}$, interstitial brachytherapy, intraoperative techniques such as electrons or x-rays at $50 \mathrm{kVp}$ or EBRT using either 3D-CRT or other methods. Conventional breast RT is delivered to the whole breast with or without the supraclavicular fossa and axilla, using standard fractionation (1.8 to 3.0 Gy per fraction) to deliver a total of 40 to $61 \mathrm{~Gy}$ at the reference point. Treatment could include a boost (using electrons, interstitial therapy, EBRT or new techniques).

\section{Types of outcome measures}

\section{Primary outcomes}

1. Local recurrence-free survival (LR-FS) in the ipsilateral breast. We defined local recurrence as a recurrence of the same histological type of cancer within the same quadrant of the breast as the primary cancer.

2. Cosmesis (cosmetic outcome or breast appearance).

\section{Secondary outcomes}

1. Overall survival (OS, time from date of randomization to death from any cause, or number of deaths from any cause).

2. Toxicity (including acute and late effects of RT, chemotherapyrelated toxicity and surgical toxicity; individual protocol-based definitions).

3. New primary tumours in ipsilateral breast, 'elsewhere primary'. We defined a new primary as a lesion arising in a quadrant of the breast that was different from the original cancer or a tumour of 
a different histological subtype occurring anywhere within the breast.

4. Cause-specific survival (C-SS, deaths due to breast cancer at five years).

5. Distant metastasis-free survival (DM-FS, in isolation or at the same time as local recurrence (the occurrence of metastases at five years)).

6. Relapse-free survival (R-FS, length of time after treatment during which no recurrence was found). Recurrence referred to breast cancer in the ipsilateral breast or elsewhere in the body, excluding a new breast cancer in the contralateral breast.

7. Loco-regional recurrence-free survival (L-RR-FS, comprised local recurrence, "elsewhere" ipsilateral breast primaries (a new primary cancer in the same breast) and regional nodal relapse).

8. Subsequent mastectomy (ipsilateral partial mastectomy, modified radical mastectomy or radical mastectomy).

9. Compliance, defined as the number of women who commenced treatment with $\mathrm{PBI} / \mathrm{APBI}$ or conventional external beam radiotherapy (EBRT) and completed the treatment course.

10. Costs (monetary costs of PBI versus EBRT) to women, government and insurance companies.

11.Quality of life (using trial-specific instruments). The effects of $\mathrm{PBI} / \mathrm{APBI}$ and EBRT on global quality of life and the physical, emotional and psychological domains.

12.Consumer preference, that is, did women prefer PBI/APBI or WBRT given the advantages and disadvantages of each approach.

\section{Search methods for identification of studies}

\section{Electronic searches}

\section{Electronic databases}

We searched the following databases:

1. the Cochrane Breast Cancer Group Specialized Register (4 May 2015). Details of search strategies used to identify studies and the procedure used to code references are outlined in the group's module (Cochrane Breast Cancer Group). We extracted studies on the specialized register with keywords 'early breast cancer', 'radiotherapy', 'partial breast irradiation', 'whole breast irradiation', 'whole breast radiotherapy', 'brachytherapy', 'high-dose-rate brachytherapy', 'accelerated partial breast irradiation', 'tumour bed boost', 'sole tumour bed irradiation', 'MammoSite', 'radiotherapy', 'PBI', 'APBI' and 'interstitial brachytherapy' for consideration;

2. the Cochrane Central Register of Controlled Trials (CENTRAL) (2015, Issue 3; Appendix 1);

3. MEDLINE (January 1966 to 4 May 2015; Appendix 2);

4. EMBASE (1980 to 4 May 2015; Appendix 3);

5. CINAHL (1981 to 4 May 2015; Appendix 4);

6. Current Contents (1998 to 4 May 2015; Appendix 5).

We modified the MEDLINE search strategy (Appendix 2) to search the other databases, without language restrictions.

\section{Unpublished literature}

We searched following registers for ongoing clinical trials:
1. the International Standard Randomised Controlled Trial Number Register (www.controlled-trials.com/isrctn) (5 May 2015);

2. the World Health Organization International Clinical Trials Registry Platform (WHO ICTRP) search portal (apps.who.int/ trialsearch/Default.aspx) (4 May, 2015; Appendix 6);

3. US clinical trials registry (www.clinicaltrials.gov) (17 June 2015; Appendix 7).

\section{Grey literature}

We checked OpenGrey (www.opengrey.eu/) (17 June 2015; Appendix 8).

\section{Searching other resources}

We contacted researchers located from the grey literature and unpublished literature to ask if they were aware of any other trials on this topic. We contacted the Barcelona authors on 15 October 2012 for more information. We contacted the IRMA authors on 2 October 2012 and they supplied us with the trial protocol. We contacted the authors of Polgár 2007 on 24 August 2013; we gratefully received and incorporated data from the authors of Polgár 2007 in November 2013.

\section{Handsearching}

We handsearched a number of conference proceedings and published abstracts including:

1. Adjuvant Therapy for Primary Breast Cancer International Conference (2001);

2. Primary Therapy of Early Breast Cancer (2001 and 2003);

3. 6th and 7th Nottingham International Breast Cancer Meeting Conference Reports;

4. 23rd and 24th Congress of the International Association for Breast Cancer Research;

5. 3rd and 4th Perspectives in Breast Cancer Conference Reports;

6. 26th and 27th Annual San Antonio Breast Cancer Symposium;

7. 4th European Breast Cancer Conference;

8. 94th and 95th American Association of Cancer Research;

9. American Society for Clinical Oncology (1995 to 2005);

10.European Society for Therapeutic and Radiation Oncology (1990, 1993, 2000 to 2010, 2012);

11.5th and 6th Milan Breast Cancer Conference;

12.Australian Breast Cancer Conference (2004);

13.27th and 28th Annual Symposium of the American Society of Breast Disease;

14.Centers for Disease Control and Prevention (CDC) Cancer Conference (2003);

15.International Journal of Radiation Oncology Biology Physics: proceedings of American Society for Radiation Oncology (ASTRO) 2011 to 2015;

16.Radiotherapy and Oncology: Proceedings of World Congress of Brachytherapy 2012;

17.American Society of Clinical Oncology (ASCO) from 1995 to 2010. 


\section{Data collection and analysis}

\section{Selection of studies}

Three review authors (ML, BH and DF) checked the titles and abstracts retrieved by the searches. Each review author independently assessed the full text of the studies thought relevant to the review and we resolved any differences in assessment by discussion. We performed trial assessments with the results masked. In cases where data were limited or information on trial methods was limited, we requested further information from the trial authors.

\section{Data extraction and management}

Two review authors ( $\mathrm{ML}$ and $\mathrm{BH}$ ) performed data extraction and resolved disagreements through discussion. We entered data into Review Manager 5 for analysis (RevMan 2012). Where possible, we extracted data on tumour stage, nodal status, margin status, receptor status, hormonal manipulation, treatment allocation and surgery performed. The information extracted on RT included overall treatment time, radiation dose, dose per fraction and method of PBI. We extracted outcome data on local recurrence, deaths (all-cause and breast cancer deaths), new ipsilateral primaries, mastectomy rate, distant metastases, treatment-related toxicity (including that related to acute and late effects of RT and to surgery), cosmesis, costs of treatment, consumer preference and quality of life.

We derived data for OS, LR-FS, DM-FS, disease-free survival and CSS from information in the text (ELIOT; Livi 2015; RAPID; Rodriguez; TARGIT) and data received from trial authors (Polgár 2007). Trial authors of Polgár 2007 provided the $\mathrm{HR}, 95 \% \mathrm{Cl}$ and $\mathrm{P}$ values, together with the number of events with further follow-up. We used the spreadsheet developed by Matthew Sydes (Tierney 2007) to derive O-E (observed minus expected events) and variance using the number of events, HRs, $\mathrm{P}$ values where available or calculated using the Review Manager 5 calculator (RevMan 2012). Although there were data for loco-regional recurrence for ELIOT, we did not include them in the analysis, because some women were treated with regional nodal RT.

We converted the radiation doses to the equivalent dose in 2 Gy fractions $\left(E D_{2}\right)$ (Maciejewski 1986; Withers 1983), using the formula: $\mathrm{EQD}_{2}=\mathrm{D}[\mathrm{d}+($ alpha/beta/2 + alpha/beta $)]$, where $\mathrm{D}=$ total dose, $d=$ dose per fraction and alpha/beta $=4$ Gy (Owen 2006). This was to facilitate comparison of radiation doses given at differing dose per fraction.

We plan to convert brachytherapy (radiation sources applied directly to the body) to the biological equivalent dose (BED) using the method of Stitt 1992 should it be necessary to pool brachytherapy data in future updates of this review.

Studies reported global cosmetic outcome using the Harvard Cosmetic Score (Polgár 2007; Livi 2015; Rodriguez), the European Organization for Research and Treatment of Cancer (EORTC) Cosmetic rating System for Breast Cancer) (Aaronson 1998; RAPID), and a software program (TARGIT). These were all four-point scales; the results were dichotomized into good/excellent and fair/poor, with occurrence of fair/poor being counted as 'events'. See Table 1.
One study reported telangiectasia (RAPID; using NCI CTCAE Version 3.0; also a three-point scale): we recorded any women with Grade 2 or higher toxicity as having events.

Three studies reported radiological or asymptomatic fat necrosis (ELIOT; Polgár 2007; RAPID); we were able to report Grade 1 fat necrosis, as this had the same definition in all three scales.

\section{Assessment of risk of bias in included studies}

$\mathrm{BH}$ and $\mathrm{ML}$ assessed trials to check that they met the inclusion criteria and independently assessed methodological quality. $\mathrm{BH}$ undertook 'Risk of bias' tables assessments, which were checked by $\mathrm{ML}$, and reported them in the text and as a figure.

We described the risk of bias for each included trial. $\mathrm{BH}$ and $\mathrm{ML}$ judged risk of bias in eight specific domains, and resolved any differences through discussion. The eight domains were:

1. random sequence generation;

2. allocation concealment;

3. blinding of participants and personnel;

4. blinding of outcome assessors for objective outcomes;

5. blinding of outcome assessors for subjective outcomes;

6. incomplete outcome data;

7. selective outcome reporting;

8. other sources of bias (i.e. early stopping and differences in follow-up examinations).

We will perform sensitivity analyses on the basis of trial quality when additional trials are available. We plan to perform the analysis both with and without trials at low risk of bias to assess the effect of bias on the results when more trials are available to examine.

\section{Measures of treatment effect}

We presented results as hazard ratios (HR) for time-to-event data and odds ratios (OR) with $95 \%$ confidence intervals $(\mathrm{Cl})$ where this was not possible (Deeks 2004).

For future updates, if we find results for continuous variables (such as quality of life), we will summarize them using the mean difference or the standardized mean difference when different measurement scales are used (Deeks 2004).

\section{Unit of analysis issues}

Because the unit of analysis was the individual participant, we did not anticipate any unit of analysis issues.

\section{Dealing with missing data}

If data are missing in future updates, we will contact the original investigators (by written correspondence).

We will specify what assumptions we make, for example, if we presume the missing data were missing at random, or that missing data were assumed to have a particular value such as a poor outcome. We will, if necessary, perform a sensitivity analysis to see how sensitive results are to the assumptions we have made. We will address the potential implications of this in the 'Discussion' section. 


\section{Assessment of heterogeneity}

We assessed heterogeneity both visually and statistically using the Chi2 test of heterogeneity (Altman 1992; Walker 1988), and ${ }^{2}$ statistic (Higgins 2002; Higgins 2003). The criterion for identification of heterogeneity is a $\mathrm{P}$ value less than 0.10 for the $\mathrm{Chi}^{2}$ test (acknowledging the limitations of this process) and an 12 statistic greater than $50 \%$. Where we identified significant heterogeneity, we explored the reasons for it and made a cautious attempt to explain the heterogeneity.

\section{Assessment of reporting biases}

We acknowledge that there are multiple potential sources of reporting biases, including, but not limited to, publication bias, time-lag bias, duplicate publication bias and selective outcome reporting. By searching multiple sources including trial registries, we hope to minimize publication bias. We noted the early reporting for the TARGIT was an example of time-lag bias. We planned to use funnel plots to evaluate funnel plot asymmetry, but took into account that visual interpretation is subjective and that statistical methods to evaluate funnel plot asymmetry are unlikely to be valid if there are fewer than 10 included trials.

\section{Data synthesis}

We applied the intention-to-treat principle in analyzing data from the trials and determined a weighted mean treatment effect using the fixed-effect model to combine results (Mantel 1959) with Review Manager 5 software (RevMan 2012).

We used the Mantel-Haenszel methods to calculate pooled results when there was no significant heterogeneity (Greenland 1985; Mantel 1959), or if otherwise, the random-effects model of Der Simonian and Laird (DerSimonian 1986).

We excluded two studies from the analysis (Dodwell 2005; Ribeiro 1993), because they used staging, surgery and RT techniques that do not reflect current practice (see Characteristics of excluded studies table).

We graded the quality of the evidence and created a 'Summary of findings' table using the following outcomes.

1. LR-FS.

2. Cosmesis.

3. Mortality (follow-up: 5-year survival).

4. Late toxicity: late subcutaneous breast fibrosis.

5. C-SS.

6. DM-FS.

7. Subsequent mastectomy.

The population included women with early breast cancer and the intervention was PBI/APBI versus WBRT. We used GRADEpro and the GRADE approach to evaluate the strength of the evidence (GRADE Working Group 2004). To calculate the absolute risk for the control group for time-to-event outcomes, we estimated the event rate at a specific time point (five years for LR-FS, BC-SS, DM-FS and OS) from the Kaplan-Meier curves or reported event rates. We entered these estimated values in GRADEpro, which automatically calculated the corresponding absolute risks for the intervention group at five years.

\section{Subgroup analysis and investigation of heterogeneity}

In future updates if data are available, we may perform subgroup analyses to investigate whether the effects of using $\mathrm{PBI} / \mathrm{APBI}$ or conventional breast RT differ depending on nodal status, margin status, receptor status, hormonal manipulation or tumour stage.

If heterogeneity is identified in future updates, we will assess it both statistically and visually using the $\mathrm{Chi}^{2}$ test of heterogeneity (Altman 1992; Walker 1988), and I2 statistic (Higgins 2002; Higgins 2003). If we do identify significant heterogeneity, we will explore the reasons for it and attempt to explain it.

\section{Sensitivity analysis}

We performed a sensitivity analysis by excluding the trials at high risk of bias for subjective outcomes (ELIOT; Livi 2015; Polgár 2007; Rodriguez). In future updates, if adequate data are available, we will perform a sensitivity analysis to assess the robustness of the results by excluding studies at high risk of bias for subjective outcomes and unpublished trials.

\section{RE S U L T S}

\section{Description of studies}

See: Characteristics of included studies table.

\section{Results of the search}

For this review update, based on our search strategy, we identified and screened 3630 references from the major medical databases and identified 46 additional references from other sources. After exclusion of duplicates and screening of references (by title or abstract), we evaluated 46 full-text references and excluded eight references (see Characteristics of excluded studies table). Of the remaining 38 references, 17 records related to five new included studies (ELIOT; GEC-ESTRO; Livi 2015; RAPID; Rodriguez), six records provided data for two previously included studies (Polgár 2007; TARGIT), 14 records for four ongoing studies (IMPORT; IRMA; NSABP-B39/RTOG; SHARE), and one record for one study awaiting classification (NCT02375048).

Overall, when combining the original and review update, there were 44 records relating to seven included studies, 14 records relating to four ongoing studies and one record awaiting classification (see Figure 1). Two studies that were included in the original review have now been excluded (Dodwell 2005; Ribeiro 1993). This is because the surgery and techniques used to define volume of breast treated and the technology used in these two studies do not reflect current RT practice. In sum, this review update included seven studies and the qualitative analysis included six studies. 


\section{Figure 1. Study flow diagram.}

\begin{tabular}{|l|l|l}
\hline $\begin{array}{l}\text { Previous review version: } \\
-4 \text { included studies } \\
-7 \text { ongoing studies } \\
-2 \text { studies awaiting assessment }\end{array}$ & $\begin{array}{l}2 \text { previously included } \\
\text { studies (Dodwell 2005 } \\
\text { and Ribeiro 1993) } \\
\text { were excluded from } \\
\text { the 2015 review } \\
\text { update (see 'Results } \\
\text { of the search' for } \\
\text { reasons) }\end{array}$ \\
\hline
\end{tabular}

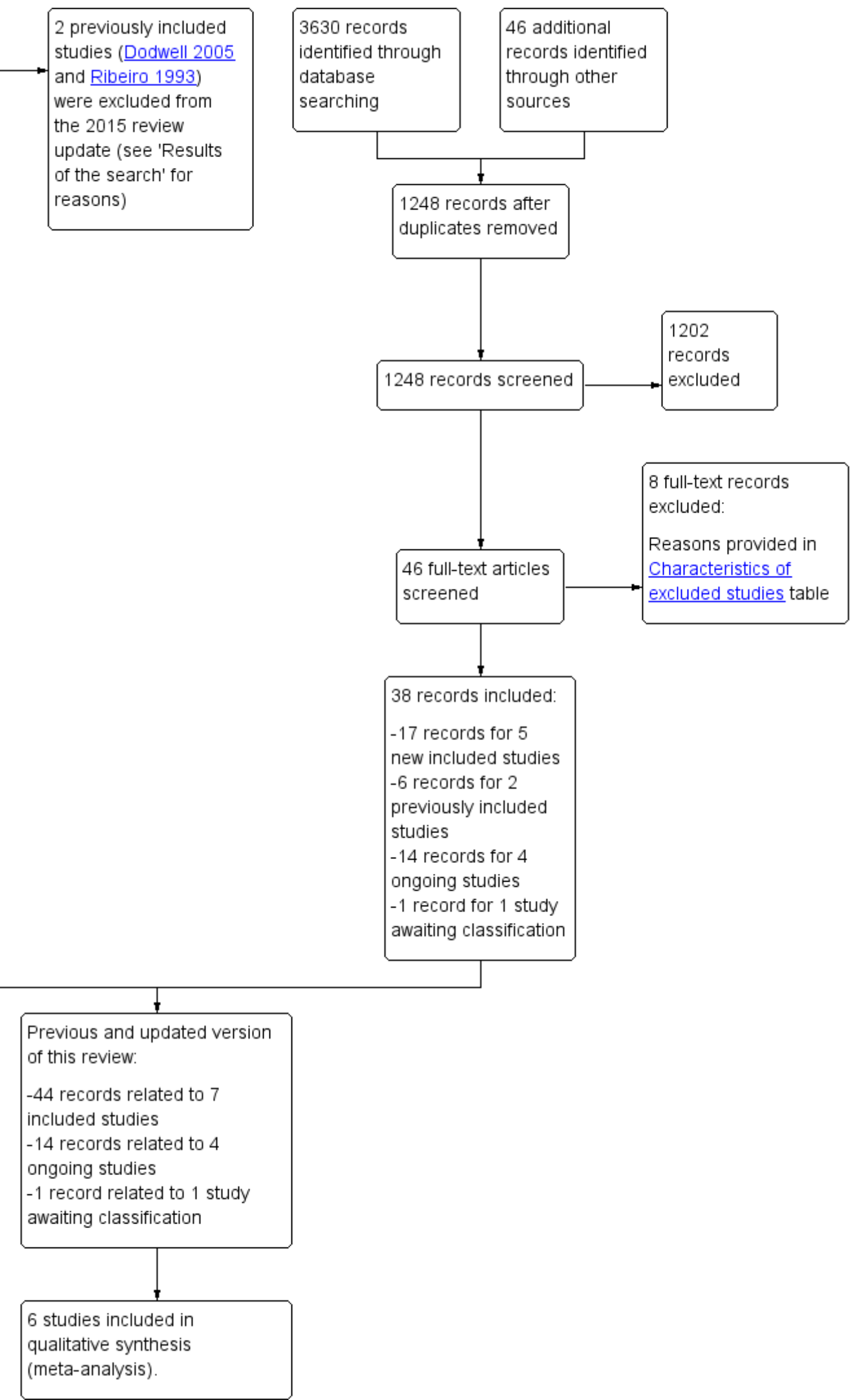




\section{Included studies}

\section{Design}

Seven RCTs enrolled 8955 women (ELIOT; GEC-ESTRO; Livi 2015; Polgár 2007; RAPID; Rodriguez; TARGIT); we studied 7586 women included in these studies. These studies enrolled women from July 1998 to May 2004 (Polgár 2007), February 2006 to July 2011 (RAPID), November 2000 to December 2007 (ELIOT), March 2000 to June 2011 (TARGIT), March 2005 to June 2013 (Livi 2015), and April 2004 to July 2009 (GEC-ESTRO); Rodriguez did not state accrual dates.

\section{Sample size}

Polgár 2007 enrolled 258 women of a planned sample size of 570 participants, RAPID enrolled 2135 women, Rodriguez enrolled 102 women, ELIOT enrolled 1305 women, TARGIT enrolled 3451 women, Livi 2015 enrolled 520 women and GEC-ESTRO enrolled 1184 women.

\section{Setting}

Four studies were single institution trials from tertiary institutions: one in Hungary (Polgár 2007), two in Italy (ELIOT; Livi 2015), and one in Spain (Rodriguez). GEC-ESTRO, TARGIT, and RAPID were multicentred, international studies.

\section{Participants}

Polgár 2007 included women with invasive breast cancer after wide local excision of tumour and negative pathological margins (unifocal tumours, tumour size less than $20 \mathrm{~mm}$, clinically or pathologically N0, or single microscopic nodal metastasis (greater than $0.2 \mathrm{~mm}$ and less than $2.0 \mathrm{~mm}$ ), that is, PT1N0-1miM0, Grade I or II; T1N0-N1miM0, Grade I or II. RAPID enrolled women with either invasive ductal carcinoma or ductal carcinoma in situ with tumours $3.3 \mathrm{~cm}$ or greater, with negative margins and no involved axillary nodes. Rodriguez included women with pT1-2pNOMO invasive ductal carcinoma, with tumour size $3 \mathrm{~cm}$ or less, with negative margins and Grade I or II histology. ELIOT enrolled women aged 48 to 75 years with early breast cancer, maximum tumour diameter $2.5 \mathrm{~cm}$, "suitable for breast conservation". TARGIT enrolled women aged 45 years or over, with $\mathrm{T} 1$ and small T2N0-1M0 invasive breast cancer, suitable for breast-conserving surgery, available for 10 years' follow-up. Livi 2015 included women aged over 40 years who had wide local excision or quadrantectomy for invasive breast cancer, negative margins and tumour size $2.5 \mathrm{~cm}$ or less. GECESTRO included women aged 40 years or more, small T1-2N0-miM0 (less than $3 \mathrm{~cm}$ ) with negative margins and no lympho-vascular invasion (LVI) and excluded women with multifocal tumours. GECESTRO included Tis. See Characteristics of included studies table.

\section{Interventions}

\section{Experimental arm}

PBI using either:

1. brachytherapy:

a. high-dose-rate (HDR) brachytherapy: seven $\times 5.2$ Gy HDR multi-catheter brachytherapy for 88/128 women (Polgár 2007); 30.3 to $32.0 \mathrm{~Gy} /$ seven or eight fractions (GEC-ESTRO);

b. pulsed-dose-rate (PDR) brachytherapy: $50 \mathrm{~Gy}$ at 0.6 to $0.8 \mathrm{~Gy} /$ hour in GEC-ESTRO or
2. EBRT to partial breast. PBI delivered via EBRT was delivered:

a. via conventionally fractionated (2 Gy per fraction) in $50 \mathrm{~Gy} / 25$ fraction electron beam RT delivered using a linear accelerator to the partial breast for 40/128 women (Polgár 2007);

b. at greater than 2 Gy per fraction delivered using a linear accelerator. RAPID used 3D-CRT in $38.5 \mathrm{~Gy} / 10$ fractions over five to eight days (with a minimum six hour gap between fractions given on the same day) and Rodriguez used $37.5 \mathrm{~Gy} / 10$ fractions twice daily over five days. Livi 2015 delivered $30 \mathrm{~Gy}$ in five fractions using intensity-modulated radiotherapy (IMRT);

c. using electrons: intraoperative electron therapy to deliver 21 Gy in one fraction at the $90 \%$ isodose delivered at the time of surgery after tumour excision using 6 to $9 \mathrm{MeV}$ (ELIOT);

d. using kilovoltage EBRT: TARGIT used a single fraction of RT given intraoperatively (using Intrabeam); 50 kV 20 Gy/one fraction at $2 \mathrm{~mm}$ beyond surface of 1.5 to $5.0 \mathrm{~cm}$ spherical applicator placed in excision cavity.

\section{Control arm}

WBRT using conventional fractionation:

1. ELIOT and Polgár 2007 used $50 \mathrm{~Gy} / 25$ fractions WBRT;

2. RAPID permitted two doses for WBRT: $50 \mathrm{~Gy} / 25$ fractions or 42.5 Gy/16 fractions;

3. Rodriguez gave $48 \mathrm{~Gy}$ in 24 fractions;

4. TARGIT gave "Standard post-operative RT ( 40 to $56 \mathrm{~Gy} \pm 10$ to 16 Gy boost)";

5. Livi 2015 used $50 \mathrm{~Gy} / 25$ fractions plus $10 \mathrm{~Gy}$ boost;

6. GEC-ESTRO used 50 to $50.4 \mathrm{~Gy}$ in 1.8 to $2.0 \mathrm{~Gy} /$ fraction using 4 to $10 \mathrm{MV}$ beams plus $10 \mathrm{~Gy} / 5$ fraction boost.

\section{Co-interventions}

Chemotherapy and hormonal manipulation: in Livi 2015, Polgár 2007, GEC-ESTRO, RAPID, and TARGIT, women received adjuvant systemic therapy according to institutional protocol, and Rodriguez treated oestrogen receptor positive women with hormonal manipulation. Systemic therapy in ELIOT was "administered according to the European Institute of Oncology policy" at the time (see Characteristics of included studies table for further details). In total, 6372/6820 (93\%) women received hormonal manipulation and $977 / 6820(14.3 \%)$ of the women received chemotherapy.

ELIOT treated any women with four or more involved nodes with regional nodal RT. No women in any of the other included studies received regional nodal $\mathrm{RT}$.

\section{Outcomes}

\section{Primary outcomes}

\section{Local recurrence-free survival}

Six trials reported local recurrence in the ipsilateral breast as a discrete outcome (GEC-ESTRO; Rodriguez; ELIOT; Livi 2015; Polgár 2007; TARGIT).

\section{Cosmesis}

Six trials reported cosmesis (cosmetic outcome). Polgár 2007, Livi 2015, and Rodriguez reported a global cosmetic result (used the Harvard Cosmetic score (see Table 1)) and RAPID used the EORTC Cosmetic rating System for Breast Cancer (Aaronson 
1998); both were four-point scales. GEC-ESTRO evaluated cosmesis using digital photos, with both participant-reported outcomes and physician-reported outcomes using a four-point scale (Wazer 1992; see Table 2). Rodriguez and RAPID reported participant-reported cosmetic outcomes. RAPID blinded assessment of cosmetic outcome. TARGIT assessed cosmetic outcome at a single centre in a sub-study that included 105 women. A software program, blinded to treatment arm, assessed digital photos at a median 23 months using a four-point scale.

\section{Secondary outcomes}

\section{Overall survival}

Six trials reported OS (GEC-ESTRO; Rodriguez; ELIOT; Livi 2015; TARGIT; Polgár 2007).

\section{Toxicity}

Four trials reported acute skin toxicity. Rodriguez, Livi 2015, and TARGIT used the Radiation Therapy Oncology Group Common Toxicity Criteria (RTOG CTC) (Cox 1995; Table 3) and ELIOT used a five-point scale (which was not referenced).

Five trials reported late toxicity (telangiectasia (small blood vessels visible on the treated skin), breast pain, fat necrosis and subcutaneous fibrosis). Polgár 2007 reported fat necrosis at four years according to a five-point institutional scale (Table 4); RAPID reported late RT toxicity (telangiectasia, induration (subcutaneous fibrosis), breast pain and fat necrosis) using the National Cancer Institute Common Toxicity Criteria ( $\mathrm{NCl}$ CTC 3.0; NCl; three-point scales; Table 5). GEC-ESTRO reported late toxicity (breast pain, late subcutaneous toxicity and late RT skin toxicity) using the RTOG CTC (Cox 1995). ELIOT reported fat necrosis and radiological radiation pneumonitis using late effects of normal tissue - subjective objective management analytic criteria (LENT-SOMA; Pavy 1995). Livi 2015 scored late RT toxicity using RTOG CTC (Cox 1995). TARGIT reported "complications arising six months after randomisation" and reported RTOG CTC (Cox 1995) Grade III or IV RT-related skin complications, haematomas/seromas requiring greater than three aspirations or surgery, wound infections requiring intravenous antibiotics or surgery and skin breakdown/delayed wound healing.

\section{New primary tumours in ipsilateral breast ('elsewhere primaries')}

Three trials reported new primary tumours in ipsilateral breast (ELIOT; GEC-ESTRO; Livi 2015).

\section{Cause-specific survival}

Five trials reported C-SS (where an independent clinician, blinded to treatment arm, determined cause of death) (ELIOT; GEC-ESTRO; Livi 2015; Polgár 2007; TARGIT).

\section{Distant metastasis-free survival}

Five trials reported DM-FS (ELIOT; GEC-ESTRO; Livi 2015; Polgár 2007; Rodriguez).

\section{Relapse-free survival}

One trial reported R-FS (Polgár 2007).

\section{Loco-regional recurrence-free survival}

Three trials reported L-RR-FS (ELIOT; GEC-ESTRO; TARGIT).

\section{Subsequent mastectomy}

Three trials reported subsequent mastectomy (GEC-ESTRO; Polgár 2007; TARGIT).

\section{Compliance}

Three trials reported compliance (GEC-ESTRO; Polgár 2007; TARGIT).

\section{Costs}

We found no trials reporting cost.

\section{Quality of life}

Two trials reported quality of life. RAPID used the Breast Cancer Questionnaire (a validated modification of the Breast Cancer Chemotherapy Quality of Life Questionnaire; Levine 1998) and GECESTRO used the EORTC QLQ-C30 and QLQ-BR23 (Levine 1998).

\section{Consumer preference}

We found no trials reporting consumer preference.

The included RCTs differed in several ways.

1. Population included: see above.

2. Surgery performed: margins were negative for women in GECESTRO ( $2 \mathrm{~mm}$ or greater); Rodriguez (greater than $3 \mathrm{~mm}$ ); Polgár 2007 (less than $2 \mathrm{~mm}$ : 1/258, $2 \mathrm{~mm}$ or greater: 246/258 or had no tumour at ink: 11/258); RAPID ("microscopically clear") and TARGIT (1 $\mathrm{mm}$ or greater). ELIOT did not describe margin status. Surgery in Livi 2015 could be either wide local excision or quadrantectomy (margins $5 \mathrm{~mm}$ or greater); in TARGIT if margins were close/involved (invasive disease or in situ disease $1 \mathrm{~mm}$ or greater from margin) re-excision was strongly advised.

3. Target volume definition for the treated PBI/APBI volume varied between the trials. Polgár 2007 clipped the cavity and the planning target volume (PTV) comprised the cavity plus a 1 to $2 \mathrm{~cm}$ margin isotropically (in all directions three dimensionally) for those women treated with interstitial therapy. If electrons were used, 6 to $15 \mathrm{MeV}$ were used to treat the cavity with a $2 \mathrm{~cm}$ margin. In RAPID, the clinical target volume (CTV) was defined as the tumour bed seen on computer tomography (CT), including the surgical clips plus a $1 \mathrm{~cm}$ margin, with a $1 \mathrm{~cm}$ margin on CTV to derive PTV. In Rodriguez, the involved breast quadrant was contoured. In ELIOT, the "clinical target volume was decided according to the site and size of the tumour". In Livi 2015, a CTV was drawn on a planning CT with a uniform $1 \mathrm{~cm}$ margin around the surgical clips, then a $1 \mathrm{~cm}$ margin added to construct the PTV. The target volume was the tumour cavity for TARGIT. In GEC-ESTRO, the target volume was defined individually for each woman, the CTV was the tumour bed plus a "safety margin" $2 \mathrm{~cm}$ or greater, this was planned using CT.

4. Radiation dose prescribed differed greatly between the trials. The PBI/APBI arm dose was higher than the WBRT dose for all studies except ELIOT (see Table 6 for dose, fraction size and dose prescription point, where it was specified).

5. The trials differed in fractionation used for APBI. In Polgár 2007, most women (88/128) received accelerated RT, RAPID used 3.85 Gy fractions, Rodriguez delivered 3.75 Gy fractions using daily RT and Livi 2015 used 6 Gy per fraction. GEC-ESTRO used seven or eight fractions for HDR and 0.6 to $0.8 \mathrm{~Gy}$ pulses for PDR. ELIOT used $21 \mathrm{~Gy}$ at the $90 \%$ isodose delivered in a single fraction. 
TARGIT used 20 Gy to the cavity surface delivered in a single fraction (Table 6).

6. RT technique for PBI/APBI delivery differed. In Polgár 2007, most women $(88 / 128)$ in the $\mathrm{PBI} / \mathrm{APBI}$ arm received interstitial brachytherapy, but 40/128 women received EBRT, as they were not suitable for brachytherapy (Table 7). RAPID and Rodriguez used 3D-CRT (using EBRT); Livi 2015 used IMRT to deliver EBRT; ELIOT delivered intraoperative electron therapy at the time of surgery after tumour excision using 6 to $9 \mathrm{MeV}$ and TARGIT inserted a spherical applicator into the operative bed and sutured it in place to treat the tumour cavity (see Table 7).

7. Quality assurance differed. RAPID included an extensive quality assurance programme with credentialling, real-time and posthoc review of radiation quality. GEC-ESTRO involved both pre- and post-implant assessment of geometry using $\mathrm{CT}$, dose prescription and calculations were in accordance with International Commission of Radiation Units and Measurements (ICRU) 58 and strict dose volume histogram and dose maximums were mandated, the post-hoc quality assurance requirements were clearly detailed in the study protocol. For the WBRT component of TARGIT, as long as treating centres conformed to a formal quality management system issued by the International Standards Organization, no additional quality assurance was required. For the $\mathrm{APBI}$, quality assurance performed according to the manufacturer's instructions was to be performed and the resulting data to be made available to the trials centre. Data were submitted either annually or after every 50th participant treated with Intrabeam. Rodriguez, ELIOT, and Livi 2015 did not mention trial-specific quality assurance to assess quality of the delivered RT. Polgár 2007 did not mention quality assurance for APBI using electrons or WBRT.

8. One study did not accrue the full sample size: Polgár 2007 stopped early because a competing multicentred RCT was started.

\section{Excluded studies}

In the 2015 review update, we excluded eight studies (see Characteristics of excluded studies table).

\section{Risk of bias in included studies}

\section{Allocation}

We judged the risk of bias for random sequence generation and allocation concealment as follows: ELIOT, GEC-ESTRO, Livi 2015, Livi 2015, RAPID, Rodriguez, and TARGIT were at low risk of bias for sequence generation. Polgár 2007 was randomized, the method (sealed envelopes) described and allocation was done by the chief investigator. TARGIT, Livi 2015, and GEC-ESTRO were at low risk of bias for allocation concealment. ELIOT, RAPID, Rodriguez, and Polgár 2007 did not clearly report allocation concealment, so were at unclear risk of bias.

\section{Blinding}

\section{Objective outcomes}

RAPID and Rodriguez did not mention blinding of participants. It would have been difficult to do so with this intervention, but the lack of blinding was unlikely to have introduced bias (Polgár 2007). Participants in GEC-ESTRO, Livi 2015, and TARGIT were not blinded to treatment arm, but we considered this unlikely to introduce bias.
ELIOT did not blind participants; for objective outcomes, the clearly pre-specified criteria for endpoints and the pre-specified follow-up protocol meant we deemed this domain at low risk of bias.

The trials did not mention blinding of physicians. It would have been difficult to do so with this intervention, but failure to do so is less likely to have introduced bias when the mammographic screening interval was pre-specified as in GEC-ESTRO, Livi 2015, RAPID, and Rodriguez. Polgár 2007 had a pre-specified followup protocol with pre-determined interval for mammographic evaluation and Polgár 2007 and Rodriguez required biopsy confirmation for any local recurrence; therefore, this domain was at low risk of bias. This served to make the objective outcomes at low risk of bias. In TARGIT, physicians were not blinded to treatment allocation, which is unlikely to have been a source of bias.

ELIOT did not blind personnel; for objective outcomes, the clearly pre-specified criteria for endpoints and the pre-specified follow-up protocol meant we deemed this domain at low risk of bias.

Polgár 2007 did not mention blinding of outcome assessors, but the pre-determined mammographic follow-up protocol and requirement for biopsy confirmation of local recurrence would have reduced the risk of bias. TARGIT did not blind outcome assessors, but the pre-specified follow-up protocol minimized the risk of bias. TARGIT reported that the analyses were done blinded, which reduced the risk of bias. ELIOT, GEC-ESTRO, Livi 2015, RAPID, and Rodriguez were at low risk of bias for this outcome.

\section{Subjective outcomes}

Blinding of participants for subjective outcomes was not reported, but it is unlikely to have introduced bias because only two trials reported participant-reported outcomes (RAPID; Rodriguez).

Polgár 2007 and Livi 2015 did not mention blinding of physicians and this may have introduced bias. In RAPID, the physician reviewers were blinded to treatment arm; this was not stated for the trained nurse observers, but we deemed the outcome at low risk of bias despite this.

As Polgár 2007 did not mention blinding of outcome assessors, it is unlikely to have been done and is potentially a source of bias and, therefore, at high risk of bias. The authors of TARGIT did not report blinding of outcome assessors, so it seems unlikely that they were. However, the use of a pre-determined data collection form for toxicity would have reduced the risk of bias, because data were collected for all women studied. TARGIT performed a blinded assessment of cosmesis in a sub-set of 105 women. The outcome assessors in ELIOT and GEC-ESTRO were not blinded for assessment of subjective outcomes, so we deemed this domain at high risk of bias. In Rodriguez, although they noted a participant-reported outcome, more data came from the physicians (not blinded to treatment arm), so this outcome of cosmesis was at high risk of bias.

\section{Incomplete outcome data}

ELIOT excluded no women, none were lost to follow-up and there was no attrition reported, thus this study was at low risk of bias. Polgár 2007 excluded no women and they reported attrition by arm (without providing reasons), and the risk of bias was low. GECESTRO reported on all women randomized, and they reported postrandomization exclusions by arm, with reasons, so we deemed this at low risk of bias. RAPID and Rodriguez were both interim reports of 
ongoing studies, so they were at unclear risk of bias for this domain. Livi 2015 reported no exclusion or attrition, so we deemed this at low risk of bias. TARGIT was at low risk of bias for this domain.

\section{Selective reporting}

For ELIOT, Livi 2015, and Polgár 2007, the trial protocols were not available for review and we judged them at unclear risk of bias. TARGIT did not report on all the outcomes pre-specified in the protocol, but it is likely that these outcomes will form the basis of future publications so we judged this at low risk of bias. RAPID and Rodriguez were interim reports; therefore, we deemed them at unclear risk of bias. GEC-ESTRO did not report on all their planned outcomes, but stated they will be the subject of a future paper, so we deemed this domain at low risk of bias.

\section{Other potential sources of bias}

Regarding other potential sources of bias: Polgár 2007 had low risk of bias. Polgár 2007 stopped the trial early because a competing trial started recruiting (GEC-ESTRO). TARGIT had short median follow-up, which put it at high risk of bias (see Figure 2). RAPID and Rodriguez were interim reports; therefore, we deemed them at unclear risk of bias. We identified no other sources of bias GECESTRO, Livi 2015, or ELIOT, so deemed them at low risk of bias (see Figure 2).

\section{Figure 2. Risk of bias summary: review authors' judgements about each risk of bias item for each included study.}

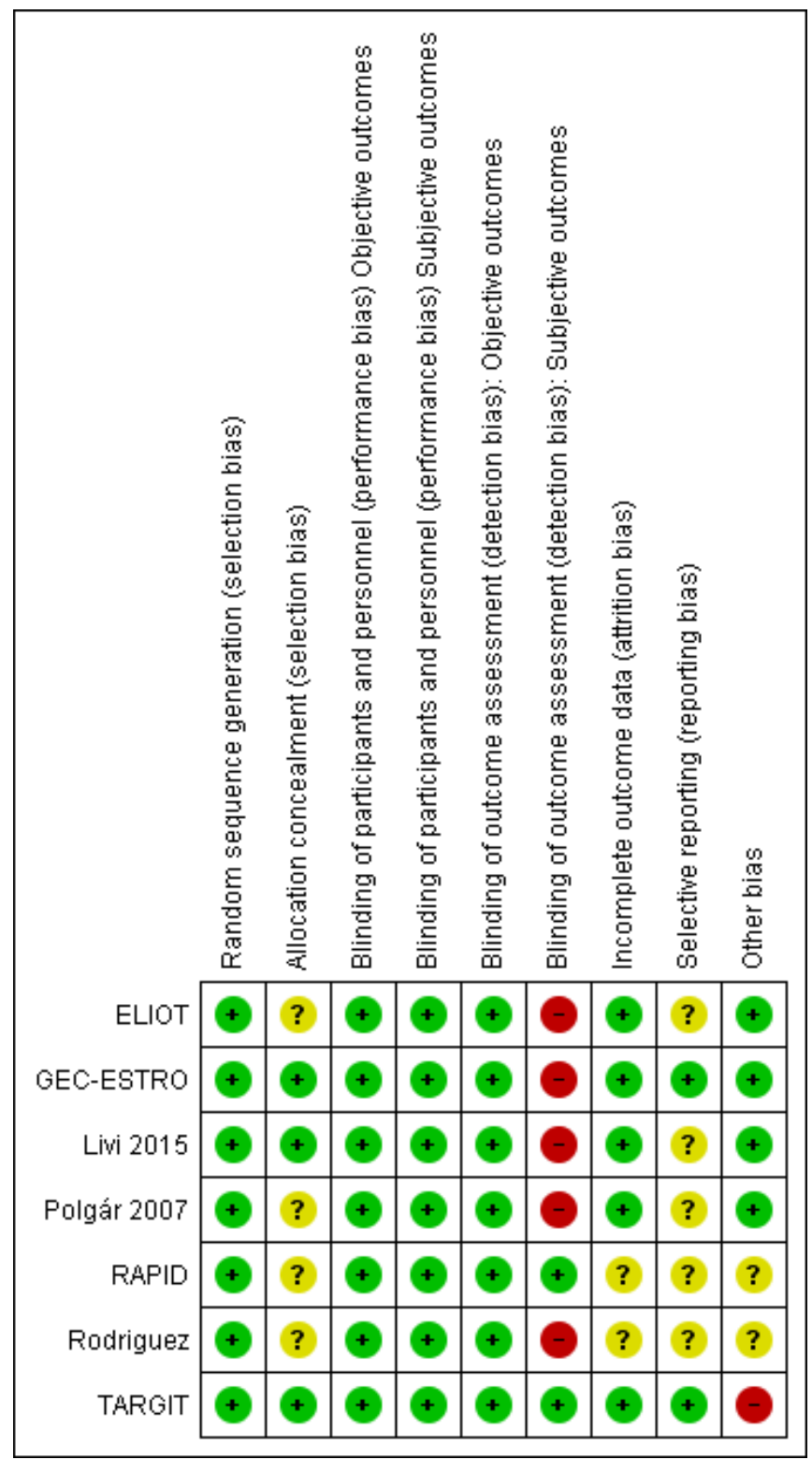

\section{Effects of interventions}

See: Summary of findings for the main comparison Partial breast irradiation (PBI)/accelerated partial breast irradiation (APBI) for early breast cancer 


\section{Primary outcomes}

\section{Local recurrence-free survival in the ipsilateral breast}

There were 89 local recurrences in the 6820 women studied in six studies.
LR-FS appeared worse with PBI/APBI (HR 1.62, 95\% Cl 1.11 to 2.35; six studies, 6820 participants; Analysis 1.1; Figure 3). There was evidence of heterogeneity on visual inspection and statistical testing $\left(\mathrm{P}\right.$ value $\left.=0.008, \mathrm{I}^{2}=71 \%\right)$

\section{Figure 3. Forest plot of comparison: 1 Partial breast irradiation (PBI)/accelerated partial breast irradiation (APBI)} versus whole breast radiotherapy (WBRT), outcome: 1.1 Local recurrence-free survival.

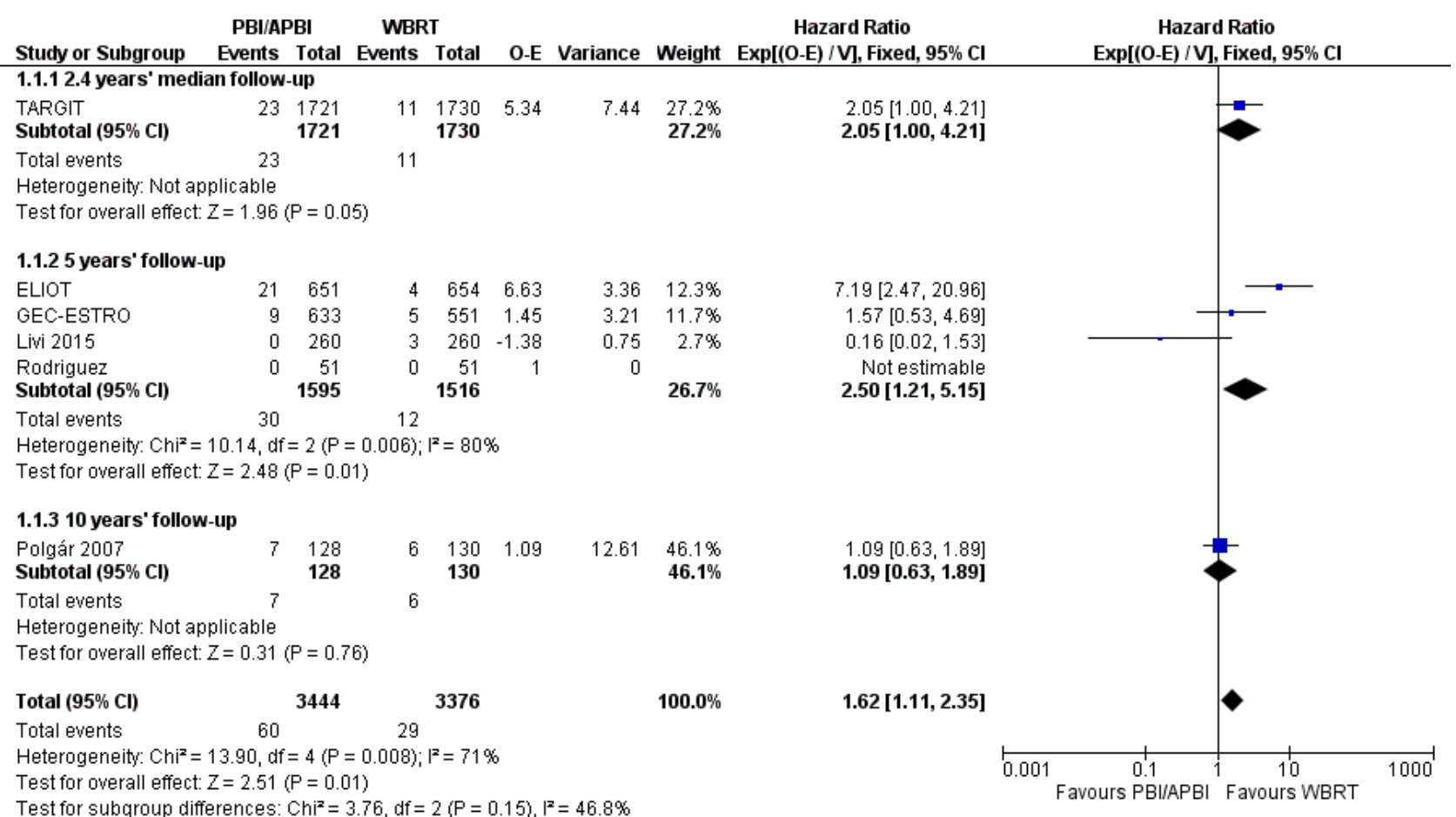

We performed sensitivity analysis based on excluding studies deemed at high risk of bias (for the domains of objective outcomes and other bias; TARGIT). We found PBI/APBI versus WBRT was associated with worse LR-FS (HR 1.48, $95 \% \mathrm{Cl} 0.95$ to 2.29). There appeared to be some evidence of heterogeneity both on visual inspection and statistical testing ( $P$ value $=0.07,12=68.6 \%$ ).

\section{Cosmesis}

Cosmetic outcome appears worse with $\mathrm{PBI} / \mathrm{APBI}$ when:

1. participant-reported $(\mathrm{OR} 1.74,95 \% \mathrm{Cl} 1.06$ to $2.87 ; \mathrm{P}$ value $=$ 0.03 , not tested for heterogeneity). We identified 89 events in 328 participants from one study (RAPID);

2. assessed by trained nurse observers (OR $3.14,95 \% \mathrm{Cl} 1.81$ to 5.45; P value $<0.0001$ ). We did not test for heterogeneity, as we studied 78 events in 335 participants deriving from one study (RAPID);

3. physician-reported $(\mathrm{OR} 1.51,95 \% \mathrm{Cl} 1.17$ to $1.95 ; \mathrm{P}$ value $=$ 0.002). There was considerable heterogeneity $\left(I^{2}=88 \%\right.$; $P$ value $=0.00004 ;$ Analysis 1.2 ). We studied 315 events in 1720 participants in five studies.

We performed sensitivity analysis by excluding studies at high risk of bias for blinding of outcome assessors for subjective outcomes (ELIOT; Livi 2015; Polgár 2007; Rodriguez) for physician reported cosmesis. We found cosmesis was worse with $\mathrm{PBI} / \mathrm{APBI}$ versus WBRT (OR 2.32, 95\% Cl 1.69 to 3.18; P value $=0.00001$ ). Testing for heterogeneity revealed the presence of considerable heterogeneity $(12=84 \% ; P$ value $=0.01)$.

\section{Secondary outcomes}

\section{Overall survival}

We found no difference in OS with PBI/APBI versus WBRT with data from 268 deaths in five studies with 6718 participants (HR 0.90, 95\% $\mathrm{Cl} 0.74$ to 1.09; $\mathrm{P}$ value $=0.27$; Analysis 1.3; Figure 4). There was no heterogeneity on either visual inspection or statistical testing $\left(1^{2}=\right.$ $40 \%$; $P$ value $=0.15$. 
Figure 4. Forest plot of comparison: 1 Partial breast irradiation (PBI)/accelerated partial breast irradiation (APBI) versus whole breast radiotherapy (WBRT), outcome: 1.3 Overall survival.

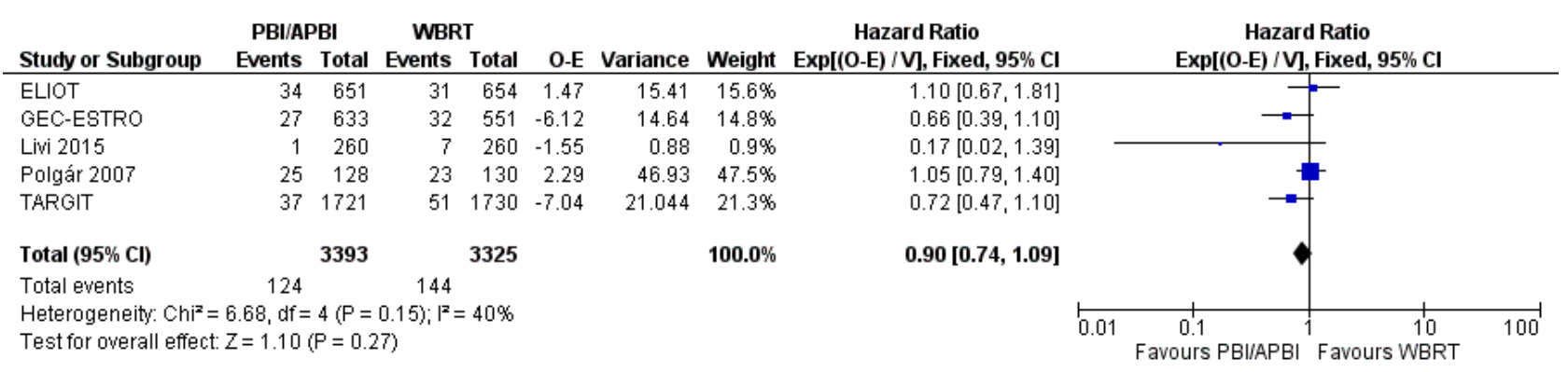

\section{Toxicity}

$\mathrm{PBI} / \mathrm{APBI}$ reduced acute skin toxicity compared with WBRT (OR 0.04 $95 \% \mathrm{Cl} 0.02$ to 0.09 ; $\mathrm{P}$ value $<0.00001$; Analysis 1.4 ). We studied 150 events in 608 participants in two studies. We found little evidence of heterogeneity $(12=27 \%$; $P$ value $=0.24)$.

There was no different in haematomas needing surgical aspiration between APBI and WBRT ( $P$ value $=0.338$; figure from text; TARGIT).

Seromas needing greater than three aspirations were more frequent with $\mathrm{APBI}$ compared with WBRT $(\mathrm{P}$ value $=0.012$; figure from text; TARGIT).

There was no difference in infection requiring intravenous antibiotics or surgical intervention between APBI and WBRT ( $P$ value $=0.292$; figure from text; TARGIT).

There was no difference in skin breakdown or delayed healing between APBI and WBRT ( $P$ value $=0.155$; figure from text; TARGIT).

Regarding late toxicity:

1. there was no difference in late skin toxicity with $\mathrm{PBI} / \mathrm{APBI}$ versus WBRT (OR 0.21, 95\% Cl 0.01 to 4.39; $\mathrm{P}$ value $=0.31$; data from two events in 608 participants in two studies; Analysis 1.5). There was no difference in late RT skin toxicity between PBI and WBRT in GEC-ESTRO ( $P$ value $=0.08$; figure from text);

2. telangiectasia appeared worse with $\mathrm{PBI} / \mathrm{APBI}$ compared with $\mathrm{PBI}$ (OR 26.56, 95\% Cl 3.59 to 196.51; $\mathrm{P}$ value $=0.001$; data from one study with 28 events in 766 evaluable women; RAPID);
3. $\mathrm{PBI} / \mathrm{APBI}$ increased radiological fat necrosis compared with WBRT (OR 1.58, 95\% Cl 1.02 to 2.43 ; $P$ value $=0.04$; three studies with 100 events in 1319 participants). We found little evidence of heterogeneity $\left(I^{2}=49 \%\right.$; $P$ value $=0.14$; Analysis 1.6);

4. $\mathrm{PBI} / \mathrm{APBI}$ increased subcutaneous fibrosis compared with WBRT (OR 6.58, 95\% Cl 3.08 to 14.06; $P$ value < 0.00001 ; data from one study with 59 events in 766 women). There was no difference in late subcutaneous toxicity between PBI and WBRT in GECESTRO ( $P$ value $=0.53$; figures from text);

5. there was no difference in breast pain with $\mathrm{PBI} / \mathrm{APBI}$ versus WBRT (OR 2.17, 95\% Cl 0.56 to 8.44; $\mathrm{P}$ value $=0.27 ; 10$ events in one study with 766 evaluable women); ELIOT reported no difference in breast pain (data not shown). Breast pain was reduced with $\mathrm{PBI}$ compared with WBRT in GEC-ESTRO (P value $=$ 0.04 ; figures from text).

\section{New primary tumours in ipsilateral breast 'elsewhere primaries'}

New primaries in the treated breast appeared more frequent with PBI/APBI compared with WBRT (OR $3.97,95 \% \mathrm{Cl} 1.51$ to 10.41 ; Analysis 1.7). There were 24 events in 3009 participants in three studies. There was evidence of heterogeneity $(12=74 \%$; $P$ value $=$ 0.02).

\section{Cause-specific survival}

We found no clear evidence that C-SS differed with PBI/APBI versus WBRT (HR $1.08,95 \% \mathrm{Cl} 0.73$ to $1.58,107$ breast cancer deaths in 6718 participants in five studies; Analysis 1.8; Figure 5). We found no evidence of heterogeneity on either visual inspection or statistical testing $\left(\mathrm{I}^{2}=0 \%\right.$; $\mathrm{P}$ value $=0.81$; Analysis 1.8$)$.

Figure 5. Forest plot of comparison: 1 Partial breast irradiation (PBI)/accelerated partial breast irradiation (APBI) versus whole breast radiotherapy (WBRT), outcome: 1.8 Cause-specific survival.

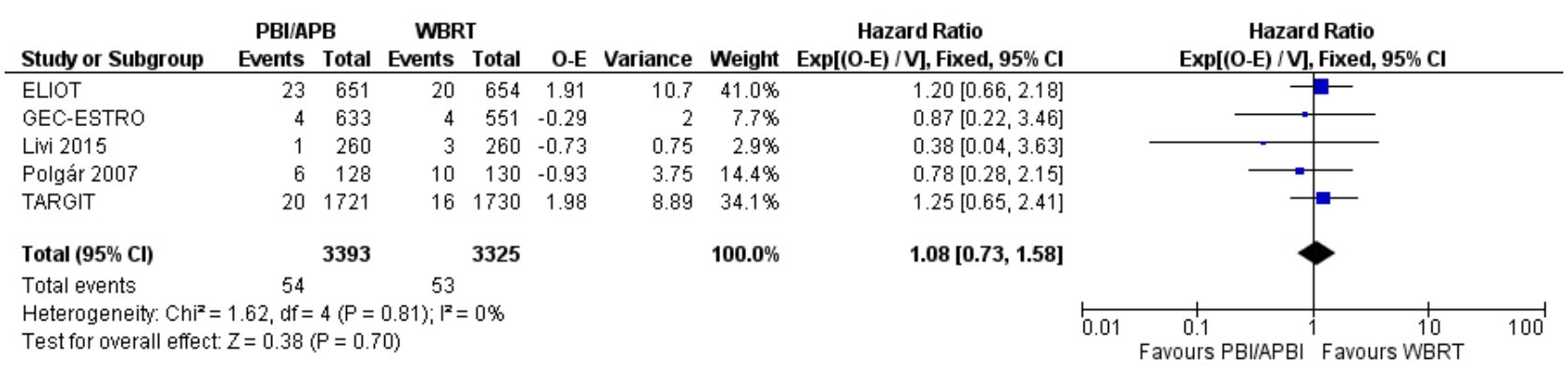




\section{Distant metastasis-free survival}

We found no clear evidence that DM-FS differed with PBI/APBI versus WBRT (HR $0.94,95 \% \mathrm{Cl} 0.65$ to $1.37,110$ events in 3267 participants in four studies; Analysis 1.9; Figure 6). We found no heterogeneity with either visual inspection or statistical testing $\left(1^{2}\right.$ $=0 \% ;$ P value $=1.0$ )

Figure 6. Forest plot of comparison: 1 Partial breast irradiation (PBI)/accelerated partial breast irradiation (APBI) versus whole breast radiotherapy (WBRT), outcome: 1.9 Distant metastasis-free survival.

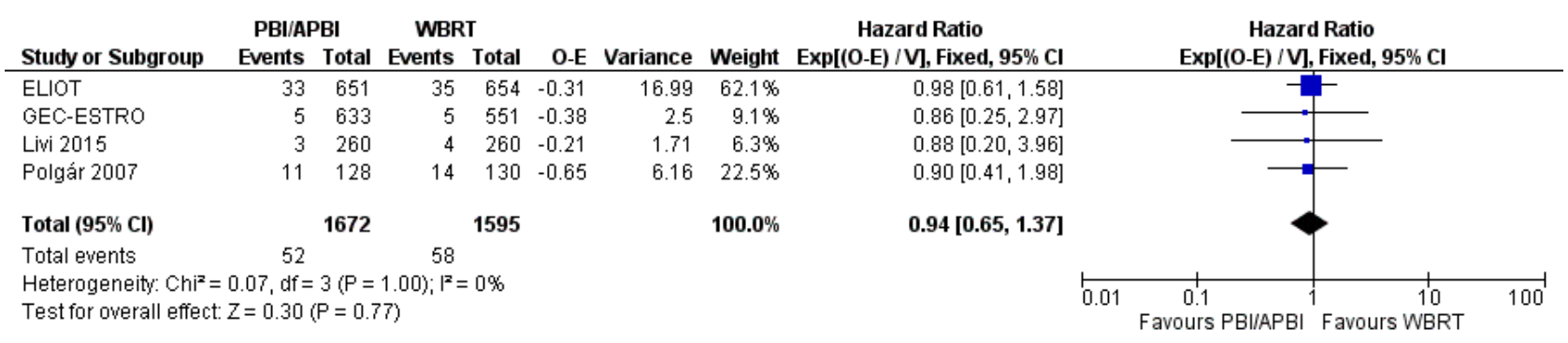

\section{Relapse-free survival}

We found no clear evidence that R-FS differed with $\mathrm{PBI} / \mathrm{APBI}$ versus WBRT (HR 1.36, 95\% Cl 0.88 to 2.09; $\mathrm{P}$ value $=0.16 ; 87$ relapses in 3811 participants in three studies; Analysis 1.10). We found little evidence of heterogeneity $\left(I^{2}=46 \%\right.$; $P$ value $\left.=0.17\right)$. R-FS did not differ in GEC-ESTRO (P value = 0.79; figure from text).

\section{Loco-regional recurrence-free survival}

We found that L-RR-FS was worse with PBI/APBI versus WBRT (HR $1.80,95 \% \mathrm{Cl} 1.00$ to 3.25; Analysis 1.11). We studied 48 events in 3553 participants in two studies.

\section{Subsequent mastectomy}

Subsequent mastectomy rate did not appear to differ between PBI/ APBI and WBRT (OR 1.20, 95\% Cl 0.77 to 1.87; Analysis 1.12). There were 79 events in 4817 participants in three studies. There was no evidence of heterogeneity $\left(I^{2}=0 \%\right.$; $\mathrm{P}$ value $\left.=0.45\right)$.

\section{Compliance}

Greater than $90 \%$ of the women randomized to $\mathrm{PBI} / \mathrm{APBI}$ received treatment in all of the included studies. For those women randomized to receive WBRT, greater than $90 \%$ of the women received the planned $R T$ in all of the included studies.

\section{Costs}

There were no data on costs.

\section{Quality of life}

There were no data on quality of life, although it was assessed in RAPID.

\section{Consumer preference}

There were no data on consumer preference.

\section{DISCUSSION}

\section{Summary of main results}

LR-FS appeared worse with PBI/APBI compared with WBRT (Analysis 1.1). Cosmetic outcome appeared worse with PBI/APBI compared with WBRT when participant-reported (OR 1.74, 95\% CI 1.06 to $2.87 ; \mathrm{P}$ value $=0.03)$, assessed by trained nurse observers $(\mathrm{OR}$
3.14, $95 \% \mathrm{Cl} 1.81$ to 5.45; $\mathrm{P}$ value $=0.00001)$ or physician-reported (OR 1.51, 95\% Cl 1.17 to 1.95 ; $P$ value $=0.002$ ) (Analysis 1.2) .

We found no evidence of a difference in OS when PBI/APBI was used compared with WBRT (HR 0.90, 95\% Cl 0.74 to 1.09 ; $\mathrm{P}$ value $=0.27$; Analysis 1.3).

We found $\mathrm{PBI} / \mathrm{APBI}$ versus WBRT was associated with decreased acute skin toxicity (OR $0.04,95 \% \mathrm{Cl} 0.02$ to 0.09 ; $\mathrm{P}$ value $<0.00001$; Analysis 1.4). Late skin toxicity did not differ with PBI/APBI versus WBRT, neither did breast pain, but we found it was associated with more telangiectasia, radiologically evident fat necrosis and more subcutaneous fibrosis. We found PBI/APBI versus WBRT was associated with more 'elsewhere primaries' (OR 3.97, 95\% Cl 1.51 to 10.41 ; Analysis 1.7).

We found no clear evidence of a difference in C-SS (Analysis 1.8), DM-FS (Analysis 1.9) or R-FS (Analysis 1.10) with PBI/APBI compared with WBRT but we could not exclude potentially important differences between the treatment groups. We found no difference with PBI/APBI versus WBRT for L-RR-FS (HR $1.80,95 \% \mathrm{Cl} 1.00$ to 3.25; $\mathrm{P}$ value $=0.05$; Analysis 1.11 ). The mastectomy rate did not appear affected with PBI/APBI compared with WBRT (Analysis 1.12). Compliance with allocated treatment was high at greater than $90 \%$ for all women studied. We found no data for the effects of PBI/APBI and WBRT on costs, quality of life and consumer preference.

Based on these findings, PBI/APBI appeared to be associated with worse LR-FS in comparison to WBRT. Local relapse was rare in the carefully selected participant population in this review. Local relapse was increased by 5 per 1000 women (range 1/1000 to $11 / 1000$ ) with $\mathrm{PBI} / \mathrm{APBI}$. The use of $\mathrm{PBI} / \mathrm{APBI}$ was associated with decreased acute toxicity. There was no strong evidence that $\mathrm{PBI} / \mathrm{APBI}$ was associated with increased breast pain or late skin toxicity. We found that PBI/APBI caused increased telangiectasia, radiologically evident fat necrosis (Table 4) and subcutaneous fibrosis (see Results, Description of studies, included studies for definitions).

\section{Overall completeness and applicability of evidence}

There were limitations in completeness and applicability of evidence due to clinical heterogeneity between the trials, duration of follow-up and little or no useful information available for some outcome measures. 


\section{Clinical heterogeneity between the trials}

There was evident clinical heterogeneity in both the study participants and the interventions.

The PBI/APBI delivered was heterogeneous in dose, technique, fractionation and target delineation.

1. The RT doses varied between the trials. In all studies, the EQD2 delivered in the APBI arm was higher than the WBRT dose (with the exception of ELIOT; see Table 6). Despite the dose escalation in the APBI arm, we found that LR-FS was worse with APBI, which suggests there may be technical issues with RT delivery (e.g. target volume definition or target coverage).

2. The RT techniques used to deliver PBI/APBI varied (see Table 7).

3. The trials differed in fractionation used; all the studies used greater than 2 Gy per fraction in the experimental arm, with the exception of Polgár 2007, where some of the women in the PBI/ APBI arm received 2 Gy per fraction (see Table 6).

4. The techniques used to define the target volume in GEC-ESTRO, Livi 2015, Polgár 2007, RAPID, and TARGIT were consistent with current practice, but ELIOT provided inadequate details for the technique used in to be certain of this.

Avoiding geographic miss is imperative in RT. Delivery of RT is a technical exercise. Peters 2010 demonstrated the extremely important role that quality assurance plays in the delivery of high-quality RT. Poor-quality RT (a non-compliant plan) for locally advanced head and neck cancer was associated with a $20 \%$ detriment in survival and a $29 \%$ detriment to loco-regional control (Peters 2010). Three studies did not mention quality assurance (ELIOT; Livi 2015; Rodriguez). Although Polgár 2007 assessed implant quality, less than $20 \%$ of the implants had post-implant $\mathrm{CT}$ to document PTV coverage and quality assurance for APBI using electrons or WBRT was not mentioned (see Characteristics of included studies table). RAPID included an extensive quality assurance programme with credentialling, real-time and post-hoc review of radiation quality. GEC-ESTRO had rigorous pre- and postimplant quality assurance procedures.

The lack of precision in target definition, the variety of methods used to deliver PBI/APBI (even within the experimental arm of the trials; see Table 7) and the omission of robust quality assurance mean that the RT delivered in some of the trials was not reproducible. We cannot be certain of the dose delivered and the volume of breast treated.

We found there was heterogeneity for the outcome of cosmesis (physician-reported). There were some possible sources of clinical heterogeneity that may have contributed to this: in Polgár 2007, $40 / 128(30 \%)$ women in the $\mathrm{PBI} / \mathrm{APBI}$ arm received 50 Gy in 25 fractions to the tumour bed using EBRT; these women who had conventionally fractionated RT at the same dose as the WBRT arm were likely to have very similar cosmetic outcome. Livi 2015 delivered PBI/APBI using IMRT, with careful dose constraints applied: we know that IMRT is associated with improvement in cosmetic outcome in the setting of WBRT (Donovan 2007; Pignol 2008).

Modern breast-conserving therapy with postoperative WBRT achieves local control rates of $3.3 \%$ to $3.4 \%$ at five years and $5.2 \%$ to $6.7 \%$ at 10 years (Haviland 2013). With careful participant selection (aged 65 years or greater, T1-2 tumours, not greater than 3 $\mathrm{cm}$, margin negative, oestrogen receptor positive and all receiving tamoxifen), surgery alone can achieve local recurrence rates of $4.1 \%$ at five years (Kunkler 2015). The risk of local recurrence continues with longer follow-up, in modern series where women with good prognosis were treated with surgery alone, the 10-year risk of loco-regional or distant recurrence was $19.9 \%$ (reduced to 6.3\% with RT; Blamey 2013; Fisher 2002; Fyles 2004; Hughes 2004; Potter 2007; Prescott 2007; Winzer 2010). Even if PBI/APBI is poorly targeted, in a low-risk population being treated with systemic therapy, low local recurrence rates can be expected.

The paradigm for $\mathrm{PBI} / \mathrm{APBI}$ relies on the basis that WBRT does not reduce the number of 'elsewhere primaries' within the treated breast, but we found that PBI/APBI appeared to be associated with an increase in 'elsewhere primaries' (OR $3.97,95 \% \mathrm{Cl} 1.51$ to 10.41 ; Analysis 1.7).

\section{Duration of follow-up}

The length of follow-up in five of the included trials was adequate to detect local recurrences (10 years (Polgár 2007), 69 months (ELIOT), 65 months (Livi 2015), 60 months (Rodriguez), 79.2 months (GECESTRO)). The median follow-up for TARGIT, of 29 months, made it inadequate for the outcome of local control. Local recurrences do continue to increase over time (at about $1 \%$ per year), as can be seen in the START data: $3.3 \%$ to $3.4 \%$ at five years and $5.2 \%$ to $6.7 \%$ at 10 years (Haviland 2013). Any effect on breast C-SS related to local control requires much longer follow-up (EBCTCG 2011). None of the included trials had long enough follow-up to report OS results.

We know that RT reduces the risk of any first recurrence, and although the proportional reduction is most evident in the first year post-treatment, it is still present in years five to nine (RR 0.59, $95 \% \mathrm{Cl} 0.5$ to 0.7 ; EBCTCG 2011). Even in modern studies that included low-risk women treated with lumpectomy (enrolled after 1989), the 10-year risk of loco-regional and distant recurrence was 19.9\% (reduced to 6.3\% with RT; Blamey 2013; Fisher 2002; Fyles 2004; Hughes 2004; Potter 2007; Prescott 2007; Winzer 2010). Even women at low risk of recurrence (if they are at risk for another 30 years) are likely to have increases in recurrence with longer followup. The use of PBI/APBI may mean they are at risk of 'elsewhere primaries' for this time period.

\section{Little or no useful information available for some outcome measures}

The authors of TARGIT (completed, but with short follow-up) indicated that cosmesis, participant satisfaction, health economics and participant preference will be the subject of a sub-protocol and information with respect to these outcomes will be available in the future. The five ongoing trials that we found are likely to address these outcomes (IMPORT; IRMA; NSABP-B39/RTOG; SHARE; see Characteristics of ongoing studies table).

\section{Quality of the evidence}

The available evidence does allow for the drawing of robust conclusions in respect of the objective of the review: to determine whether $\mathrm{PBI} / \mathrm{APBI}$ is equivalent to or better than conventional or hypo-fractionated WBRT after breast-conserving therapy for earlystage breast cancer. We found seven studies with 8895 participants. 
LR-FS: we downgraded for risk of bias because 3451/6820 (38\%) women contributing to this outcome came from a study deemed at high risk of bias because of short follow-up. We did not downgrade for indirectness because the included studies used contemporary $\mathrm{RT}$ techniques. With respect to inconsistency $\left(\mathrm{I}^{2}=71 \%\right.$; $\mathrm{P}$ value $=$ 0.008 ), there was considerable clinical heterogeneity with respect to RT dose, technique and use of quality assurance procedures. However, the RT techniques employed all delivered a dose that was the same or higher in the PBI/APBI arm than the WBRT arm, which should mean the LR-FS is better or the same (see Table 6). We downgraded for imprecision; there were fewer than 300 events, and although the optimum information size (OIS) had been met, the Cls did not exclude either clinically unimportant harms or clinically important harms. We did not downgrade for publication bias, given the systematic literature search we had performed. The overall GRADE (GRADE Working Group 2004) quality of evidence for this outcomes was low.

Cosmesis: we did not downgrade for risk of bias because less than $30 \%$ of events came from studies at high risk of bias for lack of blinding of outcome assessors, which is particularly important for a subjective outcome such as cosmesis. We did not downgrade for indirectness, but did so for inconsistency $\left({ }^{2}=88 \%\right.$; $P$ value $<0.00001$ ) even though all assessments used the same fourpoint scale. We did downgrade for imprecision (there were greater than 300 events (315 events)) and the Cls did not exclude the possibility of clinically unimportant harms. We did not downgrade for publication bias given the systematic literature search we had performed. The overall GRADE (GRADE Working Group 2004) quality of evidence for this outcomes was low.

OS: we did not downgrade for risk of bias, indirectness, inconsistency $\left(\mathrm{I}^{2}=40 \%\right.$; $\mathrm{P}$ value $\left.=0.15\right)$ or imprecision (the Cls crossed one, but excluded clinically significant harms or benefits). We did not downgrade for publication bias (based on examination of a Funnel plot). The overall GRADE (GRADE Working Group 2004) quality of evidence for this outcome was high.

Late RT toxicity (subcutaneous fibrosis): we did not downgrade for risk of bias, indirectness or inconsistency (heterogeneity testing was not appropriate as only one study contributed data for this outcome). We downgraded for imprecision, as there were fewer than 300 events and the OIS was not met (the studies in PBI/ $\mathrm{APBI}$ were powered for other endpoints than this one) and Cls did not exclude clinically important harms. We did not downgrade for publication bias. The overall GRADE (GRADE Working Group 2004) quality of evidence for this outcomes was moderate.

C-SS: we did not downgrade for risk of bias, indirectness or inconsistency $(12=0 \%$; $P$ value $=0.81)$. We did downgrade for imprecision, given there were fewer than 300 events (99 events) and the $\mathrm{Cls}$ did not include the possibility of clinically significant benefits or harms from PBI/APBI. We did not downgrade for publication bias for this outcome. The overall GRADE (GRADE Working Group 2004) quality of evidence for this outcomes was moderate.

DM-FS: we did not downgrade for risk of bias, indirectness or inconsistency $\left(I^{2}=0 \% ; \mathrm{P}\right.$ value $\left.=1.0\right)$. We did downgrade for imprecision as there were fewer than 300 events (100 events) and the $\mathrm{Cls}$ did not exclude clinical meaningful benefits or harms. We did not downgrade for publication bias. The overall GRADE (GRADE
Working Group 2004) quality of evidence for this outcomes was moderate.

Subsequent mastectomy: we downgraded for risk of bias, because one of the studies contributing data had follow-up too short for assessment of this outcome. We did not downgrade for indirectness or inconsistency $\left(1^{2}=0 \%\right.$; value $\left.=0.45\right)$. We did downgrade for imprecision as there were fewer than 300 events (78 events) and the $\mathrm{Cls}$ did not exclude clinically meaningful benefits or harms. The overall GRADE (GRADE Working Group 2004) quality of evidence for this outcomes was low.

Refer to the Summary of findings for the main comparison.

\section{Potential biases in the review process}

We consider that we have identified all the relevant completed RCTs. For reporting of adverse effects, the precision was low because the OIS was not met. This may improve in future updates, as more information with respect to these outcomes is reported.

\section{Agreements and disagreements with other studies or reviews}

We found five systematic reviews examining PBI/APBI compared with WBRT.

We found one meta-analysis (Valachis 2010), which included one study (Polgár 2007) in common with our systematic review and recruited 1140 women (Dodwell 2005; Polgár 2007; Ribeiro 1993). They found no difference for mortality (OR $0.91,95 \% \mathrm{Cl} 0.67$ to 1.23 ; $P$ value $=0.55)$ and distant metastasis (OR $0.74,95 \% \mathrm{Cl} 0.51$ to 1.08 ; $\mathrm{P}$ value $=0.12$ ) for the comparison of $\mathrm{PBI} / \mathrm{APBI}$ versus WBRT. $\mathrm{PBI} /$ APBI was associated with increased local recurrence (OR 2.15, 95\% $\mathrm{Cl} 1.40$ to 3.31; $\mathrm{P}$ value $=0.001)$ and axillary recurrence $(\mathrm{OR} 3.43$, $95 \% \mathrm{Cl} 2.06$ to 5.71; P value $<0.0001$ ) when compared with WBRT. They concluded that PBI does not seem to jeopardize survival and may be used as an alternative to WBRT (Valachis 2010). The authors pooled the data from the trials (see Data synthesis section).

We found one systematic review with a search date in 2010 (BlueCross Blueshield). They included two RCTs (Polgár 2007; Ribeiro 1993 (which we excluded)) and seven non-RCTs. They concluded that "the body of evidence on interstitial PBI/APBI compared to conventional whole-breast irradiation is weak, and it is extremely weak (i.e. no comparative studies) for balloon brachytherapy, intraoperative $\mathrm{PBI} / \mathrm{APBI}$, and external-beam PBI/ APBI. The data on PBI/APBI compared to whole-breast irradiation are insufficient to draw any conclusions about the relative effectiveness of these modalities. Furthermore, it is becoming increasingly clear that each type of PBI/APBI should be judged on its own merits, and studies comparing different PBI/APBI techniques to each other as well as to whole-breast irradiation are needed" (BlueCross BlueShield).

We found one review that used a systematic search (search date February 2014) (Marta 2015). Our review differed in that we included updated data for TARGIT and they included Dodwell 2005 and Ribeiro 1993 (which we excluded). They reported decreased local control with APBI versus WBRT (HR 4.54, $95 \% \mathrm{Cl} 1.78$ to 11.61 ; $\mathrm{P}$ value $=0.002$ ). They concluded that $\mathrm{APBI}$ was associated with an increase in local recurrence, but found no difference in other outcomes. 
Kong 2014 did a systematic search (search date June 2012). They included 10 studies, and included two retrospective cohorts, two matched pair analyses and three prospective cohort studies. They found that $\mathrm{PBI} / \mathrm{APBI}$ was associated with increased local recurrence (OR 1.54, 95\% Cl 1.15 to 2.06; $\mathrm{P}$ value $=0.004$ ). They found no difference for the comparison of PBI/APBI for the outcomes of distant metastases, OS and disease-free survival.

One review by Ye 2013 studied 919 women in four studies; their search was not systematic (search date June 2013). They included a matched pair analysis, and the fourth study was not referenced. They reported no difference in local control, but appeared to have double counted the data for Polgár 2007 at two time points. They concluded that other outcomes did not differ, although they reported more women who were treated with APBI had good/ excellent cosmesis.

The review in Clinical Evidence (search date April 2009) compared intraoperative RT versus standard postoperative RT in women receiving breast-conserving surgery, and found no fully published RCTs (see comment, ASERNIP-S 2002). The review concluded, "Studies are currently attempting to address the question as to whether partial breast irradiation may be sufficient treatment for some sub-groups of breast cancer. Until those studies are complete and the follow-up data mature, it is not possible to recommend partial breast irradiation as an appropriate treatment for breast cancer outside of a properly conducted trial" (Clinical Evidence).

Several guidelines have been published on PBI/APBI. The American Society of Therapeutic Radiology and Oncology (ASTRO) consensus evolved because it was clear that many women are treated in the US with PBI/APBI outside clinical trials (over 32,000 women have had treatment using MammoSite ${ }^{\oplus}$; Cytec). They indicated a patient population "suitable" for PBI/APBI outside the context of a clinical trial: women aged 60 years and over, with pT1NO(i-, i+)M0, margins greater than $2 \mathrm{~mm}$, unifocal disease, oestrogen receptor positive, who have had no neoadjuvant therapy. They also described women deemed unsuitable for PBI/APBI. They state that, "patients who choose treatment with PBI/APBI should be informed that whole-breast irradiation (WBI) is an established treatment with a much longer track record that has documented long-term effectiveness and safety" (Smith 2009). This statement provides guidance in selecting participants who may be appropriate for PBI/APBI outside the context of a clinical trial, but the Task Force strongly endorsed enrolment of all eligible participants considering $\mathrm{PBI} / \mathrm{APBI}$ onto NSABP-B39/RTOG and encouraged enrolment of other participants considering PBI/APBI, particularly those not in the "suitable" group, into prospective clinical studies to address many of the unanswered questions in PBI/APBI (Smith 2009). NCCN states, "patients are encouraged to enter clinical trials, and endorses the ASTRO guidelines".
In the absence of an available trial, the American College of Radiology (ACR) Appropriateness Criteria ${ }^{\circledR}$ panel recommends following the consensus guidelines of the ASTRO (Bellon 2011).

The GEC-ESTRO Breast Cancer Working Group recommends three categories guiding patient selection for $\mathrm{PBI} / \mathrm{APBI}$ :

1. a low-risk group for whom PBI/APBI outside the context of a clinical trial is an acceptable treatment option; including participants aged at least 50 years with unicentric, unifocal, pT1-2 (less than $30 \mathrm{~mm}$ ) pN0, non-lobular invasive breast cancer without the presence of an extensive intraductal component (EIC) and LVI and with negative surgical margins of at least $2 \mathrm{~mm}$;

2. a high-risk group, for whom $\mathrm{PBI} / \mathrm{APBI}$ is considered contraindicated; including participants aged 40 years or less; having positive margins, with or without any of the following pathological features (multicentric or large (greater than $30 \mathrm{~mm}$ ) tumours, EIC positive or LVI positive tumours, four or more positive lymph nodes, unknown axillary status ( $\mathrm{pNx})$ ); and

3. an intermediate-risk group, for whom $\mathrm{PBI} / \mathrm{APBI}$ is considered acceptable only in the context of prospective clinical trials (Polgár 2010).

\section{AUTHORS' CONCLUSIONS}

\section{Implications for practice}

It appears that local recurrence and 'elsewhere primaries' (new primaries in the ipsilateral breast) are increased with accelerated partial breast irradiation (APBI) or partial breast irradiation (PBI), that is, APBI does not offer the same cancer control as whole breast radiotherapy (WBRT) (but the difference is small). We found no evidence of detriment to other oncological outcomes. It appears that cosmetic outcomes and some late effects are worse with PBI/ APBI but its use is associated with less acute skin toxicity. The limitations of the data currently available mean that we cannot make definitive conclusions about the efficacy and safety or ways to deliver of PBI/APBI. We await completion of ongoing trials.

\section{Implications for research}

The ongoing trials will address relevant clinical outcomes. PBI/ APBI is a highly technical intervention that is operator dependent and requires careful quality assurance. Interpretation of these trials will require consideration of the quality of the RT delivered, with respect to target definition and treatment verification.

\section{ACKNOWLEDGEMENTS}

We thank the Princess Alexandra Hospital Cancer Collaborative Group. 


\section{R E F E R E N C E S}

\section{References to studies included in this review}

ELIOT \{published data only\}

NCT01849133. Randomized clinical trial: comparison between quadrantectomy followed by external fractionated radiotherapy and quadrantectomy associated with intraoperative radiotherapy in women $>=48$ years of age affected by early-stage breast carcinoma. clinicaltrials.gov/ct2/show/ NCT01849133 (accessed 24 September 2015).

* Veronesi U, Orecchia R, Maisonneuve P, Rotmensz N, Sangelli C, Luini A, et al. Intraoperative radiotherapy versus external radiotherapy for early breast cancer (ELIOT): a randomised equivalence trial. Lancet Oncology 2013;14(13):1269-77.

\section{GEC-ESTRO \{unpublished data only\}}

European Brachytherapy Breast Cancer GEC-ESTRO Working Group. Interstitial brachytherapy alone versus external beam radiation therapy after breast conserving surgery for low risk invasive carcinoma and low risk duct carcinoma in-situ (DCIS) of the female breast. (study protocol) 8 January 2004.

NCT00402519. APBI versus EBRT therapy after breast conserving surgery for low-risk breast cancer. clinicaltrials.gov/ct2/show/ NCT00402519 (accessed 25 July 2015).

Strnad V, Ott OJ, Hildebrandt G, Kauer-Dorner D, Knauerhase H, Major T, et al. 5-year results of accelerated partial breast irradiation using sole interstitial multicatheter brachytherapy versus whole-breast irradiation with boost after breastconserving surgery for low-risk invasive and in-situ carcinoma of the female breast: a randomised, phase 3 , non-inferiority trial. Lancet 2016;387:229-38.

Strnad V, Ott OJ, Hildebrandt G, Pötter R, Fietkau R, Lyczek J, et al. First clinical results of the GEC-ESTRO breast WG phase III multicentric PBI/APBI trial. Radiotherapy and Oncology, Proceedings of the World Congress of Brachytherapy. 2012; Vol. 103 Suppl 2:S35-6.

\section{Livi 2015 \{published data only\}}

Livi L, Buonamici FB, Simontacchi G, Scotti V, Fambrini M, Compagnucci A. Accelerated partial breast irradiation with IMRT: new technical approach and interim analysis of acute toxicity in a phase III randomized controlled trial. International Journal of Radiation Oncology, Biology, Physics 2010;77(2):509-15.

* Livi L, Meattini I, Marrazzo L, Simontacchi G, Pallotta S, Saieva C, et al. Accelerated partial breast irradiation using intensity-modulated radiotherapy versus whole breast irradiation: 5-year analysis of a phase 3 randomised controlled trial. European Journal of Cancer 2015;51(4):451-63. [DOI: 10.1016/j.ejca.2014.]

Livi L, Meattini I, Saieva C, Franceschini D, Meacci F, Franzese F. Accelerated partial breast irradiation with IMRT: 3-years interim analysis of a phase III randomised clinical trial. Radiotherapy and Oncology, Proceedings of ESTRO 31. 2012; Vol. 103 Suppl $1:$ S51.
Meattini I, Marrazzo L, Zani M, Paiar F, Pallotta S, Simontacchi G, et al. Four-dimensional computerised planning for accelerated partial breast irradiation: single series for a randomised phase III trial. Radiology Medicine 2015; Vol. 20, issue 11:1078-82.

NCT02104895. Randomised phase II trial of accelerated partial breast irradiation using intensity modulated radiotherapy versus whole breast irradiation. clinicaltrials.gov/ct2/show/ NCT02104895 (accessed 22 April 2014).

\section{Polgár 2007 \{published data only\}}

Lövey K, Fodor J, Major T, Szabó E, Orosz Z, Sulyok Z, et al. Fat necrosis after partial-breast irradiation with brachytherapy or electron irradiation versus standard whole-breast radiotherapy - 4 year results of a randomized trial. International Journal of Radiation Oncology, Biology, Physics 2007;69(3):724-31.

Polgaŕ C, Major T, Fodor J, Nemeth G, Orocz Z, Sulyok Z, et al. High-dose-rate brachytherapy alone versus whole breast radiotherapy with or without tumour bed boost after breastconserving surgery: seven-year results of a comparative study. International Journal of Radiation Oncology, Biology Physics 2004;60(4):1173-81.

Polgár C, Fodor J, Major T, Németh G, Lövey K, Orosz Z, et al. Breast-conserving treatment with partial or whole breast irradiation for low-risk invasive breast cancer - 5-year results of a randomized trial. International Journal of Radiation Oncology, Biology, Physics 2007;69(3):694-702.

Polgár C, Fodor J, Major T, Sulyok A, Kásler M. Breast-conserving therapy with partial or whole breast irradiation: ten-year results of the Budapest randomized trial. Radiotherapy and Oncology 2013;108(2):197-202.

* Polgár C, Major T, Fodor J, Sulyok Z, Takacsi-Nagy Z, Nemeth $\mathrm{G}$. Breast-conserving therapy with partial or whole breast radiation: 10-year results of the Budapest randomized trial. Radiotherapy and Oncology, Proceedings of World Congress of Brachytherapy. 2012; Vol. 103 Supp 2:S35.

Polgár C, Sulyok Z, Fodor J, Orosz Z, Major T, Takácsi-Nagy Z, et al. Sole brachytherapy of the tumor bed after conservative surgery for T1 breast cancer: five-year results of a phase I-II study and initial findings of a randomized phase III trial. Journal of Surgical Oncology 2002;80(3):121-8, discussion 129.

\section{RAPID \{unpublished data only\}}

NCT00282035. RAPID: randomized trial of accelerated partial breast irradiation. clinicaltrials.gov/ct2/show/NCT00282035 (accessed 13 January 2010).

* Olivotto IA, Whelan TJ, Parpia S, Kim DH, Berrang T, Truong PT, et al. Interim cosmetic and toxicity results from RAPID: a randomized trial of accelerated partial breast irradiation using three-dimensional conformal external beam radiation therapy. Journal of Clinical Oncology 2013;31(32):4038-45.

\section{Rodriguez \{published data only\}}

Rodriguez de Dios, Sanz X, Dengra J, Foro P, Reig A, Membrive I, et al. Interim cosmetic results and toxicity using 3D conformal 
external beam radiation therapy to deliver accelerated partial breast irradiation in patients with early-stage breast cancer. International Journal of Radiation Oncology, Biology Physics. 2012; Vol. 84:3S.

* Rodríguez N, Sanz X, Dengra J, Foro P, Membrive I, Reig A, et al. Five-year outcomes, cosmesis, and toxicity with 3-dimensional conformal external beam radiation therapy to deliver accelerated partial breast irradiation. International Journal of Radiation Oncology, Biology, Physics 2013;87(5):1051-7.

Rodríguez N, Sanz X, Foro P, Reig A, Membrive I, Lozano J, et al. [Phase III study comparing accelerated partial breast irradiation vs whole breast radiation therapy using 3D-CRT]. Radiotherapy and Oncology, Proceedings of ESTRO 31. 2012; Vol. 103 Suppl $1:$ S400.

Rodríguez XS, Foro P, Reig A, Lacruz M, Lozano J, I Membrive, et al. Phase III study comparing accelerated partial breast irradiation vs whole breast irradiation using 3D-CRT. Interim analysis. Radiotherapy and Oncology. 2008; Vol. 88:S201.

\section{TARGIT \{unpublished data only\}}

Andersen KG, Gärtner R, Kroman N, Flyger H, Kehlet H. Persistent pain after targeted intraoperative radiotherapy (TARGIT) or external breast radiotherapy for breast cancer: a randomized trial. Breast 2012;21(1):46-9.

Baum M, Joseph DJ, Tobias JS, Wenz FK, Keshtgar MR, Alvarado M, et al. Safety and efficacy of targeted intraoperative radiotherapy (TARGIT) for early breast cancer: first report of a randomized controlled trial at 10-years maximum follow-up. Journal of Clinical Oncology. 2010; Vol. 28:7S, abstract LBA517.

Holmes DR, Baum M, Joseph D. The TARGIT trial: targeted intraoperative radiation therapy versus conventional postoperative whole-breast radiotherapy after breastconserving surgery for the management of early-stage invasive breast cancer (a trial update). American Journal of Surgery 2007;194(4):507-10.

Joseph D. TARGIT. Radiotherapy and Oncology, Proceedings of World Congress of Brachytherapy. 2012; Vol. 103 Suppl 2:S4.

Keshtgar. Cosmetic outcome 1, 2, 3, and 4 years after intraoperative radiotherapy compared with external beam radiotherapy for treatment of early breast cancer: an objective assessment of patients from a randomized controlled trial. Proceedings of ASTRO. 2011; Vol. 80:S225.

Keshtgar MR, Williams NR, Corica T, Saunders C, Joseph DJ, on behalf of the TARGIT Trialists' Group. Cosmetic outcome two and three years after intraoperative radiotherapy compared with external beam radiotherapy for early breast cancer: an objective assessment of patients from a randomized controlled trial. Journal of Clinical Oncology. 2010; Vol. 28:7S, abstract 570.

* NCT00983684. Comparison of intra-operative radiotherapy with post-operative radiotherapy for women with early breast cancer (TARGIT). clinicaltrials.gov/ct2/show/NCT00983684 (accessed 29 October 2009). [NCT00983684]
Vaidya J, Bulsara M, Wenz F, Joseph D, Saunders C, Massarut S, et al. Pride, prejudice, or science: attitudes towards the results of the TARGIT - a trial of targeted intraoperative radiation therapy for breast cancer. International Journal of Radiation Oncology, Biology Physics 2015;92(3):491-7.

Vaidya JS. 34th Annual San Antonio Breast Cancer Society. 2012:S4-2.

Vaidya JS. In favour of partial breast irradiation in selected patients and a well-directed intraoperative boost. Breast 2006;15(5):581-3.

Vaidya JS. Partial breast irradiation using targeted intraoperative radiotherapy (Targit). Nature Clinical Practice Oncology 2007;4(7):384-5.

Vaidya JS, Bulsara M, Wenz F, Massarut S, Joseph D, Tobias J, et al. The lower non-breast cancer mortality with TARGIT in the TARGIT - a trial could be a systemic effect of TARGIT on tumor microenvironment. International Journal of Radiation Oncology, Biology Physics. 2013, issue 2S:S240.

Vaidya JS, Joseph D, Hilaris BS, Tobias JS, Houghton I, Keshtgar M, et al. [Targeted intraoperative radiotherapy for breast cancer (TARGIT): an international trial]. Radiotherapy and Oncology. 2002; Vol. 64, issue S1:S136.

Vaidya JS, Joseph DJ, Tobias JS, Bulsara M, Wenz F, Saunders C, et al. Targeted intraoperative radiotherapy versus whole breast radiotherapy for breast cancer (TARGIT-A trial): an international, prospective, randomised, non-inferiority phase 3 trial. Lancet 2010;376(9735):91-102.

Vaidya JS, Wenz F, Bulsara M, Massarut S, Tobias J, Williams N, et al. Omitting whole breast radiation therapy did not increase axillary recurrence in the TARGIT-A trial. International Journal of Radiation Oncology, Biology Physics. 2013; Vol. 87:2S

Vaidya JS, Wenz F, Bulsara M, Tobias JS, Joseph DJ, Keshtgar M, et al. Erratum. Lancet 2014; Vol. 383, issue 9917:602.

* Vaidya JS, Wenz F, Bulsara M, Tobias JS, Joseph DJ, Keshtgar M, et al. Risk-adapted targeted intraoperative radiotherapy versus whole-breast radiotherapy for breast cancer: 5-year results for local control and overall survival from the TARGIT - a randomised trial. Lancet 2013;383(9917):603.

Vaidya JS, Tobias JS, Baum M, Wenz F, Kraus-Tiefenbacher U, D'souza D, et al. TARGeted Intraoperative radiotherapy (TARGIT): an innovative approach to partial-breast irradiation. Seminars in Radiation Oncology 2005;15(2):84-91.

Welzel G, Boch A, Blank E, Kraus-Teifenbacher U, Keller A, Hermann B, et al. Radiation-related quality of life parameters after targeted intraoperative radiotherapy versus whole breast radiotherapy in patients with breast cancer: results from the randomized phase III trial TARGIT-A. Proceedings of ASTRO. 2011; Vol. 81:S206-7.

Wenz F, Vaidya JS, Pigorsch S, Feyer P, Roedel C, Belka C, et al. Local recurrence and survival for the German centers in the TARGIT-A (TARGeted Intraoperative Radiation Therapy - Alone) 
trial. International Journal of Radiation Oncology, Biology Physics. 2013; Vol. 87:2S.

\section{References to studies excluded from this review \\ Dodwell 2005 \{published data only\}}

* Dodwell DJ, Dyker K, Brown J, Hawkins K, Cohen D, Stead M, et al. A randomised study of whole-breast vs tumour-bed irradiation after local excision and axillary dissection for early breast cancer. Clinical Oncology 2005;17(8):618-22.

\section{NCT00892814 \{unpublished data only\}}

NCT00892814. Partial breast versus whole breast irradiation in elderly women operated on for early breast cancer. clinicaltrials.gov/ct2/show/NCT00892814 (accessed 1 August 2012).

\section{NCT01185132 \{unpublished data only\}}

NCT01185132. Intensity modulated radiotherapy (IMRT) vs. 3Dconformal accelerated partial breast irradiation (APBI) for early stage breast cancer after lumpectomy. clinicaltrials.gov/show/ NCT01185132 (accessed 11 November 2013).

\section{NCT01928589 \{unpublished data only\}}

NCT01928589. Partial breast irradiation with concurrent chemotherapy for women with breast cancer. clinicaltrials.gov/ show/NCT01928589 (accessed 11 November 2013).

\section{NCT02003560 \{unpublished data only\}}

NCT02003560. Accelerated partial breast irradiation with 3D-CRT and IMRT (APERT). clinicaltrials.gov/ct2/show/ NCT02003560 (accessed 17 June 2015).

\section{Ribeiro 1993 \{published data only\}}

Magee B, Swindell R, Harris M, Banerjee SS. Prognostic factors for breast recurrence after conservative breast surgery and radiotherapy: results from a randomised trial. Radiotherapy and Oncology 1996;39(3):223-7.

Ribeiro GG, Dunn G, Swindell R, Harris M, Banerjee SS. Conservation of the breast using two different radiotherapy techniques: interim report a clinical trial. Clinical Oncology 1990;2(1):27-34.

* Ribeiro GG, Magee B, Swindell R, Harris M, Banerjee SS. The Christie Hospital breast conservation trial: an update at 8 years from inception. Clinical Oncology 1993;5(5):278-83.

\section{TARGIT-B \{unpublished data only\}}

TARGIT-B: an international randomised controlled trial to compare targeted intra-operative radiotherapy boost with conventional external beam radiotherapy boost after lumpectomy for breast cancer in women with a high risk of local recurrence. apps.who.int/trialsearch/Trial.aspx? TrialID=ISRCTN43138042 (accessed 11 November 2013).

\section{TROG \{unpublished data only\}}

NCT00418210. Accelerated partial breast irradiation for early breast cancer. clinicaltrials.gov/ct2/show/NCT00418210 (accessed 24 November 2008).

\section{References to studies awaiting assessment}

NCT02375048 \{unpublished data only\}

NCT02375048. Randomized study on postmenopausal women with early stage breast cancer: WBI versus APBI. clinicaltrials.gov/ct2/show/NCT02375048 (accessed 25 July 2015).

\section{References to ongoing studies}

IMPORT \{unpublished data only\}

Coles C, Donovan E, Venables K, Rowlings C, Maylex H, Bentzen S, et al. Randomised trial testing intensity modulated radiotherapy and partial organ radiotherapy in early breast cancer (import trial). British Journal of Cancer 2004;91(Suppl 1):S80.

Coles C, Yarnold J. The IMPORT trials are launched (September 2006). Clinical Oncology 2006;18(8):587-90.

* NCT00814567. Radiation therapy in treating women with early-stage breast cancer who have undergone breast conservation therapy. clinicaltrials.gov/ct2/show/NCT00983684 (accessed 29 October 2009). [CDR0000629768, ICR-IMPORT-LOW, ICR-CTSU/2006/10001, ISRCTN12852634, EU-20896]

\section{IRMA \{unpublished data only\}}

Frezza G, Bertoni F, D'Amico R. Breast cancer with low risk of local recurrence: partial and accelerated radiation with threedimensional conformal radiotherapy (3DCRT) vs. standard radiotherapy after conserving surgery (phase III study). https://clinicaltrials.gov/ct2/show/NCT01803958 (accessed 10 December 2012).

\section{NSABP-B39/RTOG \{unpublished data only\}}

Anonymous. NSABP B-39, RTOG 0413: a randomized phase III study of conventional whole breast irradiation versus partial breast irradiation for women with stage 0 , I, or II breast cancer. Clinical Advances in Hematology \& Oncology 2006;4(10):719-21.

Gale A, Jain AK, Vallow LA. The effect of tumor bed location on REart dosimetry for 3-D conformal partial breast irradiation and whole breast irradiation. International Journal of Radiation Oncology, Biology, Physics 2007;69(3 Suppl 1):S735.

Jain AK, Vallow LA, Gale A. Analysis of biologically equivalent lung tissue dose for 3-D conformal partial breast irradiation and whole breast irradiation. International Journal of Radiation Oncology, Biology, Physics 2007;69(3):S622-3.

Jain AK, Vallow LA, Gale AA, Buskirk SJ. Does three-dimensional external beam partial breast irradiation spare lung tissue compared with standard whole breast irradiation?. International Journal of Radiation Oncology, Biology, Physics 2009;75(1):82-8.

Julian TB, Costantino JP, Vicini FA, White JR, Winter KA, Arthur DW, et al. Early toxicity results with $3 D$ conformal external beam therapy (CEBT) from the NSABP B-39/RTOG 0413 accelerated partial breast irradiation (APBI) trial [Abstract]. Journal of Clinical Oncology. 2011; Vol. Supp 15:A-1011. 
Kim Y, Parda DS, Trombetta MG, Colonias A, Werts ED, Miller L, et al. Dosimetric comparison of partial and whole breast external beam irradiation in the treatment of early stage breast cancer. Medical Physics 2007;34(12):4640-8.

McCormick B. Partial-breast irradiation for early staged breast cancers: hypothesis, existing data, and a planned phase III trial. Journal of the National Comprehensive Cancer Network 2005;3(3):301-7.

NCT00103181. Radiation therapy (WBI versus PBI) in treating women who have undergone surgery for ductal carcinoma in situ or stage I or stage II breast cancer. clinicaltrials.gov/ct2/ show/NCT00103181 (accessed 25 July 2015).

\section{SHARE \{unpublished data only\}}

Belkacemi Y, Bourgier C, Kramar A, Auzac G, Dumas I, Lacornerie T, et al. SHARE: a French multicenter phase III trial comparing accelerated partial irradiation versus standard or hypofractionated whole breast irradiation in breast cancer patients at low risk of local recurrence. Clinical Advances in Haematology and Oncology 2013;11(2):76-83.

* NCT01247233. Standard or hypofractionated radiotherapy versus accelerated partial breast irradiation (PBI/APBI) for breast cancer (SHARE). clinicaltrials.gov/ct2/show/ NCT01247233 (accessed 1 August 2012). [ISRCTN62704822]

\section{Additional references}

\section{Aaronson 1998}

Aaronson NK, Bartelink H, van Dongen JA, van Dam FS. Evaluation of breast conserving therapy: clinical, methodological and psychological perspectives. European Journal of Surgery 1998;14:133-40.

\section{AlHW 2012}

Australian Institute of Health and Welfare \& Australasian Association of Cancer Registries. Breast Cancer in Australia: An Overview. No 74. cat no. CAN 70. Vol. Cancer Series, Canberra: AlHW, 2012

\section{Altman 1992}

Altman DG. Practical Statistics for Medical Research. London: Chapman and Hall, 1992.

\section{ASERNIP-S 2002}

Australian Safety, Efficacy Register of New Interventional Procedures - Surgical. and the Royal Australasian College of Surgeons. A systematic review of intraoperative radiotherapy in early stage breast cancer. ASERNIP-S Report No. 27. ASERNIP-S, 2002.

\section{Bellon 2011}

Bellon JR, Harris EE, Arthur DW, Bailey L, Carey L, Goyal S, et al. ACR Appropriateness Criteria ${ }^{\circledR}$ conservative surgery and radiation - stage I and II breast carcinoma: expert panel on radiation oncology: breast. Breast Journal 2011;17(5):448-55

\section{Blamey 2013}

Blamey RW, Bates T, Chetty U, Duffy SW, Ellis IO, George D, et al. Radiotherapy and/or tamoxifen after breast conserving surgery for breast cancers of excellent prognosis: British Association of Surgical Oncology (BASO) II trial. European Journal of Cancer 2013;49:2294-302.

\section{BlueCross BlueShield}

BlueCross BlueShield Association. Accelerated partial breast irradiation as sole radiotherapy after breast-conserving surgery for early stage breast cancer - executive summary. www.bcbs.com/blueresources/tec/vols/24/acceleratedradiotherapy.html (accessed 31 August 2012).

\section{Clinical Evidence}

Stebbing J, Delaney G, Thompson A. Clinical Evidence. clinicalevidence-bmj-com.cknservices.dotsec.com/x/ systematic-review/0102/intervention/sr-0102-i22.htmlHI. BMJ, Vol. (accessed 31 August 2012).

\section{Cox 1995}

Cox JD, Stetz J, Pajak THF. Toxicity Criteria of the Radiation Therapy Oncology Group (RTOG) and the European Organisation for Research and Treatment of Cancer. International Journal of Radiation Therapy Oncology Biology Physics 1995;31:1341-6.

\section{Cytec}

Cytec. Mammosite ${ }^{\circledR}$. www.mammosite.com/physicians/ (accessed 29 August 2012).

\section{Deeks 2004}

Deeks JJ, Higgins JPT, Altman DG. Analysing and presenting results. In: Alderson P, Green S. Higgins JPT editor(s). Cochrane Reviewers' Handbook 4.2.2 [updated December 2003]. Chichester: John Wiley \& Sons, 2004.

\section{DerSimonian 1986}

DerSimonian R, Laird N. Meta-analysis in clinical trials. Controlled Clinical Trials 1986;7:177-88.

\section{Donovan 2007}

Donovan E, Bleakley N, Denholm E, Evans P, Gothard L, Hanson J, et al. Randomised trial of standard 2D radiotherapy (RT) versus intensity modulated radiotherapy (IMRT) in patients prescribed breast radiotherapy. Radiotherapy and Oncology 2007;82(3):254-64.

\section{EBCTCG 1995}

Early Breast Cancer Trialists' Collaborative Group. Effects of radiotherapy and surgery in early breast cancer. An overview of the randomised trial. New England Journal of Medicine 1995;333(22):1444-55

\section{EBCTCG 2011}

Early Breast Cancer Trialists' Collaborative Group (EBCTCG). Effect of radiotherapy after breast-conserving surgery on 10year recurrence and 15-year breast cancer death: meta-analysis of individual patient data for 10,801 women in 17 randomised trials. Lancet 2011;378(9804):1707-16. 


\section{Fisher 1995}

Fisher B, Anderson S, Redmond CK, Wolmark N, Wickerham DL, Cronin WM. Re-analysis and results after 12 years of follow-up in a randomised clinical trial comparing total mastectomy with lumpectomy with or without irradiation in the treatment of breast cancer. New England Journal of Medicine 1995;333(22):1456-61.

\section{Fisher 2002}

Fisher B, Anderson S, Bryant J, Margolese RG, Deutsch M, Fisher ER, et al. Twenty-year follow-up of a randomised trial comparing total mastectomy, lumpectomy and lumpectomy plus irradiation for the treatment of invasive breast cancer. New England Journal of Medicine 2002;347(16):1233-41.

\section{Fleming 1997}

Fleming I, Cooper J, Henson DE, Hutter R, Kennedy B, Murphy G, et al. AJCC Cancer Staging Manual. 5th Edition. Philadelphia: Lippincott-Raven, 1997.

\section{Freeman 1981}

Freeman CR, Belliveau NJ, Kim TH, Boivin JF. Limited surgery with or without radiotherapy for early breast carcinoma. Journal Canadian Association of Radiology 1981;32(2):125-8.

\section{Fyles 2004}

Fyles AW, McCready DR, Manchul LA, Trudeau ME, Merante P, Pintilie M, et al. Tamoxifen with or without breast irradiation in women 50 years of age or older with early breast cancer. New England Journal of Medicine 2004;351:963-70.

\section{GRADE Working Group 2004}

The GRADE Working Group. GRADE handbook for grading quality of evidence and strength of recommendation. www.who.int/hiv/topics/mtct/grade_handbook.pdf. The GRADE Working Group, (accessed 4 November 2013).

\section{GRADEpro}

GRADEproGDT: GRADEpro Guideline Development Tool [Software]. McMaster University, 2015 (developed by Evidence Prime, Inc.). Available from www.gradepro.org.

\section{Greenland 1985}

Greenland S, Robbins JM. Estimation of a common effect parameter from sparse follow-up data. Biometrics 1985;41(1):55-68.

\section{Haviland 2013}

Haviland JS, Owen JR, Dewar JA, Agrawal RK, Barrett J, BarrettLee PJ, et al. The UK Standardisation of Breast Radiotherapy (START) trials of radiotherapy hypofractionation for treatment of early breast cancer: 10-year follow-up results of two randomised controlled trials. Lancet Oncology 2013;14:1086-94.

\section{Higgins 2002}

Higgins JPT, Thompson SG. Quantifying heterogeneity in a meta-analysis. Statistics in Medicine 2002;21(11):1539-58.

\section{Higgins 2003}

Higgins JPT, Thompson SG, Deeks JJ, Altman GD. Measuring inconsistency in meta-analyses. BMJ 2003;327(7414):557-60.

\section{Holland 1985}

Holland R, Veling SH, Mravunac M, Hendriks JH. Histologic multifocality of Tis, T1-2 breast carcinomas. Implications for clinical trials of breast-conserving surgery. Cancer 1985;56(5):979-90.

\section{Howlader 2009}

Howlader N, Noone AM, Krapcho M, Neyman N, Aminou R, Waldron W, et al. SEER cancer statistics review, 1975-2009 (vintage 2009 populations). seer.cancer.gov/ csr/1975_2009_pops09/ (accessed 20 March 2013).

\section{Hughes 2004}

Hughes KS, Schnaper LA, Berry D, Cirrincione CT, Berry DA, McCormick B, et al. Lumpectomy plus tamoxifen with or without irradiation in women 70 years of age or older with early breast cancer. New England Journal of Medicine 2004;351:971-7.

\section{Jacobson 1995}

Jacobson JA, Danforth DN, Cowan KH, d'Angelo T, Steinberg SM, Pierce $L$, et al. Ten-year results of a comparison of conservation with mastectomy in the treatment of stage I and II breast cancer. New England Journal of Medicine 1995;332(14):907-11.

\section{Kong 2014}

Kong L, Cheng J, Ding X, Li B, Zhang J, Li H, et al. Efficacy and safety of accelerated partial breast irradiation after breastconserving surgery: a meta-analysis of published comparative studies. Breast Journal 2014;20(2):116.

\section{Krauss 2004}

Krauss DJ, Kestin LL, Mitchell C, Martinez AA, Vicini FA. Changes in temporal patterns of local failure after breast-conserving therapy and their prognostic implications. International Journal of Radiation Oncology, Biology, Physics 2004;60(3):731-40.

\section{Kunkler 2015}

Kunkler IH, Williams LJ, Jack WJ, Cameron DA, Dixon JM, PRIME II investigators. Breast-conserving surgery with or without irradiation in women aged 65 years or older with early breast cancer (PRIME II): a randomised controlled trial. Lancet Oncology 2015;16(3):266-73.

\section{Lagios 1983}

Lagios MD, Richards VE, Rose MR, Yee E. Segmental mastectomy without radiotherapy. Short-term follow-up. Cancer 1983;52(11):2173-9.

\section{Levine 1998}

Levine MN, Guyatt GH, Gent M, De Pauw S, Goodyear MD, Hryniuk WM, et al. Quality of life in stage II breast cancer an instrument for clinical trials. Journal of Clinical Oncology 1998;6:1798-810

\section{Maciejewski 1986}

Maciejewski B, Taylor JM, Withers HR. Alpha/beta value and the importance of size of dose per fraction for late complications of the supraglottic larynx. Radiotherapy and Oncology 1986; 7(4):323-6. 


\section{Mantel 1959}

Mantel N, Haenszel WH. Statistical aspects of the analysis of data for retrospective studies of disease. Journal of the National Cancer Institute 1959;22(4):719-48.

\section{Marta 2015}

Marta GN, Macedo CR, de Andrade Carvalho H, Hanna AS, Fernandes da Silva JL, Riera R. Accelerated partial irradiation for breast cancer: systematic review and meta-analysis of 8653 women in eight randomized trials. Radiotherapy and Oncology 2015;114:42-9.

\section{Montgomery 1978}

Montgomery AC, Greening WP, Levene AL. Clinical study of recurrence rate and survival time of patients with carcinoma of the breast treated by biopsy excision without any other therapy. Journal of the Royal Society of Medicine 1978;71(5):339-42.

\section{NCCN}

National Comprehensive Cancer Network. NCCN guidelines version 2.2015 invasive breast cancer. www.nccn.org/ professionals/physician_gls/pdf/breast.pdf (accessed 7 November 2015).

\section{$\mathrm{NCl}$}

Cancer Therapy Evaluation Program. Common

terminology criteria for adverse events, version 3.0, DCTD, NCl, NIH, DHHS. evs.nci.nih.gov/ftp1/CTCAE/ CTCAE_4.03_2010-06-14_QuickReference_8.5x11.pdf (accessed 29 July 2015).

\section{ONS 2010}

Office of National Statistics. Breast cancer in England, 2010 release. www.ons.gov.uk/ons/rel/cancer-unit/breast-cancer-inengland/2010/sum-1.html (accessed 20 March 2013).

\section{Owen 2006}

Owen JR, Ashton A, Bliss JM, Homewood J, Harper C, Hanson J, et al. Effect of radiotherapy fraction size on tumour control in patients with early-stage breast cancer after local tumour excision: long-term results of a randomised trial. Lancet Oncology 2006;7(6):467-71.

\section{Pavy 1995}

Pavy JJ, Denekamp J, Letshcert J, Littbrand B, Mornex F, Bernier J, et al. Later Effects Working Group. Late effects toxicity scoring: the SOMA scale. Radiotherapy and Oncology 1995;35:11-3.

\section{Peters 2010}

Peters LJ, O'Sullivan B, Giralt J, Fitzgerald TJ, Trotti A, Bernier J, et al. Critical impact of radiotherapy protocol compliance and quality in the treatment of advanced head and neck cancer; results from TROG 02.02. Journal of Clinical Oncology 2010;28(18):2996-3001.

\section{Pignol 2008}

Pignol JP, Olivotto I, Rakovitch E, Gardner S, Sixel K, Beckham W, et al. A multicenter randomized trial of breast intensity-modulated radiation therapy to reduce acute radiation dermatitis. Journal of Clinical Oncology 2008;26(13):2085-92.

\section{Poggi 2003}

Poggi MM, Danforth DN, Sciuto LC, Smith SL, Steinberg SM, Liewehr DJ, et al. Eighteen-year results in the treatment of early breast carcinoma with mastectomy versus breast conservation therapy: the National Cancer Institute Randomised Trial. Cancer 2003;98(4):697-702.

\section{Polgár 2010}

Polgár C, Van Limbergen E, Pötter R, Kovács G, Polo A, Lyczek J, et al. Patient selection for accelerated partial-breast irradiation (PBI/APBI) after breast-conserving surgery: recommendations of the Groupe Européen de Curiethérapie-European Society for Therapeutic Radiology and Oncology (GEC-ESTRO) breast cancer working group based on clinical evidence (2009). Radiotherapy and Oncology 2010;94(3):264-73.

\section{Potter 2007}

Potter R, Gnant M, Kwasny W, Tausch C, Handl-Zeller L, Pakisch B, et al. Lumpectomy plus tamoxifen or anastrozole with or without whole breast irradiation in women with favorable early beast cancer. International Journal of radiation Oncology, Biology, Physics 2007;68:334-40.

\section{Prescott 2007}

Prescott RJ, Kunkler JH, Williams LJ, King CC, Jack W, van der Pol M, et al. A randomised controlled trial of postoperative radiotherapy following breast-conserving surgery in a minimum-risk older population. The PRIME trial. Health Technology Assessment 2007;11(i-x):1-170.

\section{RevMan 2012 [Computer program]}

The Nordic Cochrane Centre, The Cochrane Collaboration. Review Manager (RevMan). Version 5.2. Copenhagen: The Nordic Cochrane Centre, The Cochrane Collaboration, 2012.

\section{Schroen 2005}

Schroen AT, Brenin DA, Kelly MD, Knauss WA, Slinguff CL Jr. Impact of patient distance to radiation therapy on mastectomy use in early-stage breast cancer patients. Journal of Clinical Oncology 2005;23(28):7074-80.

\section{Smith 2000}

Smith TE, Lee D, Turner BC, Carter D, Haffy B. True recurrence vs new primary ipsilateral breast tumour relapse: an analysis of clinical and pathologic differences and their implications in natural history, prognoses and therapeutic management. International Journal of Radiation Oncology, Biology, Physics 2000;48(5):1281-9.

\section{Smith 2009}

Smith BD, Arthur DW, Buchholz TA, Haffty BG, Hahn CA, Hardenbergh $\mathrm{PH}$, et al. Accelerated partial breast irradiation consensus statement from the American Society for Radiation Oncology (ASTRO). International Journal of Radiation Oncology, Biology, Physics 2009;74(4):987-1001. 


\section{START 2008}

START Trialists' Group, Bentzen SM, Agrawal RK, Aird EG, Barrett JM, Barrett-Lee PJ, et al. The UK standardisation of breast radiotherapy (START) trial A of radiotherapy hypofractionation for treatment of early breast cancer: a randomised trial. Lancet Oncology 2008;9(4):331-41.

\section{START B 2008}

START Trialists' Group, Bentzen SM, Agrawal RK, Aird EG, Barrett JM, Barrett-Lee PJ, et al. The UK standardisation of breast radiotherapy (START) trial B of radiotherapy hypofractionation for treatment of early breast cancer: a randomised trial. Lancet 2008;371(9618):1098-107.

\section{Stitt 1992}

Stitt JA, Fowler JF, Thomadsen BR, Buchler DA, Paliwal BP, Kinsella TJ. High dose rate intracavitary brachytherapy for carcinoma of the cervix: the Madison System 1: clinical and radiobiological considerations. International Journal of Radiation Oncology, Biology, Physics 1992;24(2):335-48.

\section{Tierney 2007}

Tierney JF, Stewart LA, Ghersi D, Burdett S, Sydes MR. Practical methods for incorporating summary time-to-event data into meta-analysis. Trials 2007; Vol. 8, issue 16:1-16.

\section{Valachis 2010}

Valachis A, Mauri D, Polyzos NP, Mavroudis D, Georgoulias V, Casazza G. Partial breast irradiation or whole breast radiotherapy for early breast cancer: a meta-analysis of randomized controlled trials. Breast Journal 2010;16(3):245-51.

\section{van Dongen 2000}

van Dongen JA, Voogd AC, Fentiman IS, Legrand C, Sylvester RJ, Tong $\mathrm{D}$, et al. Long-term results of a randomised trial comparing breast-conserving therapy with mastectomy: European Organisation for Research and Treatment of Cancer 10801 trial. Journal of the National Cancer Institute 2000;92(14):1143-50.

\section{Veronesi 1995}

Veronesi U, Salvadori B, Luini A, Greco M, Saccozzi R, del Vecchio $M$, et al. Breast conservation is a safe method in patients with a small cancer of the breast. Long-term results of three randomised trial on 1973 patients. European Journal of Cancer 1995;31(10):1574-9.

\section{Veronesi 2002}

Veronesi U, Cascinelli N, Mariani L, Greco M, Saccozzi R, Luini A, et al. Twenty-year follow-up of a randomised study comparing breast-conserving surgery with radical mastectomy for early breast cancer. New England Journal of Medicine 2002;347(16):1227-32.

\section{CHARACTERISTICS OF STUDIES}

Characteristics of included studies [ordered by study ID]

\section{Walker 1988}

Walker AM, Martin-Moreno JM, Artalejo FR. Odd man out: a graphical approach to meta-analysis. American Journal of Public Health 1988;78(8):961-6.

\section{Wallner 2004}

Wallner P, Arthur D, Bartelink H. Workshop on partial breast irradiation: state of the art and the science. Bethesda MD December 8th-10th 2002. Journal of the National Cancer Institute. 2004; Vol. 96:175-84.

\section{Wazer 1992}

Wazer DE, DiPetrillo T, Schmidt-Ullrich R, Weld L, Smith TJ, Marchant DJ, et al. Factors influencing cosmetic outcome and complication risk after conservative surgery and radiotherapy for early-stage breast carcinoma. Journal of Clinical Oncology 1992;10:356-63.

\section{Whelan 2000}

Whelan TJ, Levine M, Julian J, Kirkbride P, Skingley P. The effects of radiation therapy on quality of life of women with breast carcinoma: results of a randomised trial. Ontario Clinical Oncology Group. Cancer 2000;88(10):2260-6.

\section{Whelan 2002}

Whelan T, Mackenzie R, Julian J, Levine M, Shelley W, Grimard L, et al. Randomized trial of breast irradiation schedules after lumpectomy for women with lymph nodenegative breast cancer. Journal of the National Cancer Institute 2002;94(15):1143-50.

\section{Winzer 2010}

WInzer KJ, Sauerbrei W, Braun M, Liersch T, Dunst J, Guski H, et al. Radiation therapy and tamoxifen after breast-conserving surgery: updated results of a $2 \times 2$ randomised clinical trial in patients with low risk of recurrence. European Journal of Cancer 2010;46:95-101.

\section{Withers 1983}

Withers HR, Thames HD Jr, Peters LJ. A new isoeffect curve for change in dose per fraction. Radiotherapy and Oncology 1983;1(2):187-91.

\section{Ye 2013}

Ye X, Bao S, Guo L, Wang X, Ma Y, Zhang W, et al. Accelerated partial breast irradiation for breast cancer: a meta-analysis. Translational Oncology 2013;6:619-27.

* Indicates the major publication for the study

\section{ELIOT}


ELIOT (Continued)

Single-centred, tertiary institution

Country: Italy

Median follow-up: 68 months

\begin{tabular}{ll} 
Participants & $\begin{array}{l}\text { Women aged } 48-75 \text { years with early breast cancer, maximum tumour diameter } 2.5 \mathrm{~cm} \text {, "suitable for } \\
\text { breast conservation". All women with positive sentinel node biopsy had axillary dissection }\end{array}$ \\
\hline Interventions & $\begin{array}{l}\text { Experimental arm: intraoperative electron therapy to deliver } 21 \mathrm{~Gy} \text { at the } 90 \% \text { isodose delivered at the } \\
\text { time of surgery after tumour excision using } 6-9 \mathrm{MeV}\end{array}$ \\
Control arm: postoperative EBRT $(50 \mathrm{~Gy} / 25$ fractions $+10 \mathrm{~Gy} / 5$ fraction boost using electrons) \\
Outcomes & $\begin{array}{l}\text { 1. Ipsilateral breast tumour recurrence that included both local recurrence and new ipsilateral breast } \\
\text { primaries }\end{array}$ \\
2. Overall survival \\
3. Regional nodal failure \\
4. Distant metastases \\
5. Late toxicity (measured using LENT-SOMA
\end{tabular}

Notes Target volume: $4-12 \mathrm{MeV}$ to $90 \%$ isodose $10-30 \mathrm{~mm}$ around sutured surgical breach

NB: women with $\geq 4$ involved nodes were treated with RNI (50 Gy/25 fractions). Adjuvant therapies were administered according to the European Institute of Oncology policy at the time

\section{Risk of bias}

Bias Authors' judgement Support for judgement

Random sequence genera- Low risk tion (selection bias)
Quote: "At the data centre, allocation was done by telephone with a computer-generated list using a randomly permuted block design, stratified by tumour size ( $<1.0 \mathrm{~cm}$ vs $1.0-1.4 \mathrm{~cm}$ vs $\geq 1.5 \mathrm{~cm}$ )", page 1270 , paragraph 3

This method represented an adequate randomization method, therefore, we judged this domain at low risk of bias

Allocation concealment Unclear risk
(selection bias)

Quote: "Immediately before the intervention, the surgeon contacted the data centre by telephone to receive the allocation group. At the data centre, allocation was done by telephone", page 1270, paragraph 3

Because the details of how this was done were not reported, we judged this domain at unclear risk of bias

\begin{tabular}{|c|c|c|}
\hline $\begin{array}{l}\text { Blinding of participants } \\
\text { and personnel (perfor- } \\
\text { mance bias) Objective out- } \\
\text { comes }\end{array}$ & Low risk & $\begin{array}{l}\text { Quote: "Study coordinators, clinicians who verified eligibility criteria after } \\
\text { pathological assessment of the surgical specimen, clinicians who followed up } \\
\text { patients, investigators who did the statistical analyses, and the patients them- } \\
\text { selves were aware of the assignment", page 1270, paragraph } 3 \\
\text { We judged this domain at low risk of bias }\end{array}$ \\
\hline $\begin{array}{l}\text { Blinding of participants } \\
\text { and personnel (perfor- } \\
\text { mance bias) Subjective } \\
\text { outcomes }\end{array}$ & Low risk & $\begin{array}{l}\text { Quote: "Study coordinators... clinicians who followed up patients... and the } \\
\text { patients themselves were aware of the assignment", page 1270, paragraph } 3 \\
\text { We judged this domain at low risk of bias }\end{array}$ \\
\hline $\begin{array}{l}\text { Blinding of outcome as- } \\
\text { sessment (detection bias) } \\
\text { Objective outcomes }\end{array}$ & Low risk & $\begin{array}{l}\text { Quote: "We defined local recurrence as the reappearance of the carcinoma at } \\
\text { the site of the surgical intervention. We defined second ipsilateral breast tu- } \\
\text { mours as any new carcinoma appearing in other quadrants of the same breast. } \\
\text { IBTR was defined as the sum of local recurrence plus second ipsilateral tu- }\end{array}$ \\
\hline
\end{tabular}


mours. A regional nodal failure included any recurrence in the ipsilateral axillary, supraclavicular, or internal mammary nodal regions. Distant metastases were defined as any recurrence to distant organs. Overall survival was defined as the time from diagnosis to last follow-up or time of death"

Quote: "Patients were followed up with a clinical examination every 3 months, an ultrasound mammary scan every 6 months, and a mammogram every year; examinations of the lung, liver, and bone were modulated according to a personalised assessment of risk"

Quote: "investigators who did the statistical analyses", page 1270, paragraph 3

Although the outcome assessors for objective outcomes were not blinded, the clear pre-specified definitions of what constituted outcomes and the pre-specified follow-up protocol reduced the risk of bias for this domain

\section{Blinding of outcome as- High risk} sessment (detection bias) Subjective outcomes
Quote: "Study coordinators, clinicians who verified eligibility criteria after pathological assessment of the surgical specimen, clinicians who followed up patients, investigators who did the statistical analyses, and the patients themselves were aware of the assignment", page 1270, paragraph 3

Quote: "Side-effects were scored using the Late Effect of Normal Tissue- Subjective Objective Management Analytic criteria"

Because the assessment of subjective outcomes was not blinded, we judged this domain at high risk of bias

No exclusions were reported and there was no post-randomization attrition (see Figure 1) so we judged this domain at low risk of bias

Incomplete outcome data Low risk
(attrition bias)
All outcomes

Selective reporting (re- Unclear risk porting bias)
Outcomes specified in paper:

1. Primary outcome: IBTR (in breast true recurrences)

2. Secondary outcome: overall survival

Outcomes reported:

1. IBTR

2. True local recurrences

3. New ipsilateral breast cancer

4. Loco-regional recurrence

5. Contralateral breast cancer

6. Distant metastases

7. Non-breast cancer in other sites

8. Overall survival

9. Breast cancer deaths

10.Skin radiation toxicity

11.Pulmonary fibrosis

We did not have access to the study protocol, so judged this domain at unclear risk of bias

Other bias Low risk No other sources of bias identified

\section{GEC-ESTRO}

\begin{tabular}{ll}
\hline Methods Phase III RCT & \\
\hline Partial breast irradiation for early breast cancer (Review) & $\mathbf{3 0}$
\end{tabular}


GEC-ESTRO (Continued)

Open-label trial

Country: Germany

Median follow-up: 79.2 months

$\begin{array}{ll}\text { Participants } & \text { Women aged }>40 \text { years with Stage } 0, \text { I or II breast cancer (including DCIS), no lymph or vascular inva- } \\ \text { sion, lesions }<3 \mathrm{~cm} \text { in diameter, pNO/pNmi, DCIS alone, sentinel node biopsy optional. Clear margin }(\geq \\ 2 \mathrm{~mm} \text { in invasive disease, } 5 \mathrm{~mm} \text { in DCIS), unifocal or unicentric disease only }\end{array}$

$2 \mathrm{~mm}$ in invasive disease, $5 \mathrm{~mm}$ in DCIS), unifocal or unicentric disease only

Experimental arm: APBI
Interstitial brachytherapy
HDR $32 \mathrm{~Gy} / 8$ fractions or $30.3 \mathrm{~Gy} / 7$ fractions
PDR $50 \mathrm{~Gy}$ at $0.6-0.8 \mathrm{~Gy} /$ fractions given hourly
Control arm: external beam WBRT $50.0-50.4 \mathrm{~Gy} / 1.8-2.0 \mathrm{~Gy}$ fractions (5-28) plus $10 \mathrm{~Gy} / 5$ fraction boost
Primary:
1. Local control
Secondary:
1. Incidence and severity of acute and late adverse effects
2. Differences in cosmetic results
3. Distant metastases disease-free survival
4. Survival rates (overall survival, disease-free survival)
5. Contralateral breast cancer rate
6. Quality of life

Notes Target volume: tumour bed plus 20- to 30-mm radial margin

\section{Risk of bias}

\begin{tabular}{lll}
\hline Bias & Authors' judgement & Support for judgement \\
\hline $\begin{array}{ll}\text { Random sequence genera- } \\
\text { tion (selection bias) }\end{array}$ & Low risk & $\begin{array}{l}\text { Quote: "The randomisation was stratified by study centre, menopausal status, } \\
\text { and tumour type (e.g., invasive carcinoma vs DCIS), with a block size of ten, } \\
\text { according to an automated dynamic algorithm", page 3, randomization and } \\
\text { masking, paragraph } 1\end{array}$ \\
& \\
& We judged this at low risk of bias
\end{tabular}

\begin{tabular}{|c|c|c|}
\hline \multirow[t]{2}{*}{$\begin{array}{l}\text { Allocation concealment } \\
\text { (selection bias) }\end{array}$} & Low risk & $\begin{array}{l}\text { Quote: "Patients were randomised centrally at the Department of Medical In- } \\
\text { formatics, Biometry and Epidemiology, University Erlangen-Nuremberg, Ger- } \\
\text { many, via an online interface", page 3, randomization and masking, paragraph } \\
1\end{array}$ \\
\hline & & $\begin{array}{l}\text { This process was described as concealed and remote, so we judged this at low } \\
\text { risk of bias }\end{array}$ \\
\hline $\begin{array}{l}\text { Blinding of participants } \\
\text { and personnel (perfor- } \\
\text { mance bias) Objective out- } \\
\text { comes }\end{array}$ & Low risk & $\begin{array}{l}\text { Quote: "Neither patients nor investigators were masked to treatment alloca- } \\
\text { tion", page 3, randomization and masking, paragraph } 1 \\
\text { Although participants and personnel were not blinded, it is unlikely to have in- } \\
\text { troduced bias, so we judged this domain at low risk of bias }\end{array}$ \\
\hline
\end{tabular}




\section{GEC-ESTRO (Continued)}

Blinding of participants and personnel (performance bias) Subjective outcomes
Low risk Quote: "Neither patients nor investigators were masked to treatment allocation", page 3, randomization and masking, paragraph 1

Although participants and personnel were not blinded, it is unlikely to have introduced bias, so we judged this domain at low risk of bias

\section{Blinding of outcome as- Low risk Quote: "Follow up mammography was scheduled at 6, 12, 18 and 24 months sessment (detection bias) after radiation therapy", page 3, paragraph 8 \\ Objective outcomes \\ Although outcome assessors were not blinded, we considered the pre-speci- fied follow-up protocol meant this domain was at low risk of bias}

Blinding of outcome as- $\quad$ High risk
sessment (detection bias)

Quote: "Clinical examination included documentation of late side-effects with

Subjective outcomes Common Terminology Criteria for Adverse Events and with the Radiation Therapy Oncology Group (RTOG)/European Organisation for Research and Treatment of Cancer (EORTC) Late Radiation Morbidity Scoring Schema 14", page 3

Blinding of outcome assessors was not mentioned, we thought despite the pre-specified follow-up schema and the use of a Grading system for documenting late effects, meant this domain was at high risk of bias

Incomplete outcome data Low risk (attrition bias)

All outcomes
Quote: "after randomisation, 98 patients...administrative error", page 4, paragraph 1

Post-randomization exclusions are detailed by arm, with reasons, so we deemed this outcome at low risk of bias

Quote: "Detailed analyses of early and late side-effects, quality of life, and cosmetic results are not presented here", page 4, paragraph 1

Although detailed reporting of acute and late adverse effects and quality of life were not in this publication, the authors made it clear there will be further publications, so we judged this at low risk of bias. We had access to the study protocol

Selective reporting (re- Low risk porting bias)

We did not consider there was other bias, so judged this domain at low risk of bias.

$\begin{array}{ll}\text { Other bias Low risk } & \begin{array}{l}\text { We did not consider there was other bias, so judged this domain at low risk of } \\ \text { bias. }\end{array}\end{array}$

\section{Livi 2015}

\begin{tabular}{ll}
\hline Methods & RCT \\
& Single centre \\
& Setting: cancer centre \\
& Country: Italy \\
& Median follow-up: 60 months \\
\hline Participants & Women aged > 40 years, wide local excision or quadrantectomy for invasive breast cancer, negative \\
\hline margins, tumour size $\leq 25$ mm
\end{tabular}


Livi 2015 (Continued)

\section{Risk of bias}

\begin{tabular}{lll}
\hline Bias & Authors' judgement & Support for judgement \\
\hline $\begin{array}{l}\text { Random sequence genera- } \\
\text { tion (selection bias) }\end{array}$ & Low risk & $\begin{array}{l}\text { Quote: "Patients were randomly assigned to receive either WBI or APBI using } \\
\text { IMRT in a 1:1 ratio. Allocation was performed with a computer-generated se- } \\
\text { quence using a randomly permuted block design, without any stratification of } \\
\text { main prognostic factors", page 453, paragraph } 1\end{array}$ \\
\hline $\begin{array}{l}\text { Allocation concealment } \\
\text { (selection bias) }\end{array}$ & Low risk & $\begin{array}{l}\text { Wudged this at low risk of bias } \\
\text { cal Centre for Departmental Reference, CORD). The clinicians were required to } \\
\text { query it every time an eligible patient had provided written informed consent } \\
\text { to determine the allocation arm", page 453, paragraph } 1\end{array}$ \\
& $\begin{array}{l}\text { We judged this at low risk of bias } \\
\end{array}$
\end{tabular}

$\begin{array}{ll}\begin{array}{l}\text { Blinding of participants } \\ \text { and personnel (perfor- } \\ \text { mance bias) Objective out- } \\ \text { comes }\end{array} & \begin{array}{l}\text { Quote: "Clinicians, investigators and the patients themselves were aware of } \\ \text { the arm assignment", page 453, paragraph } 1\end{array} \\ & \begin{array}{l}\text { Blinding would have been difficult in view of the } 2 \text { very obviously different } \\ \text { treatments, we judged this domain at low risk of bias }\end{array}\end{array}$

\begin{tabular}{|c|c|c|}
\hline $\begin{array}{l}\text { Blinding of participants } \\
\text { and personnel (perfor- }\end{array}$ & Low risk & $\begin{array}{l}\text { Quote: "Clinicians, investigators and the patients themselves were aware of } \\
\text { the arm assignment", page 453, paragraph } 1\end{array}$ \\
\hline outcomes & & $\begin{array}{l}\text { Blinding would have been difficult in view of the } 2 \text { very obviously different } \\
\text { treatments, we judged this domain at low risk of bias }\end{array}$ \\
\hline
\end{tabular}

\begin{tabular}{|c|c|c|}
\hline $\begin{array}{l}\text { Blinding of outcome as- } \\
\text { sessment (detection bias) } \\
\text { Objective outcomes }\end{array}$ & Low risk & $\begin{array}{l}\text { Clinicians and investigators were not blinded to treatment arm, but the pre- } \\
\text { specified mammographic follow-up would have reduced the risk of bias relat- } \\
\text { ed to the primary outcome }\end{array}$ \\
\hline
\end{tabular}

\begin{tabular}{|c|c|c|}
\hline $\begin{array}{l}\text { Blinding of outcome as- } \\
\text { sessment (detection bias) }\end{array}$ & High risk & Quote: "mammography was annually programmed", page 454, paragraph 13 \\
\hline Subjective outcomes & & $\begin{array}{l}\text { The clinicians and investigators were not blinded to treatment arm, which } \\
\text { makes assessment of subjective outcomes at high risk of bias }\end{array}$ \\
\hline
\end{tabular}

\begin{tabular}{ll}
\hline $\begin{array}{l}\text { Incomplete outcome data } \\
\text { (attrition bias) }\end{array}$ & $\begin{array}{l}\text { No exclusions or attrition reported, so we judged this domain at low risk of } \\
\text { bias }\end{array}$ \\
All outcomes &
\end{tabular}

\begin{tabular}{lll}
\hline $\begin{array}{l}\text { Selective reporting (re- } \\
\text { porting bias) }\end{array}$ & Unclear risk & We did not review the protocol, so judged this domain at unclear risk of bias \\
\hline Other bias & Low risk & We did not identify any other sources of bias \\
\hline
\end{tabular}

Polgár 2007

\begin{tabular}{ll}
\hline Methods & SCT \\
Single-centre trial \\
Country: Hungary \\
Accrual dates July 1998 to May 2004
\end{tabular}


Polgár 2007 (Continued)

Median follow-up: 10.2 years
258 women with invasive breast cancer

Inclusion criteria: wide excision with negative margins, unifocal tumour, tumour size $<20 \mathrm{~mm}$, clinically or pathologically N0, or single microscopic nodal metastasis ( $>0.2 \mathrm{~mm}$ and $<2.0 \mathrm{~mm}$ ), i.e. pT1N0-1miM0, Grade I or II

Exclusion criteria: bilateral breast cancer, prior unilateral or contralateral breast cancer, concomitant or previous other malignancies, invasive lobular cancer, pure ductal or lobular cancer in situ (pTis). After 2001, women aged $<40$ years excluded

Mean age 58-59 years (given for each arm)
Experimental arm: PBI; 88/128 women had $7 \times 5.2$ Gy HDR multi-catheter brachytherapy and 40/128 women unsuitable for HDR had 50 Gy/25 fractions electron beam RT to partial breast

Control arm: $50 \mathrm{~Gy} / 25$ fractions WBRT (130 women)

Surgery: wide excision (resection of tumour with $\geq 1 \mathrm{~cm}$ macroscopic free margin). Cavity marked with titanium clips

Central pathology review performed

Systemic therapy given according to institutional protocol

Baseline mammography was performed at 6 months after RT then annually. Women were seen every 3 months in the first year, then once every 6 months

\section{Outcomes}

1. Local recurrence in the ipsilateral breast at 5 years

2. Cosmetic outcome (using the Harvard cosmetic score; Table 1)

Secondary:

1. Overall survival

2. Toxicity - late toxicity will be reported elsewhere

3. Cause-specific mortality (deaths due to breast cancer at 5 years)

4. Distant metastasis-free survival at 5 years

5. Relapse-free survival at 5 years

6. Subsequent mastectomy (ipsilateral partial mastectomy, modified radical mastectomy or radical mastectomy)

7. Compliance, defined as the number of women who commence treatment with PBI/APBI or conventional EBRT and complete the treatment course

Notes Early stopping at 258 women enrolled because another multicentred trial commenced

LR defined as any detection of cancer in the treated breast, confirmed histologically. An "elsewhere breast failure" defined as ipsilateral $(L R) \geq 2 \mathrm{~cm}$ from the clips. All other LR classified as true recurrence or marginal miss

Cosmetic score Harvard criteria, scored by treating radiation oncologist and chief investigator at analysis date (June to August 2006). In case of discrepancy, worst score used for analysis

Event-free intervals defined as time between date of surgery and date of event or last follow-up

\section{Risk of bias}

Bias Authors' judgement Support for judgement


Polgár 2007 (Continued)

Random sequence genera- Low risk tion (selection bias)
Quote: "were randomised". Polgár 2007, page 694, paragraph 3

Quote: "randomly allocated to treatment options by a sealed envelope system in blocks of $10 "$

Randomization was done by the main investigator (C.P.) Polgár 2007, page 695, paragraph 2

The trial was likely to have been randomized

Allocation concealment Unclear risk
(selection bias)

Quote: "randomly allocated to treatment options by a sealed envelope system in blocks of 10". Polgár 2007, page 695, paragraph 2

Allocation concealment appears to have been done, although the description was incomplete, which contributed to the judgement of unclear bias risk

Blinding of participants Low risk
mance bias) Objective outcomes

\section{Participants: not mentioned, unlikely to have been done}

Quote: "Blinding of physicians performing treatments and follow-up of patients was not possible for technical reasons". Polgár 2007, page 695, paragraph 2

Physicians: not done

Quote: "Blinding of physicians performing treatments and follow-up of patients was not possible for technical reasons". Polgár 2007, page 695, paragraph 2

We judged this domain at low risk of bias
Blinding of participants Low risk and personnel (performance bias) Subjective outcomes

Participants: not mentioned, unlikely to have been done

Quote: "Blinding of physicians performing treatments and follow-up of patients was not possible for technical reasons". Polgár 2007, page 695, paragraph 2

Physicians: not done

Quote: "Blinding of physicians performing treatments and follow-up of patients was not possible for technical reasons". Polgár 2007, page 695, paragraph 2

We judged this domain at low risk of bias

Blinding of outcome as- Low risk
sessment (detection bias)

objective outcomes
Participants: not mentioned, unlikely to have been done

Quote: "Blinding of physicians performing treatments and follow-up of patients was not possible for technical reasons". Polgár 2007, page 695, paragraph 2

Physicians: not done, but in view of pre-specified follow-up protocol, with regular mammography, unlikely to have introduced bias

Quote: "Patients were seen every three months in the first two years after RT and every six months thereafter. Baseline mammography was performed six months after completion of RT and yearly thereafter". Polgár 2007, page 697, paragraph 6

Quote: "Blinding of physicians performing treatments and follow-up of patients was not possible for technical reasons". Polgár 2007, page 695, paragraph 2 
Polgár 2007 (Continued)

Quote: "Local recurrence...proved by histological confirmation in every case".

Polgár 2007, page 697, paragraph 6

Assessors: not done

Unlikely to be a source of bias in view of the pre-specified schedule for follow-up visits and investigations. Local recurrence required biopsy confirmation, which would reduce the risk of bias in evaluation of this outcome

\section{Blinding of outcome as- High risk} sessment (detection bias) Subjective outcomes

Participants: not mentioned, unlikely to have introduced bias

Physicians: not mentioned, may be a source of bias

Assessors: not mentioned, unlikely to have been done, this is potentially a source of bias

Quote: "Cosmetic outcome scored independently by treating radiation oncologist and the main investigator...in the case of discrepancy, the worse cosmetic score was used for analysis". Polgár 2007, page 697, paragraph 5

\begin{tabular}{ll}
$\begin{array}{l}\text { Incomplete outcome data } \\
\text { (attrition bias) }\end{array}$ & Low risk \\
$\begin{array}{ll}\text { All outcomes } & \text { Attrition: } 0 \text { in experimental group, } 2 \text { in control group (declined follow-up at } 18 \\
& \text { and } 22 \text { months postoperatively) }\end{array}$ \\
\hline
\end{tabular}

Selective reporting (reporting bias)
Unclear risk

Outcomes in methods section:

1. Primary: local recurrence at 5 years

2. Differences in cosmetic outcome

Outcomes reported in paper:

1. LR

2. LR-FR at 5 years

3. 5-year actuarial LR rate, true recurrence and marginal miss

4. Overall survival at 5 years

5. Cancer-specific survival at 5 years

6. Distant metastasis-free survival at 5 years

7. Disease-free survival at 5 years

8. Probability of developing contralateral cancer at 5 years

9. Salvage therapy

10. Modified radical mastectomy rate

11. Cosmetic outcome

Outcomes in methods and protocol: protocol not reviewed

\begin{tabular}{ll}
\hline Other bias & Low risk \\
& $\begin{array}{l}\text { Trial stopped early (the trial enrolled } 258 \text { women of a planned sample size of } \\
570 \text { participants) because of a competing trial, GEC-ESTRO, started recruiting }\end{array}$ \\
\hline
\end{tabular}

RAPID

Methods

Phase III RCT; stratified for age, tumour histology, tumour size, adjuvant hormonal therapy and clinical centre

Country: Canada, Australia, New Zealand

Median follow-up: 36 months 
RAPID (Continued)

Participants Women aged $\geq 40$ years with new diagnosis of DCIS or with microscopically clear margins after BCS of non-invasive or invasive disease (or no residual disease on re-excision). Negative axillary nodal involvement including micrometastasis $(>0.2 \mathrm{~mm}$ or positive cells only identified on IHC as determined by sentinel node biopsy; axillary node dissection; or clinical examination for DCIS only. Tumour size $\leq 3 \mathrm{~cm}$

Interventions

Experimental arm: APBI (3D-CRT: 38.5 Gy in 10 fractions, bd over 5-8 days. 6-8 hour gap between doses required)

Control arm: WBRT (42.5 Gy in 16 fractions daily over 22 days). Women with large breast size: 50 Gy in 25 fractions over 25 days. Boost $10 \mathrm{~Gy}$ in 4 or 5 fractions over 4-7 days is permitted for those women deemed at moderate to high risk of LR as per local cancer centre guidelines

$\begin{array}{ll}\text { Outcomes } & \text { Primary: } \\ \text { 1. Ipsilateral breast tumour recur } \\ \text { breast including the axillary } \\ \text { Secondary: } \\ \text { 1. Adverse cosmetic outcome } \\ \text { 2. Disease-free survival } \\ \text { 3. Event-free survival } \\ \text { 4. Overall survival } \\ \text { 5. Radiation toxicity } \\ \text { 6. Quality of life } \\ \text { 7. Cost effectiveness }\end{array}$

Notes

QA: extensive QA processes (credentialling, real-time and post-hoc plan review)

NCT00282035

\section{Risk of bias}

\begin{tabular}{lll}
\hline Bias & Authors' judgement & Support for judgement \\
\hline $\begin{array}{l}\text { Random sequence genera- } \\
\text { tion (selection bias) }\end{array}$ & Low risk & $\begin{array}{l}\text { Quote: "were randomly assigned using a telephone-based central minimiza- } \\
\text { tion procedure" } \\
\end{array}$ \\
& $\begin{array}{l}\text { This was deemed an adequate method of sequence generation and the do- } \\
\text { main judged at low risk of bias }\end{array}$ \\
\hline
\end{tabular}

\begin{tabular}{ll}
\hline $\begin{array}{l}\text { Allocation concealment } \\
\text { (selection bias) }\end{array}$ & Unclear risk \\
& $\begin{array}{l}\text { The sequence generation was described as "telephone-based central minimi- } \\
\text { sation procedure", inadequate details were provided, so we deemed this at } \\
\text { unclear risk of bias }\end{array}$
\end{tabular}

\begin{tabular}{ll}
\hline $\begin{array}{l}\text { Blinding of participants } \\
\text { and personnel (perfor- }\end{array}$ & Low risk
\end{tabular}
mance bias) Objective outcomes

\begin{tabular}{ll}
\hline $\begin{array}{l}\text { Blinding of participants } \\
\begin{array}{l}\text { and personnel (perfor- } \\
\text { mance bias) Subjective }\end{array}\end{array}$ & $\begin{array}{l}\text { For technical reasons, blinding of participants and personnel was not possible, } \\
\text { but is unlikely to have introduced bias }\end{array}$ \\
outcomes &
\end{tabular}

Blinding of outcome as- Low risk Quote: "Bilateral mammograms were performed annually"
$\begin{aligned} & \text { sessment (detection bias) } \\ & \text { Objective outcomes }\end{aligned}$


We judged this domain at low risk of bias, because the mammography interval was pre-specified and this ensures the primary objective outcome (IBTR) was at low risk of bias

Blinding of outcome as- Low risk sessment (detection bias)

Subjective outcomes
Quote: "..addition to nurse and patient assessments, cosmesis was assessed by two panels of three radiation oncologists using the digital photographs. The physicians had breast cancer expertise and were trained to use the EORTC Cosmetic Rating System. After demonstrating good agreement in the ability to identify adverse cosmesis ( 0.71 ; Appendix, online only), each panel reviewed half of the available 3-year post-RT photo- graphs. The panels, blinded to treatment allocation, provided one consensus global cosmetic score for each patient (Appendix, online only)"

It was not stated whether the trained nurses evaluating the cosmetic outcome were blinded to treatment arm; however, the physician reviewers were blinded to treatment arm, so we judged this at low risk of bias

\begin{tabular}{lll}
\hline $\begin{array}{l}\text { Incomplete outcome data } \\
\text { (attrition bias) } \\
\text { All outcomes }\end{array}$ & Unclear risk & $\begin{array}{l}\text { Because this was an interim report, we were unable to assess the number of } \\
\text { exclusions or attrition, so judged the domain at unclear risk of bias }\end{array}$ \\
\hline $\begin{array}{l}\text { Selective reporting (re- } \\
\text { porting bias) }\end{array}$ & Unclear risk & $\begin{array}{l}\text { Because this was an interim report, we judged this domain at unclear risk of } \\
\text { bias }\end{array}$ \\
\hline Other bias & Unclear risk & No other sources of bias noted \\
\hline
\end{tabular}

\section{Rodriguez}

\begin{tabular}{ll}
\hline Methods & Phase III RCT (relative non-inferiority) \\
Country: Spain & Accrual dates: not stated, started accrual 2004 \\
& Median follow-up: 60 months \\
\hline Participants & $\begin{array}{l}102 \text { women with invasive ductal carcinoma (pT1-2cNO MO), aged } \geq 60 \text { years old, unifocal tumour, } \leq 3 \\
\text { cm, Grade I or II }\end{array}$ \\
\hline Interventions & $\begin{array}{l}\text { Experimental arm: PBI/APBI delivered by 3D-CRT at 48 Gy/24 fractions } \pm 10 \text { Gy boost (depending on risk } \\
\text { factors for local recurrence). 51 women }\end{array}$ \\
\hline Control arm: conventional WBRT at 48 Gy/24 fractions \pm 10 Gy boost (51 women) \\
\hline $\begin{array}{l}\text { 1. Local control } \\
\text { 2. Dosimetry and toxicity (using RTOG CTC) }\end{array}$ \\
$\begin{array}{ll}\text { 3. Skin elasticity measured using a dedicated device } \\
\text { QA: not mentioned }\end{array}$
\end{tabular}

\section{Risk of bias}

\begin{tabular}{lll}
\hline Bias & Authors' judgement & Support for judgement \\
\hline $\begin{array}{l}\text { Random sequence genera- } \\
\text { tion (selection bias) }\end{array}$ & Low risk & $\begin{array}{l}\text { Quote: "Randomization was performed by a computer-generated, randomized } \\
\text { list", page 1052, paragraph 5 }\end{array}$
\end{tabular}


Rodriguez (Continued)

This was an adequate method of sequence generation, so we judge this domain at low risk of bias

\begin{tabular}{lll}
\hline $\begin{array}{l}\text { Allocation concealment } \\
\text { (selection bias) }\end{array}$ & Unclear risk & $\begin{array}{l}\text { Allocation concealment was not clearly described, so we judged this domain } \\
\text { at unclear risk of bias }\end{array}$ \\
\hline $\begin{array}{l}\text { Blinding of participants } \\
\begin{array}{l}\text { and personnel (perfor- } \\
\text { mance bias) Objective out- } \\
\text { comes }\end{array}\end{array} \quad$ Low risk & $\begin{array}{l}\text { Binding of participants and personnel was not mentioned, and probably not } \\
\text { done, as it would have seen difficult in view of the technical aspects of the } 2 \text { in- } \\
\text { tervention arms. We judged this domain at low risk of bias }\end{array}$
\end{tabular}

\begin{tabular}{|c|c|c|}
\hline $\begin{array}{l}\text { Blinding of participants } \\
\text { and personnel (perfor- } \\
\text { mance bias) Subjective } \\
\text { outcomes }\end{array}$ & Low risk & $\begin{array}{l}\text { Binding of participants and personnel was not mentioned, and probably not } \\
\text { done, as it would have seen difficult in view of the technical aspects of the } 2 \text { in- } \\
\text { tervention arms. We judged this domain at low risk of bias }\end{array}$ \\
\hline
\end{tabular}

\begin{tabular}{ll}
\hline $\begin{array}{l}\text { Blinding of outcome as- } \\
\text { sessment (detection bias) } \\
\text { Objective outcomes }\end{array}$ & $\begin{array}{l}\text { Quote: "Baseline mammography was performed } 6 \text { months after the comple- } \\
\text { tion of radiation therapy and yearly thereafter. Abdominal ultrasonography, } \\
\text { chest radiography, and blood tests were performed at least annually. Local } \\
\text { recurrence was defined as any histologically confirmed cancer tissue in the } \\
\text { treated breast", page 1053, paragraph } 2\end{array}$ \\
& $\begin{array}{l}\text { Because the mammography intervals were pre-specified and local recurrence } \\
\text { required histological confirmation, the lack of blinding on the part of the out- } \\
\text { come assessors was not judged at high risk of bias }\end{array}$
\end{tabular}

\begin{tabular}{|c|c|c|}
\hline $\begin{array}{l}\text { Blinding of outcome as- } \\
\text { sessment (detection bias) } \\
\text { Subjective outcomes }\end{array}$ & High risk & $\begin{array}{l}\text { Quote: "Cosmetic results were evaluated according to the Harvard criteria at } \\
\text { baseline and at each follow-up visit by the treating radiation oncologist", page } \\
\text { 1053, paragraph } 5\end{array}$ \\
\hline
\end{tabular}

$\begin{array}{ll}\text { Subjective outcomes } & \text { 1053, paragraph } 5\end{array}$

All participants who had a minimum of 1 year follow-up were asked to rate cosmetic results on a 10-point scale, as follows: excellent (10-9), good (8-6), fair (5-4), or poor (3-1)

Acute, late RT toxicity and cosmesis were evaluated by the treating physician (not blinded, so at risk of bias). However, participants also rated the cosmetic outcome as well. Despite this participant-reported outcome, we judged this outcome at high risk of bias

\begin{tabular}{lll}
\hline $\begin{array}{l}\text { Incomplete outcome data } \\
\text { (attrition bias) } \\
\text { All outcomes }\end{array}$ & Unclear risk & Because this was an interim report, we judged it at unclear risk of bias \\
\hline $\begin{array}{l}\text { Selective reporting (re- } \\
\text { porting bias) }\end{array}$ & Unclear risk & Because this was an interim report, we judged it at unclear risk of bias \\
\hline Other bias & Unclear risk & Because this was an interim report, we judged it at unclear risk of bias \\
\hline
\end{tabular}

\section{TARGIT}

Multicentre international randomized non-inferiority Phase III trial
Accrual: March 2000 - data lock 2 May 2010
Country: 11 countries (across Europe, UK, US and Australia)
Median follow-up: 29 months $(1222 / 3451(35 \%))$ had 60 months' follow-up


TARGIT (Continued)

Participants 1113 women aged $\geq 45$ years, with T1 and small T2N0-1M0 invasive breast cancer, suitable for BCS, available for 10 years' follow-up

Interventions

Experimental arm: 1 fraction of RT given intraoperatively (using Intrabeam); $50 \mathrm{kV} 20 \mathrm{~Gy} /$ fraction at 2 $\mathrm{mm}$ beyond surface of $1.5-5.0 \mathrm{~cm}$ spherical applicator placed in excision cavity

Control arm: standard postoperative RT (40-56 Gy $\pm 10-16$ Gy boost)

Outcomes
Primary:
1. Pathologically confirmed local relapse within the treated breast
1. Site of relapse within the breast
2. Relapse-free survival and overall survival
3. Local toxicity
4. Local morbidity

Notes

Intrabeam uses low kilovolt x-rays to deliver $20 \mathrm{~Gy}$ at the surface of the tumour bed, attenuating to 5-7 Gy at $1 \mathrm{~cm}$. QA: training and auditing by member of International Standards Organisation (ISO) required before centre could join

NCT00983684, ISCTN 34086741, ISRCTN 34086741, REC No. 99/0307, UKCRN

\section{Risk of bias}

\begin{tabular}{lll}
\hline Bias & Authors' judgement & Support for judgement \\
\hline $\begin{array}{l}\text { Random sequence genera- } \\
\text { tion (selection bias) }\end{array}$ & Low risk & $\begin{array}{l}\text { Quote: "The randomisation schedules were generated centrally by computer } \\
\text { (securely kept in trial centres in Perth for Australian centres and London, UK, } \\
\text { for all other centres)", page 94, paragraph 1 }\end{array}$ \\
& &
\end{tabular}

Allocation concealment Low risk Quote: "Patients were randomly assigned in a 1:1 ratio...with blocks stratified (selection bias) by centre". Abstract, page 1, paragraph 2

Quote: "The randomisation schedules were generated centrally by computer (securely kept in trial centres in Perth for Australian centres, and London, UK for all other centres). Requests for randomisation were via telephone or fax to the trials office (Perth or London), where a trained member of staff checked patient eligibility. Treatment was allocated from a pre-printed randomisation schedule available to authorised staff only. Written confirmation of randomisation was sent by fax to the site". Methods, page, 94, paragraph 1

This trial was likely to have had adequate allocation concealment

\section{Blinding of participants Low risk} and personnel (performance bias) Objective outcomes
Participants: "Neither patients nor investigators or their teams were masked to treatment assignment". Abstract, page 1, paragraph 2

Physicians: "Neither patients nor investigators or their teams were masked to treatment assignment". Abstract, page 1, paragraph 2

Quote: "Individual centres were unblinded to treatment given in their own centres, but they were not given access to these data for other sites". Methods, page 1, paragraph 3

Quote: "Patient assessments were scheduled at entry"

Because of the nature of the intervention, it was not possible to blind the women participating or the personnel involved in their care, this is not likely to have resulted in bias. Because the patient assessments were scheduled at trial 
entry with pre-specified times for follow-up visits this is likely to have reduced the risk of bias from the lack of blinding of personnel

Blinding of participants Low risk
and personnel (performance bias) Subjective outcomes Participants: "Neither patients nor investigators or their teams were masked to
treatment assignment". Abstract, page 1, paragraph 2

Physicians: "Neither patients nor investigators or their teams were masked to treatment assignment". Abstract, page 1, paragraph 2

Quote: "Individual centres were unblinded to treatment given in their own centres, but they were not given access to these data for other sites". Methods, page 4, paragraph 3

Quote: "Patient assessments were scheduled at entry"

Because of the nature of the intervention, it was not possible to blind the women participating or the personnel involved in their care, this is not likely to have resulted in bias. Because the participant assessments were scheduled at trial entry with pre-specified times for follow-up visits this is likely to have reduced the risk of bias from the lack of blinding of personnel

\begin{tabular}{|c|c|c|}
\hline $\begin{array}{l}\text { Blinding of outcome as- } \\
\text { sessment (detection bias) }\end{array}$ & Low risk & Participants: not relevant \\
\hline Objective outcomes & & Physicians: not relevant \\
\hline
\end{tabular}

Assessors: "Patient's assessments were scheduled at entry, 3 months and 6 months", page 94, paragraph 4

This means the risk of lead time bias was reduced

Quote: "We recommend that mammography of the ipsilateral breast occurs annually and of the contralateral breast at least every three years". TARGIT protocol, 7.1 page 25

Quote: "Confidential unblinded reports for the DMC, and blinded reports for the ISO were produced by the trial statistician. Unblinded analyses were done according to a prespecified statistical analysis plan". Methods, page 4, paragraph 3

If there were pre-specified time intervals for mammography, this would have reduced the risk of bias for detection of the primary endpoint: local relapse

Blinding of outcome as- Low risk sessment (detection bias) Subjective outcomes
Quote: "The secondary outcome measure of local toxicity, or morbidity was assessed from data recorded on the complications form which contained a prespecified checklist", page 94, paragraph 3

It was not stated who assessed the subjective outcomes, however, we know: "Neither patients nor investigators or their teams were masked to treatment assignment". Abstract, page 1, paragraph 2

The blinding of outcome assessors was not reported, this does mean that there was risk of bias with assessment of toxicity; however, the use of a prespecified form would help to reduce bias because the data would be collected for all women

Quote: "digital photographs...were assessed, blinded to treatment arm" (Keshtgar et al. Journal of Clinical Oncology Vol. 28. 2010:7S, abstract 570)

Quote: "All randomised patients were included in the intention-to-treat analysis". Abstract, page 1, paragraph 2
Incomplete outcome data Low risk (attrition bias)

All outcomes 
TARGIT (Continued)

Quote: "When displaying the results, we restricted the duration of follow up to four years...since fewer than $420(<20 \%)$ patients had follow up beyond this point", page 95, paragraph 4

Because the outcomes were reported with a follow-up duration of 4 years, this does mean there is a high risk of bias because they reported on $<20 \%$ of the participants

Selective reporting (re- Low risk porting bias)

Outcomes specified in the protocol:

1. Local tumour control

2. Site of relapse within the breast

3. Relapse-free survival

4. Overall survival

5. Local toxicity and morbidity

6. Cosmesis, participant satisfaction, health economics, participant preference will be the subject of a sub-protocol

Outcomes specified in methods:

1. Primary:

a. "Pathologically confirmed local relapse within the treated breast", page 94, paragraph 5

2. Secondary:

a. Prospectively collected local toxicity or morbidity (checklist included haematoma, seroma, wound infection, skin breakdown, delayed wound healing)

b. RTOG Grade III/IV dermatitis

c. Telangiectasia

d. Pain in irradiated field or other

e. "To assess extent of local surgery we analysed specimen weight, margin status and re-operation for margins", page 95, paragraph 1

Outcomes reported in paper:

1. Median amount of tissue resected

2. Re-excision rates

3. Any complication

4. Clinically significant complications

5. RTOG toxicity score of III/IV

6. Major toxicity rate

7. Axillary recurrences

8. Uncontrolled local recurrences

9. Local recurrences at 4 years

The authors stated that, "no changes were made to trial outcomes after commencement of the trial"

The outcomes pre-specified in the protocol were not all reported, this probably reflects the short follow-up duration, but we consider these outcomes are likely to be reported in future publications

3D-CRT: 3-dimensional conformal radiotherapy; APBI: accelerated partial breast irradiation; BCS: breast-conserving surgery; bd: twice a day; DCIS: ductal carcinoma in situ; DMC: data monitoring committee; EBRT: external beam radiotherapy; Gy: Gray; HDR: high-dose-rate; IBRT: ipsilateral breast tumour recurrence; IHC: immunohistochemistry; IMRT: intensity-modulated radiotherapy; LENT-SOMA: late effects in normal tissues - subjective, objective, management and analytic; LR: local recurrence; M: metastases; MeV: mega electron volts; N: lymph 
node; PBI: partial breast irradiation; PDR: pulsed-dose-rate; QA: quality assurance; RCT: randomized controlled trial; RNI: regional nodal irradiation; RT: radiotherapy; RTOG CTC: Radiation Therapy Oncology Group Common Toxicity Criteria; WBRT: whole breast radiotherapy.

Characteristics of excluded studies [ordered by study ID]

\begin{tabular}{ll}
\hline Study & Reason for exclusion \\
\hline Dodwell 2005 & $\begin{array}{l}\text { RCT, but used surgical, systemic management and RT techniques that were not consistent with } \\
\text { contemporary practice }\end{array}$ \\
\hline NCT00892814 & Phase II RCT \\
\hline NCT01185132 & PBI used in both study arms \\
\hline NCT01928589 & PBI used in both study arms \\
\hline NCT02003560 & PBI used in both study arms \\
\hline Ribeiro 1993 & $\begin{array}{l}\text { RCT, but used surgical, systemic management and RT techniques that were not consistent with } \\
\text { contemporary practice }\end{array}$ \\
\hline TARGIT-B & WBRT used in both study arms \\
\hline TROG & Feasibility study and not an RCT \\
\hline
\end{tabular}

PBI: partial breast irradiation; RCT: randomized controlled trial; RT: radiation treatment; WBRT: whole breast radiotherapy.

Characteristics of studies awaiting assessment [ordered by study ID]

\section{NCT02375048}

\begin{tabular}{|c|c|}
\hline Methods & Randomized Phase II trial \\
\hline Participants & $\begin{array}{l}\text { Women aged } 55-70 \text { years } \\
\text { Inclusion criteria: } \\
\text { 1. aged } 55-70 \text { years } \\
\text { 2. Tumour size } \leq 2 \mathrm{~cm} \\
\text { 3. pNO (SN biopsy or ALND) } \\
\text { 4. ER/PgR positive } \\
\text { 5. Margins }>5 \mathrm{~mm} \text { (either at initial surgery or at re-excision) } \\
\text { 6. Clips placed in the surgical bed (minimum of } 4 \text { clips) } \\
\text { 7. Unicentric only } \\
\text { 8. No lympho-vascular invasion } \\
\text { 9. Any grade } \\
\text { 10. No extensive intraductal component (> } 25 \% \text { ) } \\
\text { 11. Written informed consent } \\
\text { Exclusion criteria: } \\
\text { 1. Prior thoracic radiotherapy } \\
\text { 2. Oncoplastic surgery/no clips in the surgical bed } \\
\text { 3. Multicentric cancer } \\
\text { 4. Autoimmune disease, vasculitis, collagenopathy or scleroderma that may predispose to late se- } \\
\text { quelae }\end{array}$ \\
\hline
\end{tabular}


NCT02375048 (Continued)

Interventions
Experimental arm: APBI

APBI was delivered at a dose of 30 Gy in 5-6 Gy/day fractions over 10 days (every other day) with IGRT at each treatment

Control arm: hypofractionated WBRT

Dose prescription was 40.5 Gy to planning target volume whole breast (PTV WB) and 48.0 Gy to PTV boost in 15 fractions over 3 weeks, with simultaneous integrated boost delivering 2.7 and $3.2 \mathrm{~Gy} /$ fraction for each PTV, respectively. Daily IGRT were generated before each treatment session in each participant to verify the set-up

Notes Primary:

1. Toxicity will be measured with CTCAE v.4.0

2. Cosmesis will be measured with Harvard scale

Secondary:

1. Rate of local control

2. Disease-free survival

3. Overall survival

4. Quality of life questionnaire

Randomized study on postmenopausal women with early-stage breast cancer: adjuvant hypofractionated WBI vs. APBI. Starts 2015, 700 women

Email: marta.scorsetti\%40humanitas.it

ALND: axillary lymph node dissection; APBI: accelerated partial breast irradiation; ER: oestrogen receptor; GTV: gross tumour volume; Gy: Gray; IGRT: image-guided radiotherapy; N: lymph node; PgR: progesterone receptor; PTV: planning target volume; SN: sentinel node biopsy; WBI: whole breast irradiation.

Characteristics of ongoing studies [ordered by study ID]

\section{IMPORT}

Trial name or title Randomized Trial Testing Intensity Modulated and Partial Organ Radiotherapy After Breast Conservation Surgery for Early Breast Cancer

Methods Randomized, Phase III multicentre trial

Participants

Women aged $>50$ years, with invasive breast cancer $\mathrm{pT} 1-2 \mathrm{pN} 0$, who have had BCS with negative margins $(\geq 2 \mathrm{~mm}$ ) who have $<1 \%$ annual risk of local recurrence

Interventions

Experimental arm 1: reduced WBRT and standard PBI once daily on days 1-5 for 3 weeks

IMRT

Arm 1: 40 Gy/15 fractions

Arm 2: $40 \mathrm{~Gy} / 15$ fractions + integrated boost to WB $36 \mathrm{~Gy} / 15$ fractions

Experimental arm 2: PBI daily on days 1-5 for 3 weeks

Control: standard WBRT day 1-5 for 3 weeks

Outcomes

Primary: local tumour control in the ipsilateral breast 
IMPORT (Continued)

Secondary: location of tumour relapse, contralateral primary breast cancer, regional or distant metastases, late adverse effects in normal tissues (photographic, physician and participant assessments), quality of life, cost-effectiveness

\begin{tabular}{ll}
\hline Starting date & October 2006 \\
\hline Contact information & J Yarnold, Royal Marsden, London \\
\hline Notes & NCT00814567 \\
& CSDR0000629765, ICR-IMPORT-LOW, ICR-CTSU/2006/10001, ISCTN12852634, EU-20896 \\
& Target volume: 6 pairs of clips in cavity $=$ CTV +10 mm = PTV \\
\hline
\end{tabular}

IRMA

Trial name or title

\begin{tabular}{ll}
\hline Methods & Multicentre Phase III controlled randomized, unblinded study of non-inferiority \\
\hline Participants & $\begin{array}{l}\text { Women aged } \geq 49 \text { years, ECOG } 0-2, \text { undergoing conservative breast surgery for invasive breast can- } \\
\text { cer, } \mathrm{pT} 1-2(<3 \mathrm{~cm} \text { in diameter) pN0-N1 M0, unifocal, resection margins histologically negative }(2 \\
\mathrm{mm}) \text { at first intervention or after subsequent widening }\end{array}$ \\
\hline
\end{tabular}

Interventions

Experimental arm: $38.5 \mathrm{~Gy}$ total in 10 fractions (3.85 Gy per fraction), twice a day with an interval of at least 6 hours between the 2 fractions, for 5 consecutive working days of the sole cavity

Control arm: 50.0 Gy in 25 fractions (2 Gy per fraction), once a day for 5 days in the week RT of the entire breast

\section{Outcomes}

Primary: survival free of local ipsilateral recurrence as prime event

Secondary: global survival, loco-regional recurrence-free, distant recurrence-free, acute and late toxicity (RTOG) and cosmetic result

\begin{tabular}{ll}
\hline Starting date & Data Center Office \\
\hline Contact information & Clinical Trials Office, Integrated Department of Oncology and Hematology \\
& Polyclinic Hospital, University of Modena and Reggio Emilia \\
& R. D'Amico, G. Jovic, R. Vicini \\
& Tel. 059 4223865 \\
& Email: Roberto.damico@unimore.it \\
\hline Notes & Study currently accruing participants. Target volume: GTV + 15 mm = CTV +5 mm = PTV \\
\hline
\end{tabular}


NSABP-B39/RTOG

Trial name or title

A Randomised Phase II Study of Conventional Whole Breast Irradiation (WBI) Versus Partial Breast Irradiation (PBI) for Women with Stage 0, I, or II Breast Cancer

\begin{tabular}{|c|c|}
\hline Methods & Randomized, multicentre Phase III trial \\
\hline Participants & $\begin{array}{l}\text { Women aged }>18 \text { years with histologically confirmed DCIS or invasive adenocarcinoma of the } \\
\text { breast, negative histological margins, no more than } 3 \text { axillary nodes involved, must have had BCS }\end{array}$ \\
\hline \multirow[t]{5}{*}{ Interventions } & Experimental arm: PBI 5 days per week for 5-7 weeks \\
\hline & $\begin{array}{l}\text { Control arm: WBRT bd on } 5 \text { days over 5-10 days ( } 50 \text { Gy in } 25 \text { fractions at } 1.8-2 \text { Gy per fraction, op- } \\
\text { tional boost to } 60-66 \text { Gy) }\end{array}$ \\
\hline & Brachytherapy 34 Gy/10 fractions \\
\hline & MammoSite $34 \mathrm{~Gy} / 10$ fractions \\
\hline & 3DCRT $38.5 \mathrm{~Gy} / 10$ fractions \\
\hline
\end{tabular}

\begin{tabular}{ll}
\hline Outcomes & $\begin{array}{l}\text { Primary: in-breast tumour recurrence } \\
\text { Secondary: survival, event-free survival, distant disease-free survival, quality of life and partici- } \\
\text { pant-reported cosmesis, physician-reported cosmesis and toxicity }\end{array}$ \\
\hline Starting date & March 2005 \\
\hline Contact information & Study chair: F Vicini, William Beaumont Hospital- Royal Oak Campus \\
& J White, Medical College of Wisconsin \\
\hline Notes & NCT00103181 \\
& NSABP B-39/RTOG 0413, SWOG-NSABP-B-39 \\
& Collaborators: Southwest Oncology Group, National Cancer Institute, RTOG, National Surgical Ad- \\
juvant Breast and Bowel Project & For brachytherapy and 3DCRT: cavity plus 15 mm = CTV + 10 mm = PTV \\
MammoSite: PTV = 10 mm expansion on balloon minus balloon volume
\end{tabular}

\section{SHARE}

\begin{tabular}{ll}
\hline Trial name or title & $\begin{array}{l}\text { Standard or Hypofractionated Radiotherapy Versus Accelerated Partial Breast Irradiation (PBI/AP- } \\
\text { BI) for Breast Cancer (SHARE) Phase III Multicentric Trial Comparing Accelerated Partial Breast Irra- } \\
\text { diation (PBI/APBI) Versus Standard or Hypofractionated Whole Breast Irradiation in Low Risk of Lo- } \\
\text { cal Recurrence of Breast Cancer }\end{array}$ \\
\hline Methods & Multicentre RCT \\
\hline Participants & Inclusion criteria: \\
1. Women aged $\geq 50$ years \\
2. Menopausal status confirmed \\
3. Pathology confirmation of invasive carcinoma (all types) \\
4. Complete tumour removal and conservative surgery \\
5. Pathologic tumour size of invasive carcinoma $\leq 2 \mathrm{~cm}$ (including the in situ component) pT1 \\
6. All histopathological grades
\end{tabular}


SHARE (Continued)

7. Clear lateral margins for the invasive and in situ disease $(>2 \mathrm{~mm})$
8. $\mathrm{pNO}$ or $\mathrm{pN}(\mathrm{i}+)$
9. No metastasis
10.RT should be started $>4$ weeks and $<12$ weeks after last surgery
11.Surgical clips ( 4 or 5 clips in the tumour bed)
12.No prior breast or mediastinal RT
13.ECOG 0 - 1
14.Information to the participant and signed informed consent

Exclusion criteria:

1. Multifocal invasive ductal carcinoma defined as the presence of $\geq 2$ distinct tumours that are separated by normal tissue or when the distance between the 2 lesions does not permit conservative surgery

2. Bilateral breast cancer

3. No or $<4$ surgical clips in the tumour bed

4. Nodal involvement: $\mathrm{pN} 1$ (including micrometastasis, mi+), pN2, pN3

5. Metastatic disease

6. Internal mammary node involvement or supraclavicular lymph node involvement

7. Indication of chemotherapy or trastuzumab

8. Involved or close lateral margins for the invasive with or without in situ components ( $<2 \mathrm{~mm}$ ) AND impossibility to re-operate or impossible to perform another conservative surgery

9. Women with known BRCA1 or BRCA2 mutations

10.Previous mammoplasty

11.Previous homolateral breast or mediastinal irradiation, or both

12.Previous invasive cancer (except basocellular epithelioma or in situ carcinoma of the cervix)

13.No geographical, social or psychological reasons that would prevent study follow-up
Experimental arm: APBI

\section{D-CRT}

\section{$40 \mathrm{~Gy} / 10$ fractions}

Tumour bed 40 Gy in 10 fractions, 2 fractions of 4 Gy per day in 5-7 days. PBI/APBI using 3D-CRT technique, in 5 days, 40 Gy to the tumour bed

Control arm: standard or hypofractionated radiotherapy

Outcomes

Primary:

1. Rate of local recurrence

Secondary:

1. Ipsilateral breast recurrence-free survival

2. Nodal regional recurrence-free survival

3. Distant recurrence-free survival

4. Disease-specific survival

5. Overall survival

6. Toxicities: measurement of the rate and type of toxicity (acute and late toxic effects)

7. Cosmetic: comparison of the cosmetic result (according to both the physician and the participant)

8. Quality of life and satisfaction

9. Medico-economic study 
SHARE (Continued)

Contact information

Jerome Lemonnier, PhD; Tel: +33 17193 6702; Email: j-lemonnier@unicancer.fr

Notes

3D-CRT: 3-dimensional conformal radiotherapy; APBI: accelerated partial breast irradiation; BCS: breast-conserving surgery; bd: twice a day; CTV: clinical target volume; DCIS: ductal carcinoma in situ; ECOG: Eastern Cooperative Oncology Group; ER: oestrogen receptor; GTV: gross tumour volume; Gy: Gray; IGRT: image-guided radiotherapy; IMRT: intensity-modulated radiotherapy; M: metastases; N: lymph node; PBI: partial breast irradiation; PgR: progesterone receptor; PTV: planning target volume; RCT: randomized controlled trial; RT: radiotherapy; RTOG: Radiation Therapy Oncology Group; SN: sentinel node biopsy; WB: whole breast; T: tumour; WBRT: whole breast radiotherapy.

DATA AND ANALYSES

\section{Comparison 1. Partial breast irradiation (PBI)/accelerated partial breast irradiation (APBI) versus whole breast radiotherapy (WBRT)}

\begin{tabular}{|c|c|c|c|c|}
\hline Outcome or subgroup title & $\begin{array}{l}\text { No. of } \\
\text { studies }\end{array}$ & $\begin{array}{l}\text { No. of } \\
\text { partici- } \\
\text { pants }\end{array}$ & Statistical method & Effect size \\
\hline $\begin{array}{l}1 \text { Local recurrence-free sur- } \\
\text { vival }\end{array}$ & 6 & 6820 & Hazard Ratio $(95 \% \mathrm{Cl})$ & $1.62[1.11,2.35]$ \\
\hline $\begin{array}{l}1.12 .4 \text { years' median fol- } \\
\text { low-up }\end{array}$ & 1 & 3451 & Hazard Ratio (95\% Cl) & $2.05[1.00,4.21]$ \\
\hline 1.25 years' follow-up & 4 & 3111 & Hazard Ratio $(95 \% \mathrm{Cl})$ & $2.50[1.21,5.15]$ \\
\hline 1.310 years' follow-up & 1 & 258 & Hazard Ratio (95\% CI) & $1.09[0.63,1.89]$ \\
\hline $\begin{array}{l}2 \text { Cosmesis, physician-report- } \\
\text { ed }\end{array}$ & 5 & 1720 & Odds Ratio (M-H, Fixed, 95\% Cl) & $1.51[1.17,1.95]$ \\
\hline 3 Overall survival & 5 & 6718 & Hazard Ratio $(95 \% \mathrm{Cl})$ & $0.90[0.74,1.09]$ \\
\hline $\begin{array}{l}4 \text { Acute radiotherapy (RT) } \\
\text { skin toxicity }\end{array}$ & 2 & 608 & Odds Ratio (M-H, Fixed, 95\% Cl) & $0.04[0.02,0.09]$ \\
\hline 5 Late RT skin toxicity & 2 & 608 & Odds Ratio (M-H, Fixed, 95\% Cl) & $0.21[0.01,4.39]$ \\
\hline 6 Fat necrosis & 3 & 1319 & Odds Ratio (M-H, Fixed, 95\% Cl) & $1.58[1.02,2.43]$ \\
\hline 7 'Elsewhere primary' & 3 & 3009 & Odds Ratio (M-H, Fixed, 95\% Cl) & $3.97[1.51,10.41]$ \\
\hline 8 Cause-specific survival & 5 & 6718 & Hazard Ratio (95\% CI) & $1.08[0.73,1.58]$ \\
\hline $\begin{array}{l}9 \text { Distant metastasis-free sur- } \\
\text { vival }\end{array}$ & 4 & 3267 & Hazard Ratio $(95 \% \mathrm{Cl})$ & $0.94[0.65,1.37]$ \\
\hline 10 Relapse-free survival & 3 & 3811 & Hazard Ratio (95\% Cl) & $1.36[0.88,2.09]$ \\
\hline $\begin{array}{l}11 \text { Loco-regional recur- } \\
\text { rence-free survival }\end{array}$ & 2 & 3553 & Hazard Ratio $(95 \% \mathrm{Cl})$ & $1.80[1.00,3.25]$ \\
\hline 12 Mastectomy & 3 & 4817 & Odds Ratio (M-H, Fixed, 95\% Cl) & $1.20[0.77,1.87]$ \\
\hline
\end{tabular}




\section{Analysis 1.1. Comparison 1 Partial breast irradiation (PBI)/accelerated partial breast irradiation (APBI) versus whole breast radiotherapy (WBRT), Outcome 1 Local recurrence-free survival.}

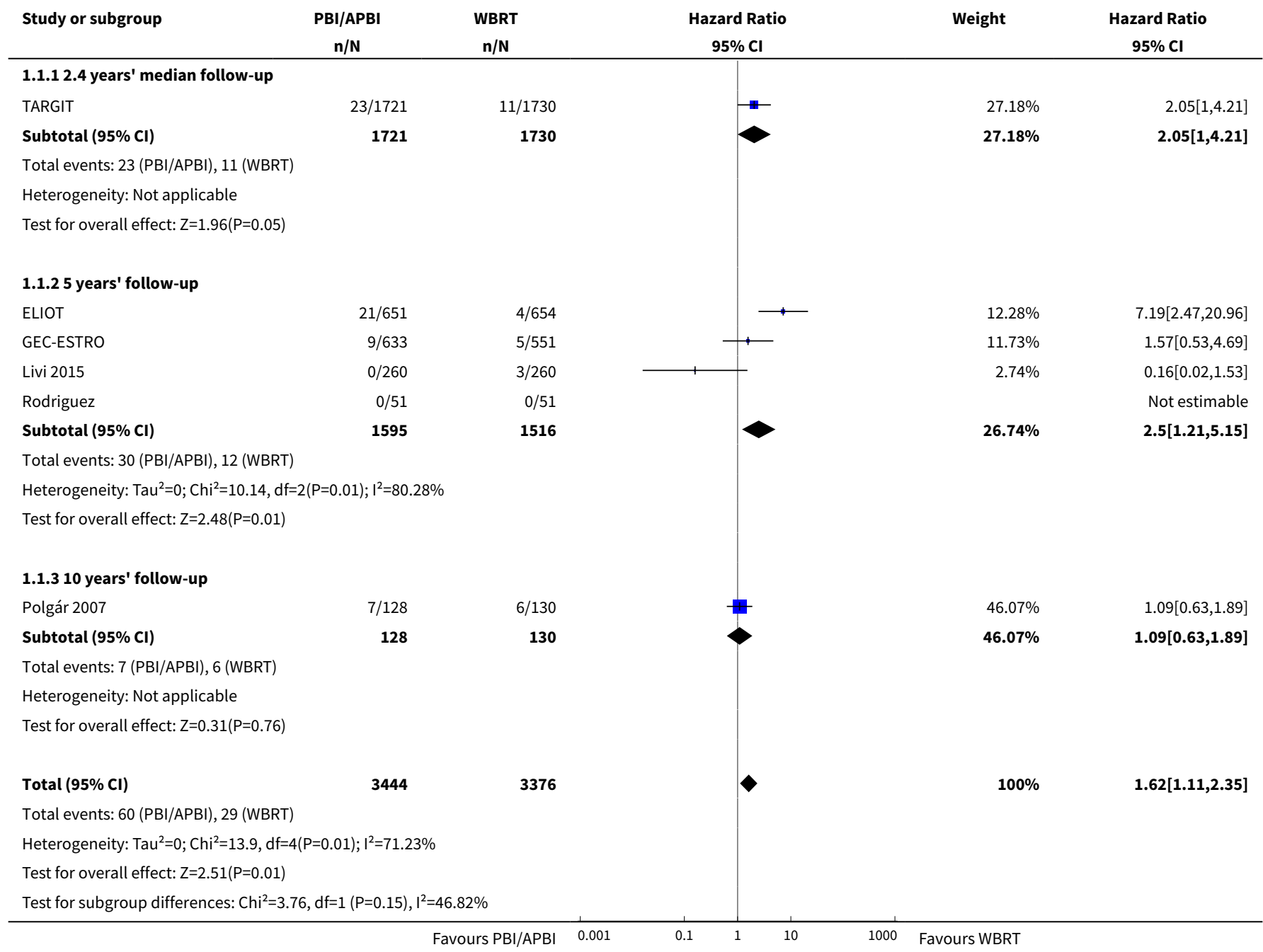

\section{Analysis 1.2. Comparison 1 Partial breast irradiation (PBI)/accelerated partial breast irradiation (APBI) versus whole breast radiotherapy (WBRT), Outcome 2 Cosmesis, physician-reported.}

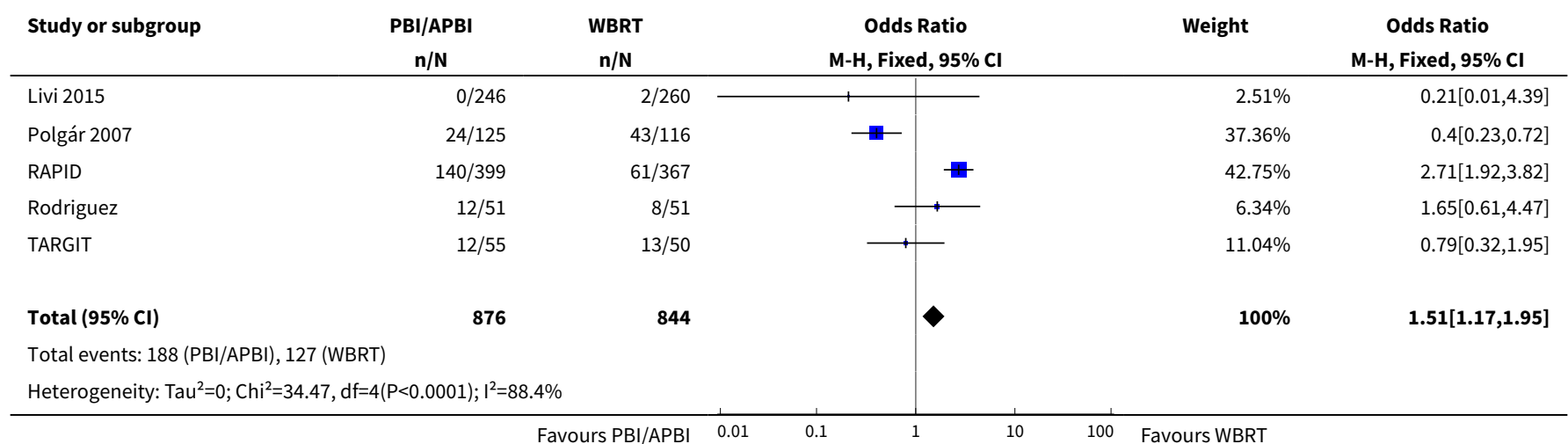




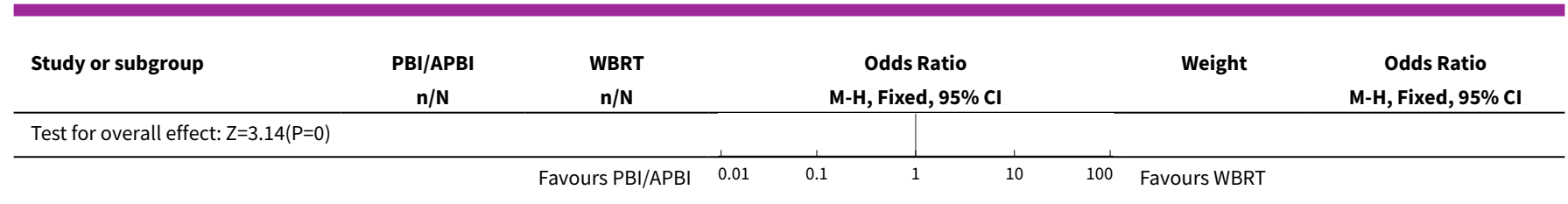

Analysis 1.3. Comparison 1 Partial breast irradiation (PBI)/accelerated partial breast irradiation (APBI) versus whole breast radiotherapy (WBRT), Outcome 3 Overall survival.

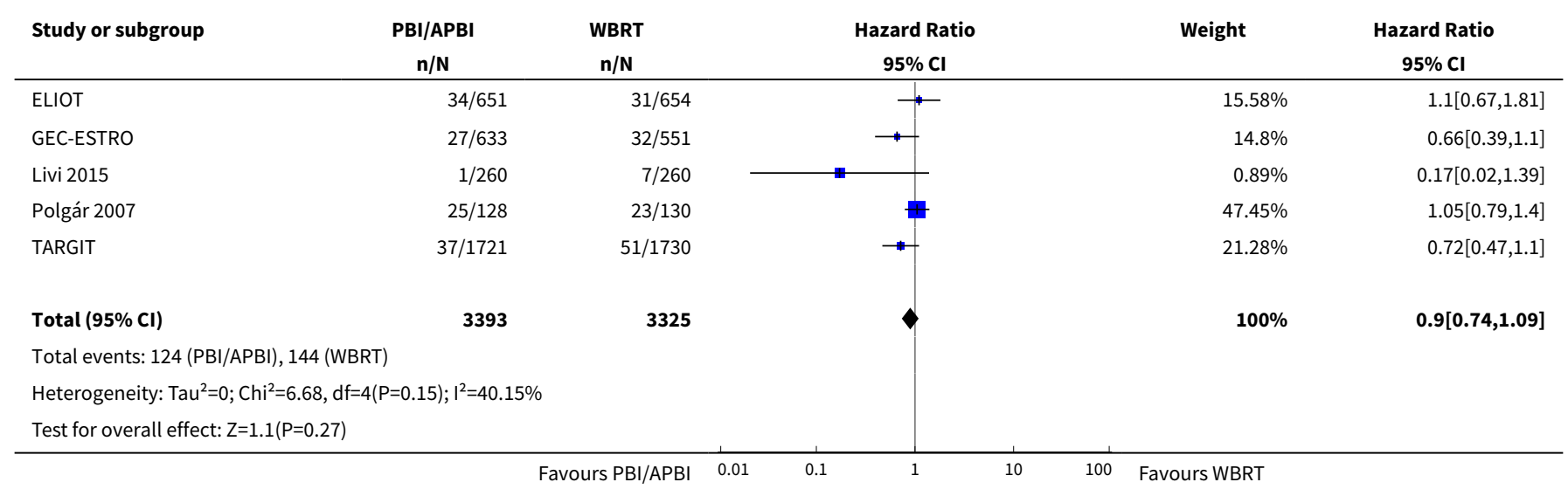

Analysis 1.4. Comparison 1 Partial breast irradiation (PBI)/accelerated partial breast irradiation (APBI) versus whole breast radiotherapy (WBRT), Outcome 4 Acute radiotherapy (RT) skin toxicity.

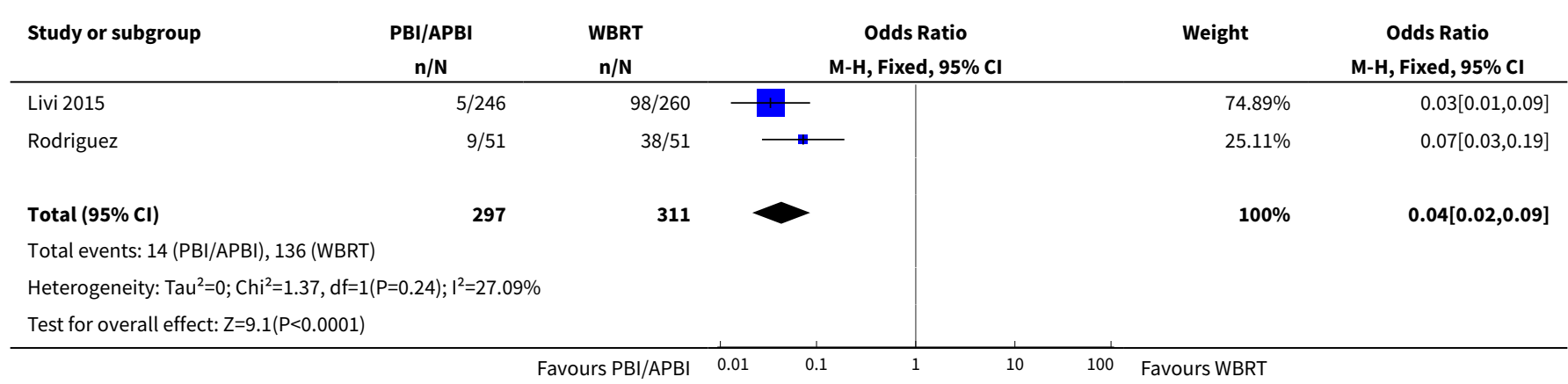

Analysis 1.5. Comparison 1 Partial breast irradiation (PBI)/accelerated partial breast irradiation (APBI) versus whole breast radiotherapy (WBRT), Outcome 5 Late RT skin toxicity.

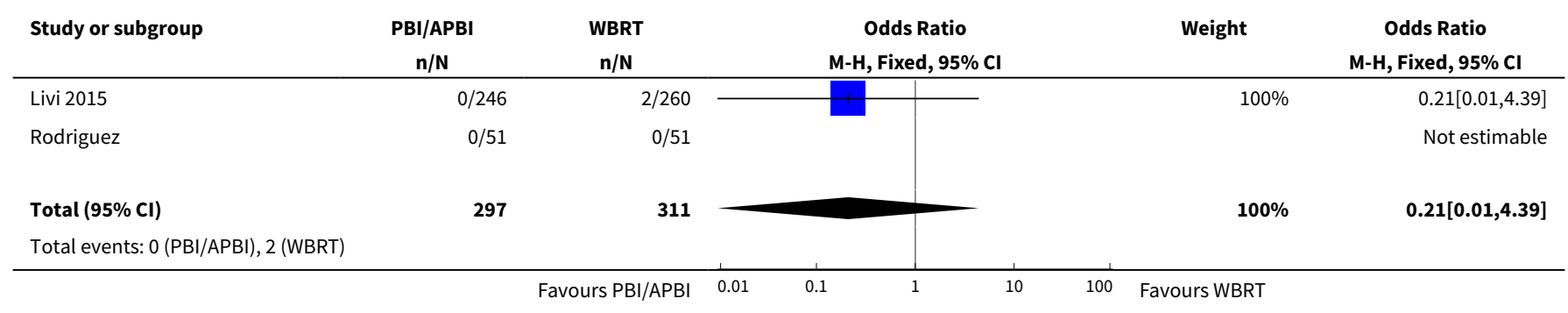




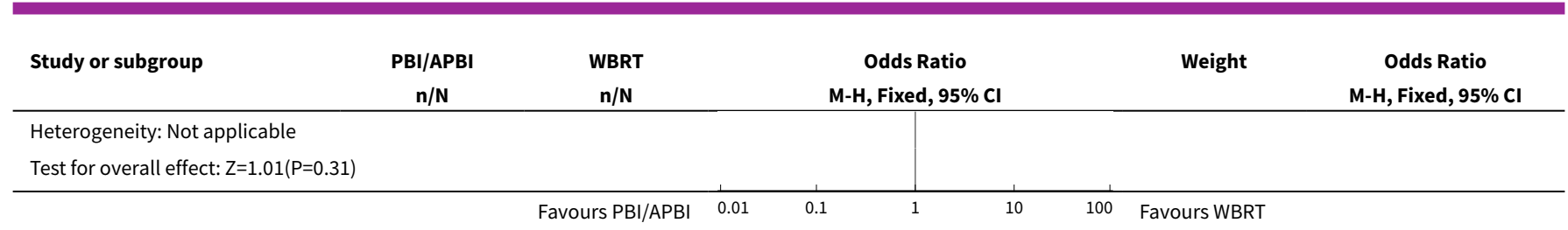

Analysis 1.6. Comparison 1 Partial breast irradiation (PBI)/accelerated partial breast irradiation (APBI) versus whole breast radiotherapy (WBRT), Outcome 6 Fat necrosis.

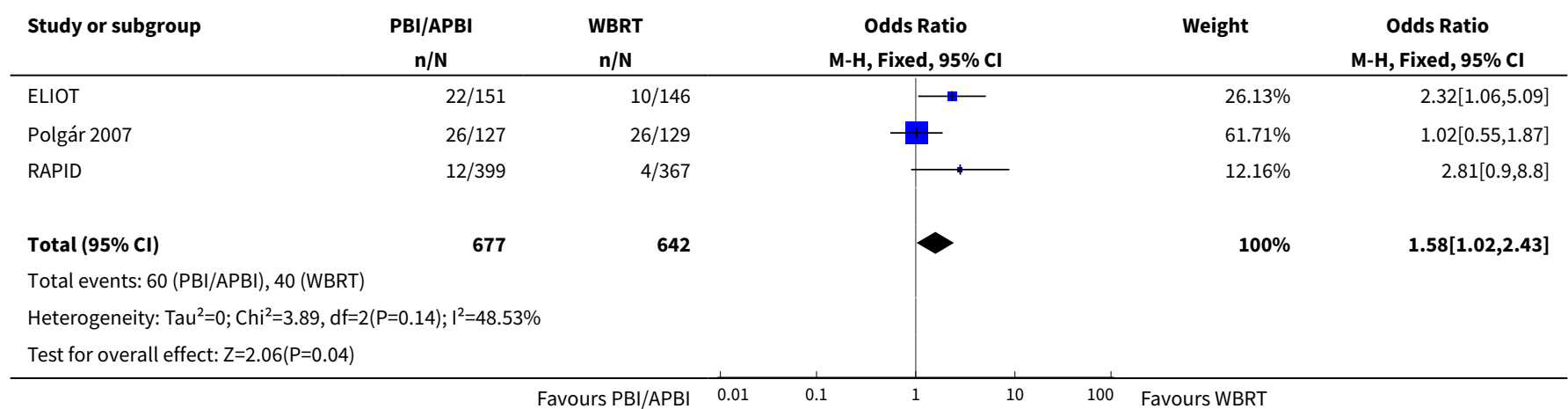

Analysis 1.7. Comparison 1 Partial breast irradiation (PBI)/accelerated partial breast irradiation (APBI) versus whole breast radiotherapy (WBRT), Outcome 7 'Elsewhere primary'.

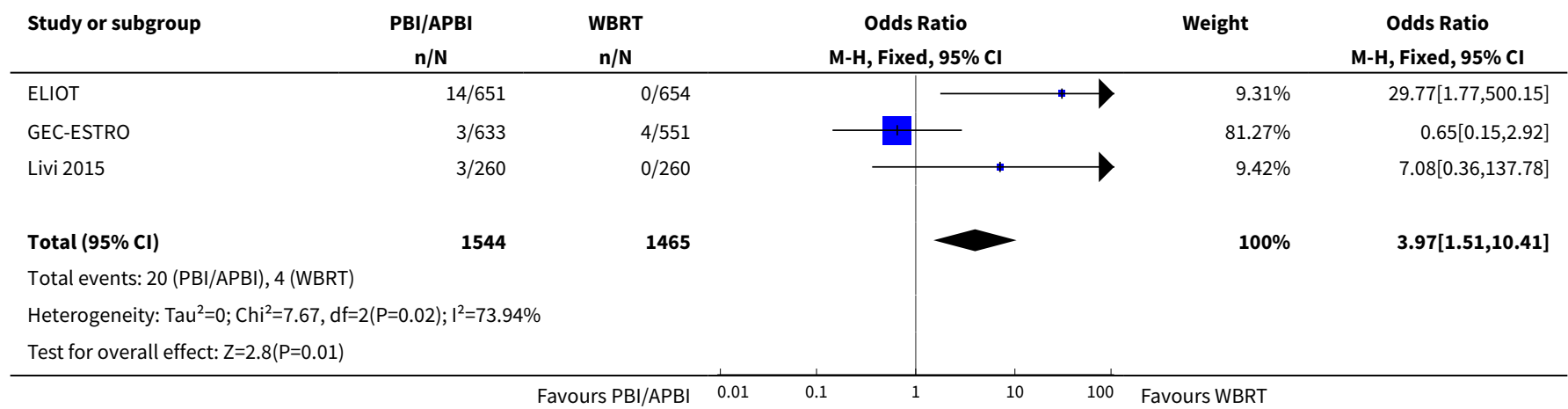

Analysis 1.8. Comparison 1 Partial breast irradiation (PBI)/accelerated partial breast irradiation (APBI) versus whole breast radiotherapy (WBRT), Outcome 8 Cause-specific survival.

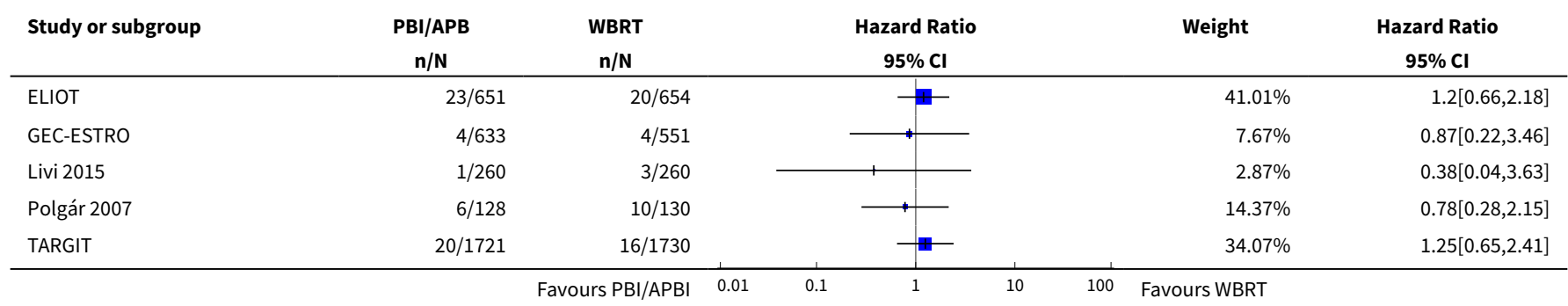




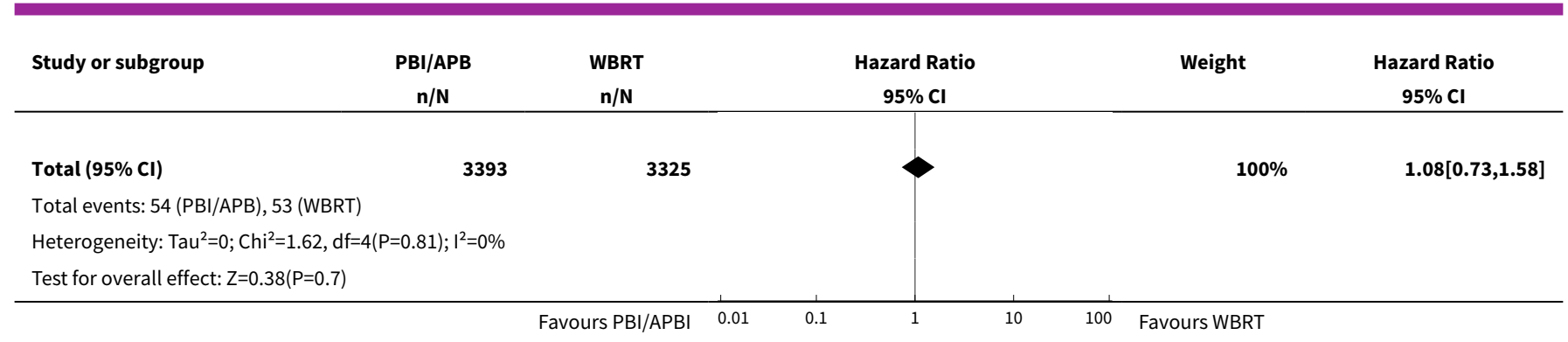

Analysis 1.9. Comparison 1 Partial breast irradiation (PBI)/accelerated partial breast irradiation (APBI) versus whole breast radiotherapy (WBRT), Outcome 9 Distant metastasis-free survival.

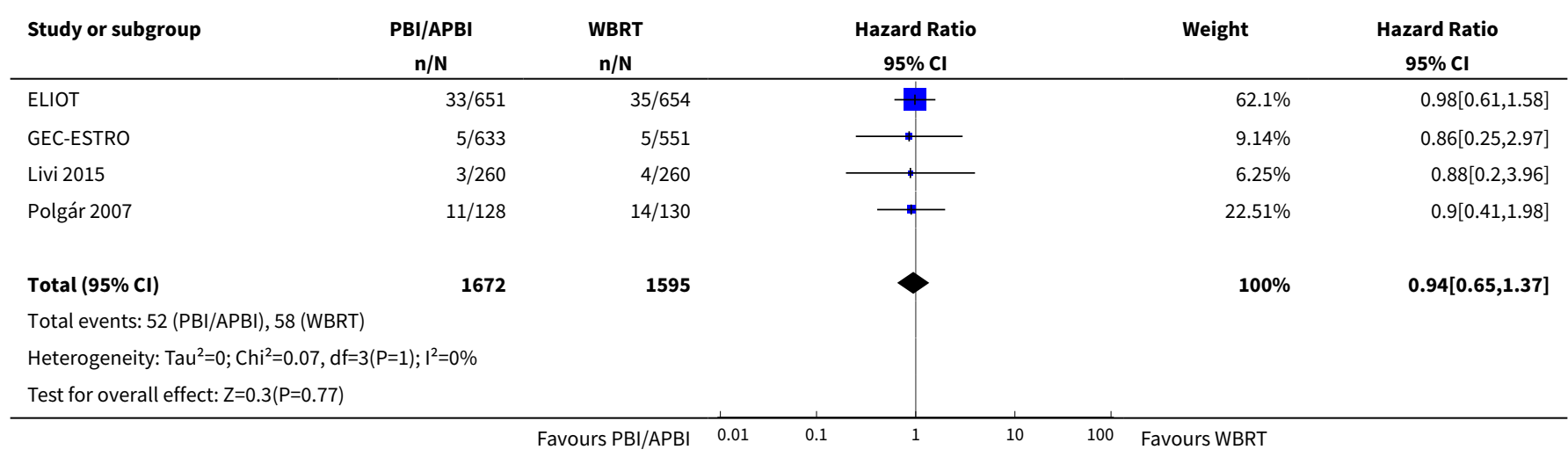

Analysis 1.10. Comparison 1 Partial breast irradiation (PBI)/accelerated partial breast irradiation (APBI) versus whole breast radiotherapy (WBRT), Outcome 10 Relapse-free survival.

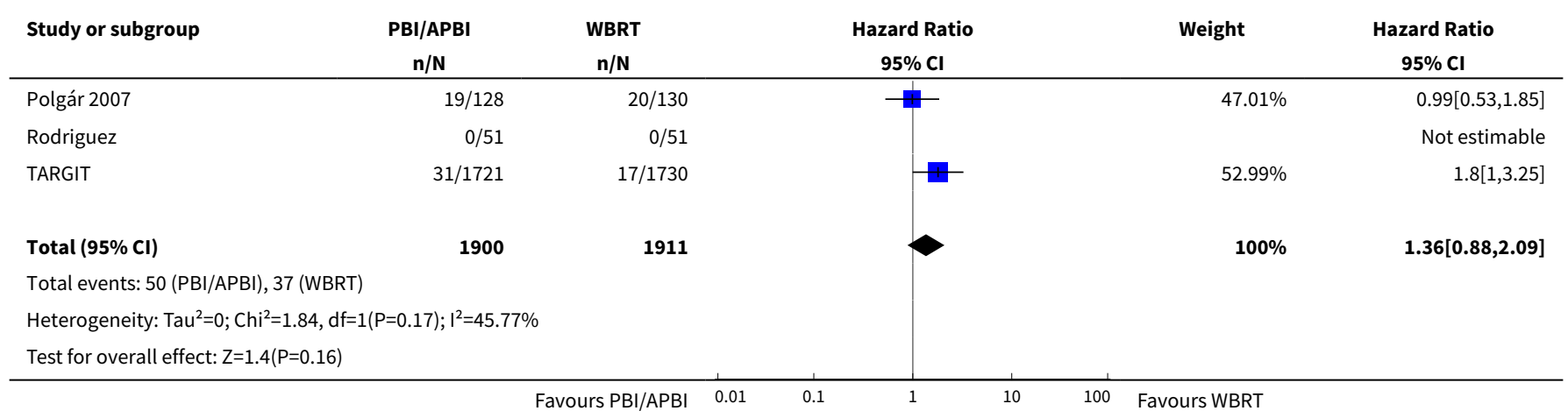

Analysis 1.11. Comparison 1 Partial breast irradiation (PBI)/accelerated partial breast irradiation (APBI) versus whole breast radiotherapy (WBRT), Outcome 11 Loco-regional recurrence-free survival.

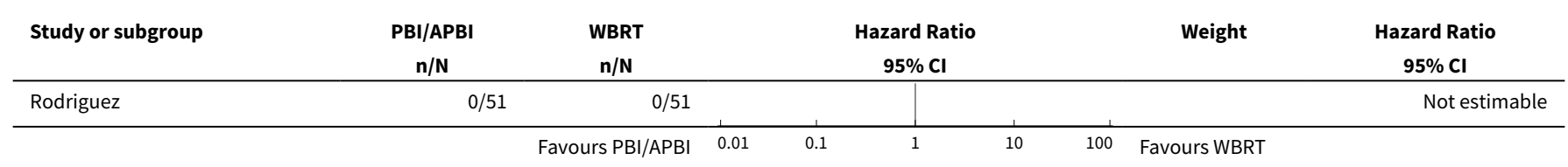




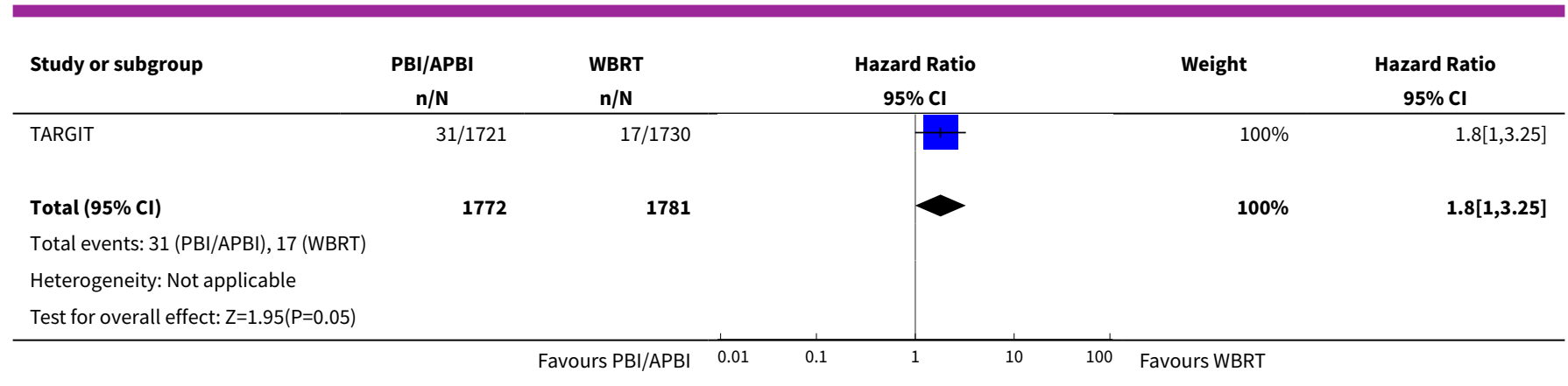

Analysis 1.12. Comparison 1 Partial breast irradiation (PBI)/accelerated partial breast irradiation (APBI) versus whole breast radiotherapy (WBRT), Outcome 12 Mastectomy.

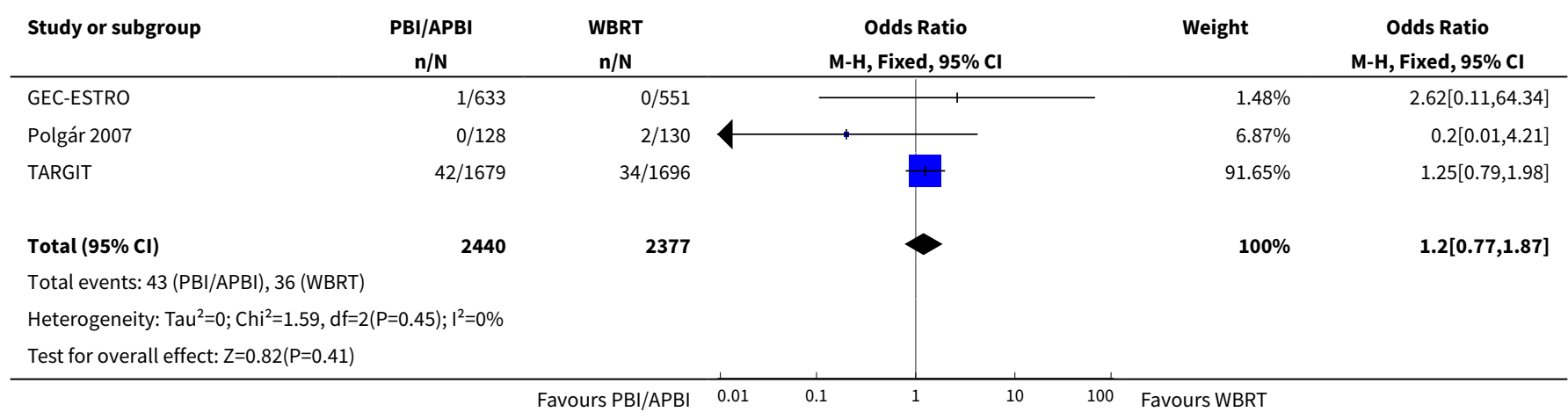

\section{ADDITIONAL TABLES}

Table 1. Harvard cosmetic score

\section{Cosmetic score}

Excellent

\section{Good}

Fair

Poor

Table 2. Brachytherapy cosmetic score

\begin{tabular}{ll}
\hline Score & Definition \\
\hline Excellent & Perfect symmetry, no visible distortion or skin changes and no visible catheter entry/exit sequelae \\
\hline Good & $\begin{array}{l}\text { Slight skin distortion, retraction or oedema, any visible telangiectasia, any visible catheter en- } \\
\text { try/exit scar or mild hyperpigmentation }\end{array}$ \\
\hline
\end{tabular}


Table 2. Brachytherapy cosmetic score (Continued)

Fair

Moderate distortion of the nipple or breast symmetry, moderate hyperpigmentation, or prominent skin retraction, oedema or telangiectasia

Table 3. RTOG CTC acute skin toxicity

\begin{tabular}{lllll}
\hline RTOG CTC & Grade I & Grade II & Grade III & Grade IV \\
\hline $\begin{array}{l}\text { Descrip- } \\
\text { tion }\end{array}$ & $\begin{array}{l}\text { Follicular, faint or dull erythema / } \\
\text { epilation / dry desquamation / } \\
\text { decreased sweating }\end{array}$ & $\begin{array}{l}\text { Tender or bright erythema, } \\
\text { patchy moist desquamation / } \\
\text { moderate oedema }\end{array}$ & $\begin{array}{l}\text { Confluent, moist desquama- } \\
\text { tion other than skin folds, pit- } \\
\text { ting oedema }\end{array}$ & $\begin{array}{l}\text { Ulceration, } \\
\text { haemorrhage, } \\
\text { necrosis }\end{array}$ \\
\hline
\end{tabular}

RTOG CTC: Radiation Therapy Oncology Group Common Toxicity Criteria.

Table 4. Fat necrosis

\begin{tabular}{ll}
\hline Grade & Findings \\
\hline 0 & No fat necrosis \\
\hline 1 & $\begin{array}{l}\text { Asymptomatic fat necrosis (only radiological or } \\
\text { cytological findings, or both) }\end{array}$ \\
\hline 2 & $\begin{array}{l}\text { Symptomatic fat necrosis not requiring medication } \\
\text { (palpable mass with or without mild pain) }\end{array}$ \\
\hline 3 & $\begin{array}{l}\text { Symptomatic fat necrosis requiring medication } \\
\text { (palpable mass with significant pain) }\end{array}$ \\
\hline 4 & $\begin{array}{l}\text { Symptomatic fat necrosis requiring surgical } \\
\text { intervention }\end{array}$ \\
\hline
\end{tabular}

Table 5. NCI CTC 3.0

\begin{tabular}{|c|c|c|c|c|}
\hline Toxicity & Grade 1 & Grade 2 & Grade 3 & Grade 4 \\
\hline $\begin{array}{l}\text { Induration } \\
\text { (subcuta- } \\
\text { neous fi- } \\
\text { brosis) }\end{array}$ & $\begin{array}{l}\text { Increased densi- } \\
\text { ty on palpation }\end{array}$ & $\begin{array}{l}\text { Moderate increase in density, not interfer- } \\
\text { ing with ADL; marked increase in density and } \\
\text { firmness on palpation with or without mini- } \\
\text { mal retraction }\end{array}$ & $\begin{array}{l}\text { Dysfunction interfering with } A D L ; \\
\text { very marked density, retraction or } \\
\text { fixation }\end{array}$ & - \\
\hline $\begin{array}{l}\text { Telangiec- } \\
\text { tasia }\end{array}$ & Few & Moderate & Many and confluent & - \\
\hline Pain & $\begin{array}{l}\text { Pain mild, not } \\
\text { interfering with } \\
\text { function }\end{array}$ & $\begin{array}{l}\text { Moderate pain; pain or analgesics interfering } \\
\text { with function, but not with } A D L\end{array}$ & $\begin{array}{l}\text { Severe pain; pain or analgesics in- } \\
\text { terfering with } A D L\end{array}$ & Disability \\
\hline
\end{tabular}

ADL: activities of daily living; NCI CTC: National Cancer Institute Common Toxicity Criteria. 
Table 6. Radiotherapy doses prescribed

\begin{tabular}{|c|c|c|c|c|c|c|}
\hline Trial & PBI/APBI dose & $\begin{array}{l}\text { Fraction } \\
\text { size (Gy) }\end{array}$ & $\begin{array}{l}\text { EQD2 PBI/ } \\
\text { APBI }\end{array}$ & Control dose & $\begin{array}{l}\text { Fraction } \\
\text { size (Gy) }\end{array}$ & $\begin{array}{l}\text { EQD2 } \\
\text { Control }\end{array}$ \\
\hline TARGIT & $\begin{array}{l}20 \text { Gy at surface of } \\
\text { the applicator (at- } \\
\text { tenuated to } 5-7 \mathrm{~Gy} \\
\text { at } 1 \mathrm{~cm})(\mathrm{APBI})\end{array}$ & $\begin{array}{l}80 \text { at cavi- } \\
\text { ty surface } \\
12.8 \text { at } 1 \\
\mathrm{~cm}\end{array}$ & $\begin{array}{l}80 \text { Gy at } \\
\text { cavity } \\
\text { surface } \\
12.8 \text { Gy at } \\
1 \mathrm{~cm}\end{array}$ & 40-56 Gy/20-28 fractions $\pm 10-16$ Gy boost & 2 & $\begin{array}{l}40-56 \mathrm{~Gy} \pm \\
10-16 \mathrm{~Gy}\end{array}$ \\
\hline Livi 2015 & $\begin{array}{l}30 \text { Gy/5 daily frac- } \\
\text { tions EBRT IMRT. } \\
100 \% \text { of the PTV } \\
\text { was covered by } \\
95 \% \text { of the pre- } \\
\text { scribed dose }\end{array}$ & 6 & $75 \mathrm{~Gy}$ & $\begin{array}{l}50 \mathrm{~Gy} / 25 \text { fractions }+10 \mathrm{~Gy} / 5 \text { fractions } \\
\text { boost }\end{array}$ & 2 & $\begin{array}{l}50+10= \\
60 \mathrm{~Gy}\end{array}$ \\
\hline RAPID & $\begin{array}{l}38.5 \mathrm{~Gy} / 10 \text { fractions } \\
\text { bd (with } 6 \text { hour } \\
\text { gap) } \\
\text { Dose-evaluation } \\
\text { volume (that part } \\
\text { of PTV within the } \\
\text { breast) received } \\
95-107 \% \text { of pre- } \\
\text { scription dose }\end{array}$ & 3.85 & $74.1 \mathrm{~Gy}$ & $\begin{array}{l}50 \mathrm{~Gy} / 25 \text { fractions or } 42.5 \mathrm{~Gy} / 16 \text { fractions } \\
\pm \text { boost ( } 10 \mathrm{~Gy} / 4-5 \text { fractions) based on cri- } \\
\text { teria such as young age or close margins, } \\
\text { pre-specified by centre }\end{array}$ & 2 or 2.65 & $\begin{array}{l}50 \text { or } 47.1 \\
\text { Gy }\end{array}$ \\
\hline Rodriguez & $\begin{array}{l}37.5 \text { Gy } / 10 \text { frac- } \\
\text { tions bd (with } 6 \\
\text { hour gap) (APBI). } \\
\text { PTV covered by } \geq \\
95 \% \text { of prescribed } \\
\text { dose, with }<105 \% \\
\text { hot spot }\end{array}$ & 3.75 & $71.22 \mathrm{~Gy}$ & $\begin{array}{l}48 \mathrm{~Gy} / 24 \text { fractions } \pm 10 \mathrm{~Gy} / 5 \text { fractions } \\
\text { boost }\end{array}$ & 2 & $\begin{array}{l}48 \pm 10= \\
48-58 \mathrm{~Gy}\end{array}$ \\
\hline $\begin{array}{l}\text { Polgár } \\
2007\end{array}$ & $\begin{array}{l}7 \times 5.2 \text { Gy HDR (AP- } \\
\text { BI) or } 50 \text { Gy/25 frac- } \\
\text { tions (PBI). } \\
\text { Women not suit- } \\
\text { able for HDR had } \\
6-15 \mathrm{MeV} \text { beam to } \\
\text { tumour bed plus } \\
2 \mathrm{~cm} \text { margin (field } \\
\text { size defined using } \\
\text { CT-planning or sim- } \\
\text { ulation films) }\end{array}$ & 5.2 or 2 & $\begin{array}{l}53.6 \mathrm{~Gy} \text { or } \\
50 \mathrm{~Gy}\end{array}$ & $50 \mathrm{~Gy} / 25$ fractions (3D-CRT was not used) & 2 & $50 \mathrm{~Gy}$ \\
\hline $\begin{array}{l}\text { GEC- } \\
\text { ESTRO }\end{array}$ & $\begin{array}{l}30.3 \mathrm{~Gy} / 7 \text { fractions } \\
\text { or } 32 \mathrm{~Gy} / 8 \text { fractions } \\
\text { HDR twice daily or } \\
50 \text { Gy at } 0.6-0.8 \mathrm{~Gy} / \\
\text { hour pulses ( } 1 \text { pulse } \\
\text { per hour, } 24 \text { hours } \\
\text { per day) PDR }\end{array}$ & $7-8$ & $\begin{array}{l}41.64-42.67 \\
\text { Gy }\end{array}$ & $\begin{array}{l}50.0-50.4 \text { Gy to a reference point }+10 \\
\text { Gy/5 fractions boost. Electron dose was } \\
\text { prescribed to the point of maximum dose } \\
\text { on the beam axis }\left(D_{\text {max }}\right) \text {, ensuring the } \\
85 \% \text { isodose encompassed the tumour } \\
\text { bed }\end{array}$ & $1.8-2.0$ & $\begin{array}{l}48.72-50 \\
+10= \\
58.72-60 \\
\text { Gy }\end{array}$ \\
\hline
\end{tabular}


Table 6. Radiotherapy doses prescribed (Continued)

$\begin{array}{llllll}21 \mathrm{~Gy} / 1 \text { fraction at } & 21 & 131.2 \mathrm{~Gy} & \begin{array}{l}50 \mathrm{~Gy} / 25 \text { fractions }+10 \mathrm{~Gy} / 5 \text { fractions } \\ \text { boost (using electrons) }\end{array} & 2.0 & 50+10 \mathrm{~Gy}\end{array}$

3D-CRT: 3-dimensional conformal radiotherapy; APBI: accelerated partial breast irradiation; bd: twice daily; CT: computer tomography; EBRT: external beam radiotherapy; EQD2: equivalent dose in 2 Gy fractions; Gy: Gray; HDR: high-dose-rate; IMRT: intensity-modulated radiotherapy; MeV: mega electron volt; PBI: partial breast irradiation; PDR: pulsed-dose-rate; PTV: planning target volume.

\section{Table 7. Radiotherapy techniques}

\begin{tabular}{ll}
\hline Trial & RT technique \\
\hline Polgár 2007 & Interstitial brachytherapy (88/128) \\
\hline ELIOT & intra-operative electrons \\
\hline Livi 2015 & EBRT (IMRT) \\
\hline TARGIT & intra-operative kV RT \\
\hline RAPID & EBRT \\
\hline Rodriguez & EBRT (3D-CRT) \\
\hline
\end{tabular}

3D-CRT: 3-dimensional conformal radiotherapy; EBRT: external beam radiotherapy; IMRT: intensity-modulated radiotherapy; RT: radiotherapy.

\section{APPENDICES}

\section{Appendix 1. The Cochrane Central Register of Controlled Trials (CENTRAL)}

1. MESH DESCRIPTOR Breast Neoplasms EXPLODE ALL TREES

2. breast AND (cancer* OR tumour ${ }^{\star}$ OR tumor $^{\star}$ OR neoplas $^{\star}$ )

3. \#1 OR \#2

4. brachytherapy:MH

5. brachytherapy

6. partial breast

7. partial breast irradiation

8. whole breast irradiation

9. whole breast radiotherapy

10. less than whole breast rad\$

11. high-dose-rate brachytherapy

12. acceleration partial breast irradiation

13. acceleration irradiation 
14. tumour bed boost

15. sole tumour boost

16. tumour bed boost

17. tumor bed boost

18. sole tumour bed irradiation

19. mammosite

20. MESH DESCRIPTOR Radiotherapy, Conformal EXPLODE ALL TREES WITH QUALIFIERS AE

21. MESH DESCRIPTOR Radiotherapy, Conformal EXPLODE ALL TREES WITH QUALIFIERS MT

22. (balloon dilation):MH

23. MESH DESCRIPTOR Radiotherapy

24. OR/4-23

25. \#3 AND \#24

\section{Appendix 2. MEDLINE (Ovid) (1966 to present)}

1.RANDOMIZED CONTROLLED TRIAL.pt

2. CONTROLLED CLINICAL TRIAL.pt

3. RANDOMIZED CONTROLLED TRIALS.sh

4. RANDOM ALLOCATION.sh

5. DOUBLE BLIND METHOD.sh

6. SINGLE BLIND METHOD.sh

7. or/1-6

8. (ANIMALS not HUMANS).sh

9. 7 not 8

10. CLINICAL TRIAL.pt

11. $\exp$ CLINICAL TRIALS/

12. (clin\$ adj25 trial\$).ti,ab

13. ((singl\$ or doubl\$ or trebl\$ or tripl\$) adj25 (blind\$ or mask\$)).ti,ab

14. PLACEBOS.sh

15. placebo\$.ti,ab

16. random $\$ . t i, a b$

17. RESEARCH DESIGN.sh

18. or $/ 10-16$

19. 18 not 8

20. 19 not 9

21.9 or 20

22. exp breast neoplasms/

23. exp "neoplasms, ductal, lobular, and medullary"/

24. exp breast/

25. exp neoplasms/

26. 24 AND 25

27 (breast\$ adj5 (neoplasm\$ or cancer\$ or tumo?r\$ or carcinoma\$ or adenocarcinoma\$ or sarcoma\$ or dcis or ductal or infiltrat\$ or intraductal\$ or lobular or medullary)).mp.

28 exp mammary neoplasms/

29 (mammar\$ adj5 (neoplasm\$ or cancer\$ or tumo?r\$ or carcinoma\$ or adenocarcinoma\$ or sarcoma\$ or dcis or ductal or infiltrat\$ or intraductal\$ or lobular or medullary)).mp

30. or/22, 23,26-29

31. partial breast irradiation.sh,kw,ti,ab

32. partial breast.sh,kw,ti,ab

33. whole breast irradiation.sh,kw,ti,ab

34. whole breast radiotherapy. $\mathrm{mp}$

35. less than whole breast rad\$.mp

36. brachytherapy.sh,kw,ti,ab

37. high-dose-rate brachytherapy.sh,kw,ti,ab

Partial breast irradiation for early breast cancer (Review)

Copyright (c) 2016 The Cochrane Collaboration. Published by John Wiley \& Sons, Ltd. 
38. accelerated partial breast irradiation.sh,kw,ti,ab

39. tumour bed boost.sh.kw.ti.ab

40. sole tumour bed irradiation.sh,kw,ti,ab

41. MammoSite.sh.kw.ti.ab

42. Breast Neoplasms/rt.sh

43. Radiotherapy, Conformal/adverse events.sh

44. Radiotherapy, Conformal/methods.sh

45. Brachytherapy.sh

46. Balloon dilation.sh

47. Radiotherapy/.sh

48. or $/ 31-47$

49. 48 AND 30

50. 49 AND 21

\section{Appendix 3. EMBASE}

1. randomised AND controlled AND trial

2. controlled AND clinical AND trial

3. randomi*ed:ab

4. placebo:ab

5. randomly:ab

6. trial:ab

7. groups:ab

8. \#1 OR \#2 OR \#3 OR \#4 OR \#5 OR \#6 OR \#7

9. 'breast'/exp AND 'neoplasm'/exp

10. locally AND advance* NEAR/6 breast AND cancer ${ }^{\star}$

11. locally AND advance* NEAR/6 breast AND neoplas*

12. locally AND advance* NEAR/6 breast AND carcinoma*

13. locally AND advance* NEAR/ 6 breast AND tumour *

14. locally AND advance* NEAR/ 6 breast AND tumor*

15. early NEAR/ 6 breast AND cancer*

16. early NEAR/6 breast AND neoplas*

17. early NEAR/ 6 breast AND carcinoma*

18. early NEAR/6 breast AND tumour*

19. early NEAR/6 breast AND tumor*

20. \#10 OR \#11 OR \#12 OR \#13 OR \#14 OR \#15 OR \#16 OR \#17 OR \$18 OR \$19

21. 'radiotherapy'/exp OR radiotherapy

22. 'adjuvant'/exp OR adjuvant AND ('radiotherapy'/exp OR radiotherapy)

23. 'radiation/exp OR radiation AND ('therapy'/exp OR therapy)

24. \#21 OR \#22 OR\#23

25. \#8 AND \#20 AND \#24

Partial breast irradiation for early breast cancer (Review) 


\section{Appendix 4. CINAHL}

1. MH Clinical Trials

2. PT Clinical Trial

3. TX clini $^{\star} \mathrm{n} 1$ trial $^{\star}$

4. TX ((singl` $n 1$ blind $\left.{ }^{\star}\right)$ or $\left(\right.$ singl ${ }^{\star} n 1$ mask $\left.\left.^{\star \star}\right)\right)$

5. TX randomi ${ }^{\star}$ control $^{\star}$ trial $^{\star}$

6. $\mathrm{MH}$ random assignment

7. TX random* allocat*

8. TX placebo*

9. $\mathrm{MH}$ "Placebos"

10. MH Quantitative Studies

11. \#1 OR \#2 OR \#3 OR \#4 OR \#5 OR \#6 OR \#7 OR \#8 OR \#9 OR \#10

12. MH breast neoplasms

13. TI breast cancer OR SU breast cancer OR AB breast cancer

14. TI breast tumour OR SU breast tumour OR AB breast tumour

15. MM "Carcinoma, Ductal, Breast"

16. \#12 OR \#13 OR \#14 OR \#15

17. MM "radiotherapy, Conformal/AE"

18. MM "radiotherapy, Conformal/methods"

19. SU partial breast OR TI partial breast OR AB partial breast

20. SU whole breast irradiation OR TI whole breast irradiation OR AU whole breast irradiation

21. SU whole breast radiotherapy

22. SU whole breast rad\$ OR TI whole breast rad\$ OR AB whole breast rad\$

23. SU brachytherapy OR TI brachytherapy OR AB brachytherapy

24. MH brachytherapy

25. $\mathrm{MH}$ radiotherapy

26. SU whole breast radiotherapy OR TI whole breast radiotherapy OR AB whole breast radiotherapy

27. SU high-dose-rate brachytherapy OR AB high-dose-rate brachytherapy OR TI high-dose-rate brachytherapy

28. SU accelerated partial breast irradiation OR TI accelerated partial breast irradiation OR AB accelerated partial breast irradiation

29. SU tumour bed boost OR TI tumour bed boost OR AB tumour bed boost

30. SU MammoSite OR TI MammoSite OR AB MammoSite

31. MH "Breast Neoplasms+/RT"

32. \#17 OR \#18 OR \#19 OR \#20 OR \#21 OR \#22 OR \#23 OR \#24 OR \#25 OR \#26 OR \#27 OR \#28 OR \#29 OR \#30 OR \#31

33. \#11 AND \#16 AND \#32 


\section{Appendix 5. Current Contents}

1. TS = clinical trial ${ }^{*}$

2. TS = research design

3. $\mathrm{TS}=$ comparative stud ${ }^{*}$

4. TS = evaluation stud ${ }^{*}$

5. TS = controlled trial ${ }^{*}$

6. TS = follow-up study

7. $\mathrm{TS}=$ prospective stud ${ }^{*}$

8. $\mathrm{TS}=$ random $^{\star}$

9. $\mathrm{TS}=$ placebo

10. TS = single blind ${ }^{\star}$

11. $\mathrm{TS}=$ double blind ${ }^{*}$

12. \#1 OR \#2 OR \#3 OR \#4 OR \#5 OR \#6 OR \#7 OR \#8 OR \#9 OR \#10 OR \#11

13. $\mathrm{TS}=$ breast cancer

14. $\mathrm{TS}=$ breast neoplasms

15. \#12 OR \#13

16. $\mathrm{TS}=$ partial breast irradiation

17. $\mathrm{TS}=$ whole breast irradiation

18. $\mathrm{TS}=$ less than whole breast

19. TS = brachytherapy

20. TS = tumour bed boost

21. TS = Mammosite

22. \#15 OR \#16 OR \#17 OR \#18 OR \#19 OR \#20

23. $\mathrm{TS}=$ radiotherapy

24. $\mathrm{TS}=$ radiation therapy

25. \#22 OR \#23

26. \#12 AND \#21 AND \#24

\section{Appendix 6. WHO ICTRP search portal}

\section{Basic search:}

1. Partial irradiation for early breast cancer

2. Early breast cancer AND partial irradiation

3. Early breast cancer AND partial breast irradiation

4. Early breast cancer AND Mammosite

5. Early breast cancer AND Intracavitary brachytherapy

6. Early breast cancer AND Interstitial brachytherapy

7. Early breast cancer AND accelerated partial breast irradiation

8. Early breast cancer and less than whole breast radiotherapy 


\section{Advanced search:}

1. Title: Partial irradiation for early breast cancer

Recruitment status: all

\section{Condition: early breast cancer}

Intervention: partial breast irradiation OR Mammosite OR intracavitary brachytherapy OR interstitial brachytherapy OR accelerated partial breast irradiation OR less than whole breast radiotherapy

Recruitment status: all

\section{Appendix 7. ClinicalTrials.gov}

\section{Basic searches:}

1. Partial irradiation for early breast cancer

2. Early breast cancer AND partial irradiation

3. Early breast cancer AND partial breast irradiation

4. Early breast cancer AND Mammosite

5. Early breast cancer AND Intracavitary brachytherapy

6. Early breast cancer AND Interstitial brachytherapy

7. Early breast cancer AND accelerated partial breast irradiation

8. Early breast cancer and less than whole breast radiotherapy

\section{Advanced searches:}

1. Search terms: Partial irradiation for early breast cancer

Recruitment: All studies

Study type: All studies

Gender: All studies

\section{Condition: Early breast cancer}

Intervention: Partial breast irradiation OR Mammosite OR intracavitary brachytherapy OR interstitial brachytherapy OR accelerated partial breast irradiation OR less than whole breast radiotherapy

Recruitment: All studies

Study type: All studies

Gender: All studies

\section{Appendix 8. OpenGrey}

1. (breast cancer OR breast neoplasm* OR breast adenocarcinoma) AND (radiation OR irradiation OR radiotherapy OR radio-therapy))

\section{WHAT'S NEW}

\begin{tabular}{lll}
\hline Date & Event & Description \\
\hline 5 May 2015 & New search has been performed & Performed search for new studies on 4 May 2015 \\
\hline 4 May 2015 & $\begin{array}{l}\text { New citation required but conclusions } \\
\text { have not changed }\end{array}$ & $\begin{array}{l}\text { Five new studies were included, adding 5333 participants. An ad- } \\
\text { ditional 2 'ongoing studies' have been identified }\end{array}$ \\
\hline
\end{tabular}




\section{H IS T O RY}

Protocol first published: Issue 2, 2008

Review first published: Issue 6, 2014

\begin{tabular}{lll}
\hline Date & Event & Description \\
\hline 15 May 2008 & Amended & Converted to new review format. \\
\hline
\end{tabular}

\section{CONTRIBUTIONS OF AUTHORS}

$\mathrm{ML}, \mathrm{BH}$ and $\mathrm{DF}$ wrote the protocol.

BH extracted data, created 'Risk of bias' tables and 'Characteristics of included studies' tables, analyzed the data, wrote the results section and discussion, and responded to editorial and peer review (in consultation with $\mathrm{ML}$ ).

ML checked the analyses, 'Risk of bias' tables, collaborated with writing the results, discussion and conclusion sections.

AS checked the extracted data and ran the search strategy.

\section{DECLARATIONSOF INTEREST}

$\mathrm{MH}$ : none known.

BH: none known.

DF: none known.

AS: none known.

\section{SOURCES OF SUPPORT}

\section{Internal sources}

- No sources of support supplied

\section{External sources}

- Princess Alexandra Cancer Collaborative Group, Australia.

\section{DIFFERENCES BETWEEN PROTOCOLANDREVIEW}

We reported time-to-event data where possible for cancer-related outcomes. We reported local relapse-free survival (LR-FS) rather than local relapse (LR), distant metastasis-free survival (DM-FS) rather than distant metastases (DM), we reported loco-regional relapse-free survival (L-R R-FS) rather than loco-regional control (LRC) as a secondary endpoint. We added the words "elsewhere primary" to the name of the endpoint "new primary in ipsilateral breast" because this term is used in the relevant literature, in order to add clarity for the reader.

We initially indicated that we would convert doses to their biological equivalent (BED), but have in fact used equivalent dose in 2 Gy fractions $\left(E Q D_{2}\right)$. This allows numerical addition of separate components of a treatment and is more readily understood by clinical radiation oncologists because it results in numbers which can be directly related to clinical experience.

We added $\mathrm{APBI}$ as well as PBI: modern RT techniques that reduce the treated volume allow the use of high dose per fraction to the smaller treated volume. The ongoing studies tend to use APBI, which reflects modern RT practice, making the review results more applicable.

We added blinding to assessment of risk of bias, because the lack of blinding for the primary outcome of cosmesis would be a significant cause of bias. We searched an additional database (i.e. EMBASE.com) and trial registry (WHO ICTRP) to our search strategy, and also handsearched other resources. This ensured that our searches were as comprehensive as possible, and complied with Cochrane search requirements.

We included studies which included women with ductal carcinoma in situ (RAPID) for reporting of toxicity endpoints. ELIOT used regional nodal irradiation for those women with more or more involved nodes ( $5 \%$ of the cohort), we excluded ELIOT from the analysis of L-RR-FS. 
We pooled the studies in a quantitative meta-analysis, but excluded the older studies, which used surgical, RT and systemic management practices which do not reflect current practice. We had planned sensitivity analysis based on excluding studies which used outmoded RT and surgical techniques, but as we decided to exclude them from our analysis, we did not do so. These studies were included in the previous iteration of this review, but were removed for the 2015 update.

We corrected the list and table of excluded studies so we are now compliant with MECIR guidelines, so that this list only includes studies that might reasonably be expected to be included, but which we deemed ineligible.

\section{NDEX TERMS}

\section{Medical Subject Headings (MeSH)}

Breast [radiation effects]; Breast Neoplasms [pathology] [*radiotherapy] [surgery]; Combined Modality Therapy [methods]; DiseaseFree Survival; Mastectomy, Segmental; Neoplasm Recurrence, Local [prevention \& control]; Organ Sparing Treatments [ ${ }^{\star}$ methods]; Radiation Dose Hypofractionation; Radiotherapy [adverse effects] [methods]; Randomized Controlled Trials as Topic

\section{MeSH check words}

Female; Humans 